\title{
WestVirginiaUniversity
}

THE RESEARCH REPOSITORY @ WVU

Graduate Theses, Dissertations, and Problem Reports

1998

\section{Semi-automated modeling approaches to route selection in GIS}

Binfei Chen

West Virginia University

Follow this and additional works at: https://researchrepository.wvu.edu/etd

\section{Recommended Citation}

Chen, Binfei, "Semi-automated modeling approaches to route selection in GIS" (1998). Graduate Theses, Dissertations, and Problem Reports. 879.

https://researchrepository.wvu.edu/etd/879

This Thesis is protected by copyright and/or related rights. It has been brought to you by the The Research Repository @ WVU with permission from the rights-holder(s). You are free to use this Thesis in any way that is permitted by the copyright and related rights legislation that applies to your use. For other uses you must obtain permission from the rights-holder(s) directly, unless additional rights are indicated by a Creative Commons license in the record and/ or on the work itself. This Thesis has been accepted for inclusion in WVU Graduate Theses, Dissertations, and Problem Reports collection by an authorized administrator of The Research Repository @ WVU. For more information, please contact researchrepository@mail.wvu.edu. 
Semi-automated Modeling Approaches To Route Selection In GIS

\author{
Binfei Chen
}

A Thesis Submitted to

\title{
The College of Arts and Sciences
}

at

West Virginia University

in partial fulfillment of the requirements for the degree of

Master of Arts

in

Geography

\author{
Dr. Gregory A. Elmes \\ Dr. Trevor M. Harris, Committee Chair \\ Dr. Timothy A. Warner
}

November 17, 1998

Morgantown, WV, USA

Keywords: Geographic Information System, Power Line Route Siting, Spatial Decision Support System (SDSS)

Copyright 1998: Binfei Chen 


\section{ACKNOWLEDGMENTS}

Special thanks to Dr. Trevor M. Harris, Chair of my Committee, who provided me with great encouragement in this research work and persistent supervision in my whole thesis writing. I would like to thank my committee members Dr. Gregory A. Elmes and Dr. Timothy A. Warner for their careful review and insight suggestions to my final thesis. I would also like to thank Mr. Joel Halverson and Mr. Kurt Donaldson for their valuable advice and technical support in my research preparation. 


\begin{abstract}
As an alternative to traditional graphical intuitive approaches (GIA), a semi-automated modeling approach (SMA) can more efficiently identify linear routes by using powerful iterative and automated methods. In this research, two case studies were investigated to examine critical issues relating to the accuracy and effectiveness of raster-defined algorithmic approaches to linear route location. The results illustrate that different shortest-path algorithms do not necessarily result in markedly different linear routes. However, differing results can occur when using different neighboring-cell links in the cell-based route network construction. Cell-based algorithmic approaches in both Arc/Info and IDRISI software generate very similar results which are comparable to linear modeling with greater than eight neighboring-cell links. Given a specific shortest-path algorithm and its route searching technique, the use of a finer spatial resolution only results in a narrower and smoother route corridor. Importantly, cost surface models can be generated to represent differing cumulative environmental 'costs' or impacts in which different perceptions of environmental cost can be simulated and evaluated.
\end{abstract}

Three different simulation techniques comprising Ordered Weighted Combination models (OWC), Dynamic Decision Space (DDS), and Gateway-based approaches, were used to address problems associated with concurrent and dynamic changes in multi-objective decision space. These approaches provide efficient and flexible simulation capability within a dynamic and changing decision space. When aggregation data models were used within a Gateway approach the match of resulting routes between GIA and SMA analyses is close. The effectiveness of SMA is greatly limited when confronted by extensive linear and impermeable barriers or where data is sparse. Overall, achieving consensus on environmental cost surface generation and criteria selection is a prerequisite for a successful SMA outcome. It is concluded that SMA has several positive advantages that certainly complement a GIA in linear route siting and spatial decision-making. 


\section{TABLE OF CONTENTS}

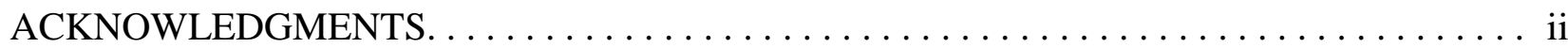

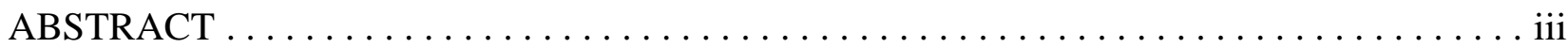

LIST OF FIGURES $\ldots \ldots \ldots \ldots \ldots \ldots \ldots \ldots \ldots \ldots \ldots \ldots \ldots \ldots \ldots \ldots \ldots \ldots \ldots$

LIST OF TABLES $\ldots \ldots \ldots \ldots \ldots \ldots \ldots \ldots \ldots \ldots \ldots \ldots \ldots \ldots \ldots \ldots \ldots \ldots$ viii

1. INTRODUCTION $\ldots \ldots \ldots \ldots \ldots \ldots \ldots \ldots \ldots \ldots \ldots \ldots \ldots \ldots \ldots \ldots \ldots \ldots \ldots \ldots \ldots$

1.1. General Approaches To Linear Facility Route Siting $\ldots \ldots \ldots \ldots \ldots \ldots \ldots \ldots$

1.2. Dealing With Uncertainty In Semi-automated Modeling For Route Selection . . . . 7

1.3. Improving Routing Accuracy In Using Semi-automated Modeling Approach . . . . . . 8

1.4. Research Objectives $\ldots \ldots \ldots \ldots \ldots \ldots \ldots \ldots \ldots \ldots \ldots \ldots \ldots \ldots \ldots$

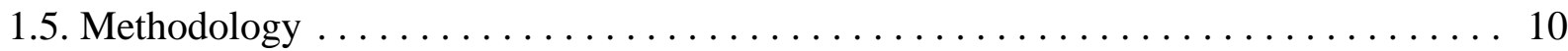

2. ISSUES ASSOCIATED WITH A SEMI-AUTOMATED MODELING $\ldots \ldots \ldots \ldots$

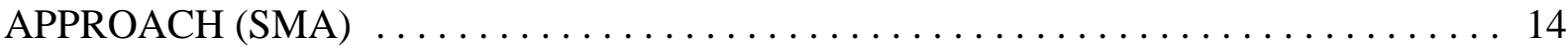

2.1. Network Models For Route-Location Problem $\ldots \ldots \ldots \ldots \ldots \ldots \ldots \ldots$

2.2. Parameter Ambiguity In Data Rasterization $\ldots \ldots \ldots \ldots \ldots \ldots \ldots \ldots \ldots \ldots \ldots \ldots \ldots$

2.3. Subjective Suitability Score Assignment $\ldots \ldots \ldots \ldots \ldots \ldots \ldots \ldots \ldots \ldots$

2.4. Infinite Directional Moves To Routing In A Lattice Surface . . . . . . . . . . . . . 19

2.5. The Multi-objective Dynamic Routing Problem $\ldots \ldots \ldots \ldots \ldots \ldots \ldots \ldots$

3. SOLUTIONS TO ROUTING UNCERTAINTY WITH SMA $\ldots \ldots \ldots \ldots \ldots \ldots \ldots \ldots$

3.1. Suitable Cell Size Determination $\ldots \ldots \ldots \ldots \ldots \ldots \ldots \ldots \ldots \ldots \ldots \ldots \ldots \ldots \ldots \ldots \ldots$

3.2. Environmental Quantification And Evaluation $\ldots \ldots \ldots \ldots \ldots \ldots \ldots \ldots$

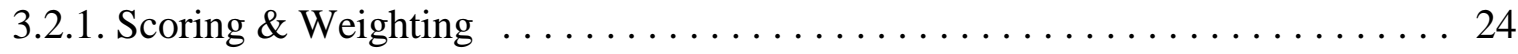

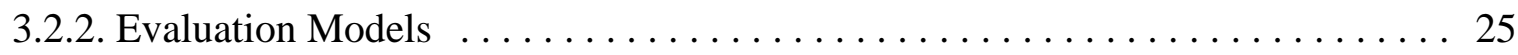

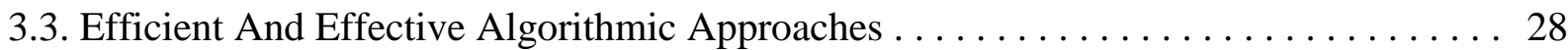

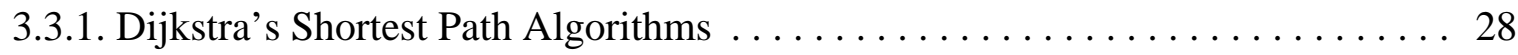

3.3.2. The Arc/Info Approach . . . . . . . . . . . . . . . . . . . . 29

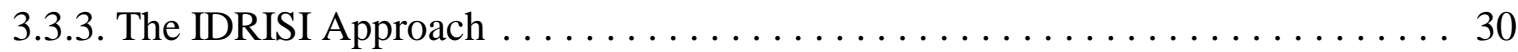




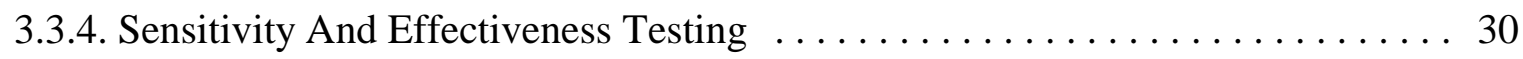

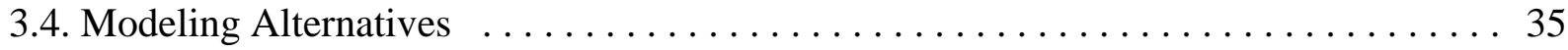

3.4.1. Multiobjective Optimization Method $\ldots \ldots \ldots \ldots \ldots \ldots \ldots \ldots \ldots \ldots \ldots$

3.4.2. Gateway Path Generation Method $\ldots \ldots \ldots \ldots \ldots \ldots \ldots \ldots \ldots \ldots . \ldots . \ldots . \ldots$

3.5. Optimal Analysis For Preferred Route Selection $\ldots \ldots \ldots \ldots \ldots \ldots \ldots \ldots . . \ldots 1$

3.5.1. Impact Matrix Manipulation $\ldots \ldots \ldots \ldots \ldots \ldots \ldots \ldots \ldots \ldots \ldots \ldots \ldots \ldots \ldots$

3.5.2. Heuristic Approach . . . . . . . . . . . ...................... 42

4. TRANSMISSION LINE ROUTE SELECTION USING SMA $\ldots \ldots \ldots \ldots \ldots \ldots \ldots$

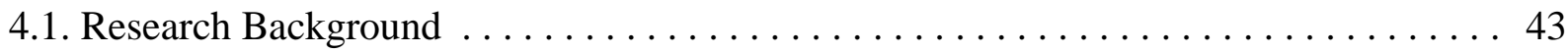

4.1.1. Background To The AEP Project $\ldots \ldots \ldots \ldots \ldots \ldots \ldots \ldots \ldots \ldots \ldots, \ldots \ldots$

4.1.2. Research Area And Data Selection ......................... 43

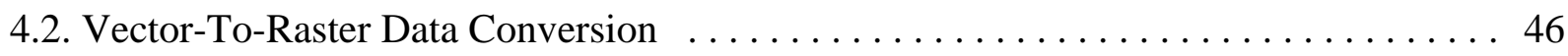

4.2.1. Primary Cell Size Determination $\ldots \ldots \ldots \ldots \ldots \ldots \ldots \ldots \ldots \ldots . \ldots \ldots$

4.2.2. Cell Resolution Sensitivity Analysis . . . . . . . . . . . . . ....... 46

4.3. Constructing Environmental Cost Surface $\ldots \ldots \ldots \ldots \ldots \ldots \ldots \ldots \ldots \ldots \ldots \ldots \ldots \ldots \ldots \ldots$

4.3.1. Quantifying The Environment $\ldots \ldots \ldots \ldots \ldots \ldots \ldots \ldots \ldots \ldots \ldots \ldots$

4.3.2. Cumulative Impact Modeling $\ldots \ldots \ldots \ldots \ldots \ldots \ldots \ldots \ldots \ldots \ldots$

4.3.3. Cost Surface Generation ............................... 52

4.4. Least Impact Power Line Route Siting $\ldots \ldots \ldots \ldots \ldots \ldots \ldots \ldots \ldots \ldots \ldots \ldots \ldots \ldots \ldots$

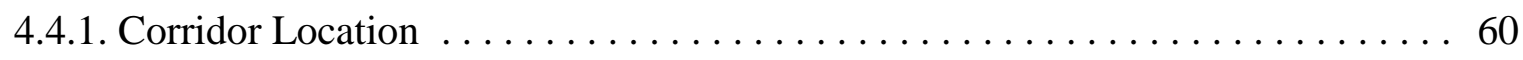

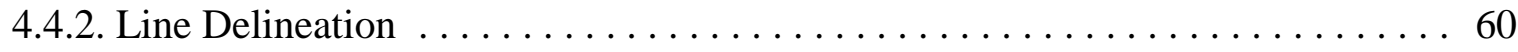

5. EVALUATING SMA IN LINEAR ROUTE SITING $\ldots \ldots \ldots \ldots \ldots \ldots \ldots \ldots \ldots \ldots$

5.1. The Sensitivity Of SMA To Multi-Objective Planning Problems $\ldots \ldots \ldots \ldots . \ldots 6$

5.1.1. Multiple Objective Decision Spaces ...................... 67

5.1.2. OWC Based Sensitivity Route Simulation . . . . . . . . . . . . . . . 68

5.2. Sensitivity Of SMA To Dynamic Routing Problem .................... 69

5.2.1. Dynamic Decision Spaces ................................. 69

5.2.2. DDS-Based Sensitivity Route Simulation $\ldots \ldots \ldots \ldots \ldots \ldots \ldots \ldots \ldots$

5.2.3. Gateway-Based Sensitivity Route Simulation $\ldots \ldots \ldots \ldots \ldots \ldots \ldots$ 
5.3. Comparative Analysis of SMA With GIA $\ldots \ldots \ldots \ldots \ldots \ldots \ldots \ldots \ldots \ldots$

5.3.1. Spatial Analysis Of Power Line Route Placement . . . . . . . . . . . 83

5.3.2. Corridor Impact Matrix Analysis $\ldots \ldots \ldots \ldots \ldots \ldots \ldots \ldots \ldots \ldots \ldots \ldots \ldots \ldots \ldots$

6. SUMMARY AND CONCLUSIONS $\ldots \ldots \ldots \ldots \ldots \ldots \ldots \ldots \ldots \ldots \ldots$

6.1. Effectiveness And Efficiency Assessment $\ldots \ldots \ldots \ldots \ldots \ldots \ldots \ldots \ldots$

6.2. Study Limitations And Further Questions $\ldots \ldots \ldots \ldots \ldots \ldots$

6.3. Concluding Remarks $\ldots \ldots \ldots \ldots \ldots \ldots \ldots \ldots \ldots \ldots \ldots \ldots \ldots \ldots \ldots \ldots \ldots \ldots \ldots$

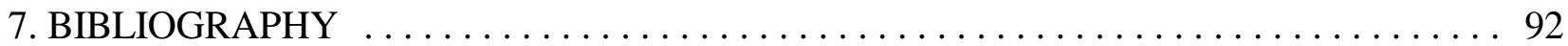

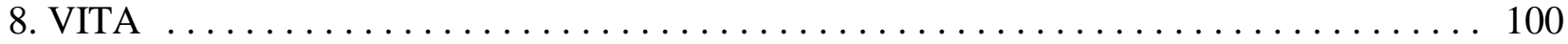




\section{LIST OF FIGURES}

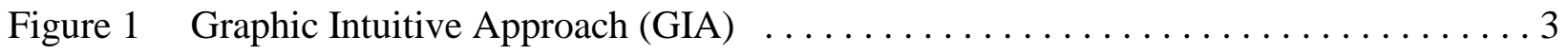

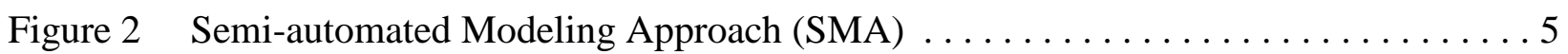

Figure 3 The Difference Of SMA \& GIA In Using Remote Sensing \& GIS Technology . . . . 6

Figure 4 A Classical Vector Network Model ........................... 14

Figure 5 General Model Of Multi-Criteria Evaluation (MCE) $\ldots \ldots \ldots \ldots \ldots \ldots \ldots$

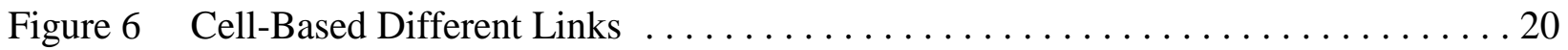

Figure 7 A Hypothetical Data Set For Routing Process Simulation . . . . . . . . . . . . . 32

Figure 8 Routing Sensitivity To Different Shortest-path Algorithms ................ 33

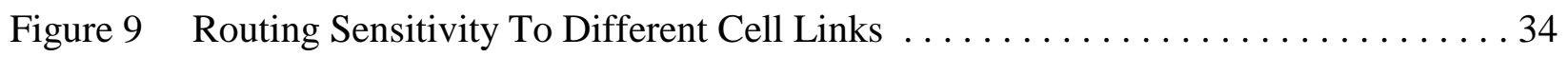

Figure 10 Route Sensitivity To Different Spatial Resolutions $\ldots \ldots \ldots \ldots \ldots \ldots \ldots$

Figure 11 Routing Sensitivity Of IDRISI To Spatial Positional Accuracy . . . . . . . . . 38

Figure 12 Routing Sensitivity Of Arc/Info To Spatial Positional Accuracy . . . . . . . . . . 39

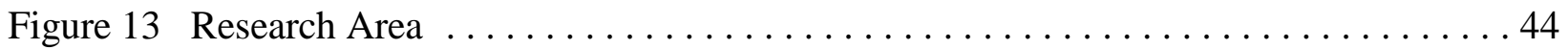

Figure 14 Cell Resolution Sensitivity Analysis Around Narrow USGS Topo Quads . . . . . . 48

Figure 15 Environmental Modeling And Seven Resultant Friction Surfaces ........... 53

Figure 16a Powerline Route Simulation With 30 Meter Resolution ................. 61

Figure 16b Powerline Route Simulation With 90 Meter Resolution Rasterized Dataset . . . . . 62

Figure 16c Powerline Route Simulation With 90 Meter Resolution Resampled Dataset . . . . 63

Figure 17 Powerline Route Simulation Within Real Decision Space ................. 65

Figure 18 Route Geometric Distortions . . . . . . . . . . . . . . . . . . . . . 66

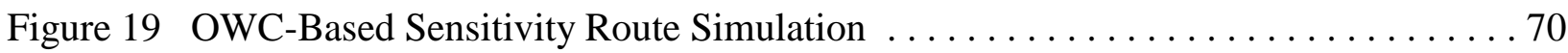

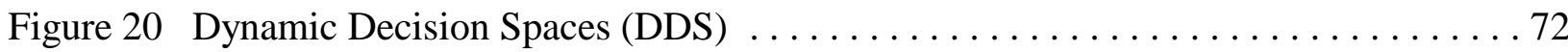

Figure 21a DDS-A Based Sensitivity Route Simulation $\ldots \ldots \ldots \ldots \ldots \ldots \ldots \ldots \ldots \ldots$

Figure 21b DDS-B Based Sensitivity Route Simulation ....................... 74

Figure 21c DDS-C Based Sensitivity Route Simulation $\ldots \ldots \ldots \ldots \ldots \ldots \ldots \ldots \ldots \ldots$

Figure 22a Crossing \& Turning Points Targeted By GIA $\ldots \ldots \ldots \ldots \ldots \ldots \ldots \ldots \ldots 77$

Figure 22b Three Sets Of Crossing Points Simulated By SMA $\ldots \ldots \ldots \ldots \ldots \ldots \ldots \ldots$

Figure 23a Gateway Based GIA_P91 Simulation $\ldots \ldots \ldots \ldots \ldots \ldots \ldots \ldots \ldots \ldots$

Figure 23b Gateway Based GIA_P96 Simulation $\ldots \ldots \ldots \ldots \ldots \ldots \ldots \ldots \ldots \ldots \ldots \ldots$

Figure $23 \mathrm{c}$ Gateway Based GIA_P97 Simulation $\ldots \ldots \ldots \ldots \ldots \ldots \ldots \ldots \ldots \ldots \ldots \ldots \ldots \ldots$

Figure 24 SMA Simulated 12 Corridors With The Most Spatial Fit To

The Preferred Routes Generated By GIA . . . . . . . . . . 8 84 


\section{LIST OF TABLES}

Table 1 Digital Landscape Dataset For Modeling Powerline . . . . . . . . . . . . . . 45

Table 2 Environmental Constraints Quantification $\ldots \ldots \ldots \ldots \ldots \ldots \ldots \ldots \ldots$

Table 3 Theoretical Thresholds For Three EM Selected $\ldots \ldots \ldots \ldots \ldots \ldots \ldots \ldots \ldots$

Table 4 DDS-Based Friction Surface Generation $\ldots \ldots \ldots \ldots \ldots \ldots \ldots \ldots \ldots \ldots \ldots$

Table 5 Gateway-Based Sensitivity Route Simulation $\ldots \ldots \ldots \ldots \ldots \ldots \ldots \ldots$

Table 6 Corridor Environmental Impact Matrix Analysis $\ldots \ldots \ldots \ldots \ldots \ldots \ldots \ldots$ 


\section{Chapter 1: INTRODUCTION}

\subsection{General Approaches To Linear Facility Route Siting}

Route selection for large linear facilities such as transmission lines and pipelines often consist of numerous intuitive and trade-off judgments made by analysts with a variety of experiences in economic development and environmental assessment. It invariably involves a complex spatial decision-making process requiring the exploration of numerous options based on physical, ecological, visual, cultural, and socio-economic factors, and usually extends over a large area. More recently, in order to tackle these complicated applied location problems efficiently, computerized algorithms, software, and decision making support systems have been developed. The methods can be grouped into three general approaches.

\subsubsection{General Approaches To Route Selection}

The linear routing problem can be defined as one of finding a path between a given origin and a destination, which either minimizes 'cost' or maximizes 'benefit'. This may also involve linking via an intermediate location or, indeed, several crossing points or "gateways". There is an extensive literature on linear route selection procedures involving, for example, oil and gas pipelines (Carpenter \& Callen, 1984; Sandra et al., 1995), irrigation canals and shipping routes ( Martin, 1987), transportation networks (Magnanti \& Wong, 1984; Friesz, 1985), and power transmission lines (Giles et al., 1976; Howlett, 1976; Choobineh, 1984; Huber \& Church, 1985; Lombard and Church, 1993; Warner \& Diab, 1996). Generally, three methods dominate the literature: (1) a traditional analog system in which experts manually site routes based on colored overlay acetate sheets (sometimes known as the 'McHarg Method' (McHarg, 1967 \& 1968)), or on contour and engineering construction paper maps (Liu and Sessions, 1993); (2) a graphical intuitive approach (GIA) (Schaal, 1972; Howlett, 1976; Moreno et al., 1988; and Harris, 1991 \& 1997) in which computer or computer-based GIS/Remote Sensing technologies are used as a means to generate constraint maps and other information allowing 'experts' to 
contextually manipulate and analyze linear route selection in a primarily graphical mode; (3) a semiautomatic modeling approach (SMA) in which linear routes are determined based on network analysis within a computer-based or GIS defined digital cost surface (Ostresh, 1973; Hopkins, 1973; Giles et al., 1976; Goodchild, 1977; Economides \& Sharifi, 1978; Huber \& Church, 1985; Eastman, 1989; Wang, 1992; Chang \& Chang, 1993; Lombard and Church, 1993; Zhan et al., 1993; Warner \& Diab, 1996; and Dean, 1997).

Usually, GIA and SMA have a common basis in using computer-based technology including GIS and remote sensing, which greatly facilitate the generation, organization, and analysis of vast quantities of spatial data. Among many benefits, these technologies have proven capabilities to handle multiple data sources, the production of customized outputs such as maps and tabular information, support multi-key sorting and re-organization of information, and allow for rapid digital data retrieval in graphical and multi-dimensional space (Clark et al., 1994; Koller et al., 1995; Rhyne, 1997; Buckley et al., 1998). Furthermore, these technologies increasingly possess special abilities for better public access via the Internet (GIS World, 1997; ARC News, 1997 \& 1998). Perhaps more importantly, these technologies can provide analysts with a better spatial decision-making environment by incorporating intelligent computing techniques such as genetic algorithms, network analysis, and dynamic systems theory with many of their own sophisticated spatial modeling capabilities, including recoding, overlays, buffering, averaging, contouring, local area interpolation, and Boolean operations (Zhou \& Civco, 1996; Singh \& Treleaven, 1997). Thus, GIS is an ideal tool for specialists to handle and investigate locational problems invariably associated with large amounts of information (Jensen, 1994). With the increasing availability of digital spatial data for much of the USA, GIA and SMA will likely be used increasingly to handle complex linear route-location problems.

\subsubsection{The Graphical Intuitive Approach}

A typical model of the GIA was used by Harris et al. $(1991,1997)$ and comprises three major steps as shown in Figure 1. Building a multi-source database is a key step to providing the information required for routing decision-making. More than sixty 
Figure 1: Graphic Intuitive Approach (GIA)

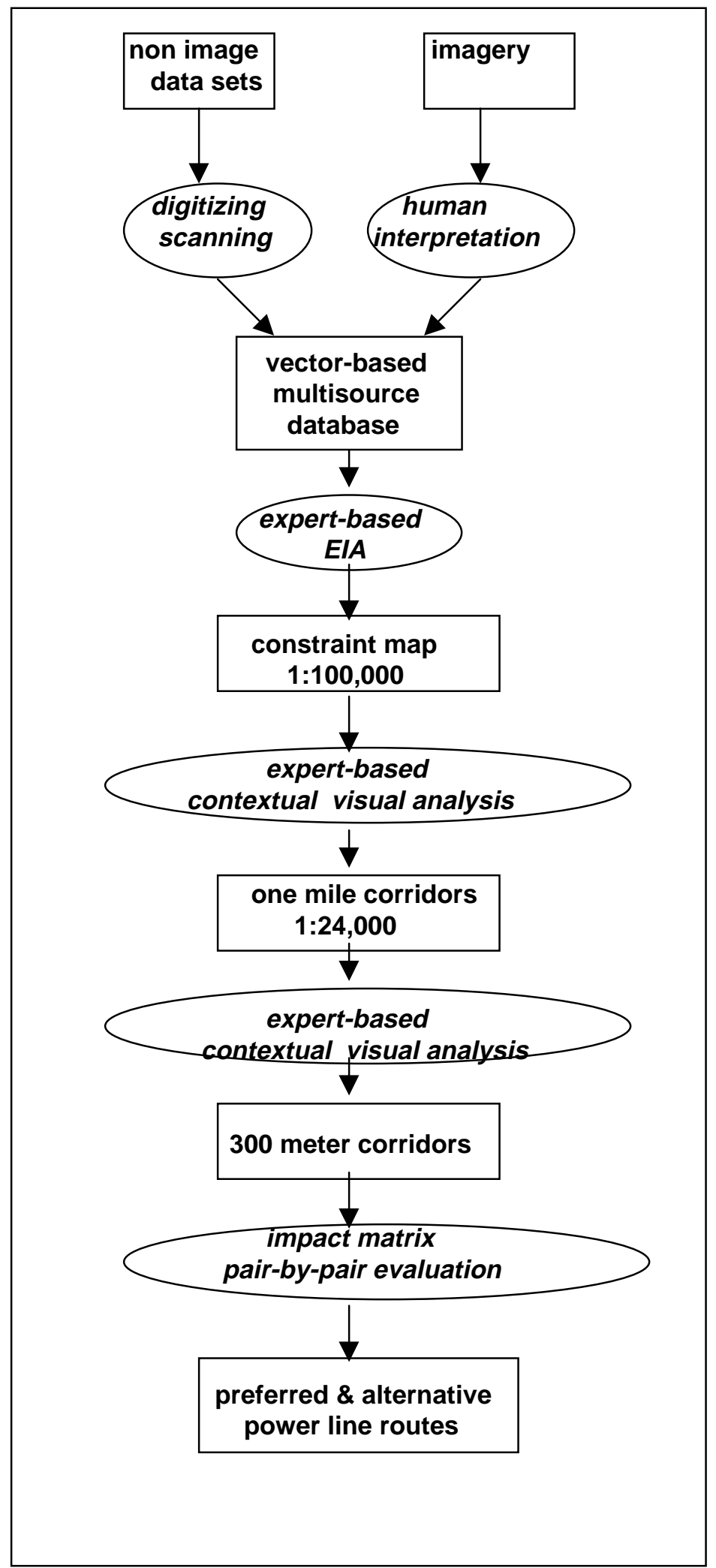


environmental data sets or constraints were collected in the Harris study. Creating the high quality data is often extremely time and resource consuming but can provide a consolidated foundation for further spatial analysis and route selection. Secondly, GIS is used extensively to provide a framework to both organize and integrate the numerous spatial data sets; to facilitate public communication and participation by displaying comprehensive constraint, environmental, and route maps; and to replicate and evaluate alternative routing possibilities. Thirdly, power line routes or corridors have traditionally been identified based on the contextual visual analysis of constraint maps, other geographical information, and involving intuitive judgments. One of the biggest advantages to using GIA is the ability to communicate clearly at public hearings in a tangible form the logic and basis on which routing judgments were made using graphical products. By removing as many uncertainties as possible, and by demonstrating a systematic process based on the available information, understanding is gained and the route selection process becomes one of agreeing on the best of alternatives within the context of the existing socioeconomic structures and environmental constraints. The GIA has been proven a well-defined and pragmatic approach to route selection in the real world.

\subsubsection{Semi-automated Modeling Approach}

Siting a linear route over a large area with GIA is time-consuming and very expensive. Moreover, even though experts can undertake manual route delineation very well based on intelligent visualizations, human intuitive judgments are often intangible and potentially nonreplicable. Because of these costs, and the judgmental basis of GIA route selection, attention has focused in recent years on the use of GIS and an integrated semi-automated modeling approach (Figure 2) to identify potential linear routes or corridors.

At the outset SMA would appear to have several advantages over the more traditional GIA in linear routing selection. Firstly, SMA can more efficiently identify linear routes or alternative corridors by using powerful automated and iterative methods. Because a large linear facility siting project is usually a dynamic process involving multi-objective decision 


\section{Figure 2: Semi-automated Modeling Approach (SMA)}

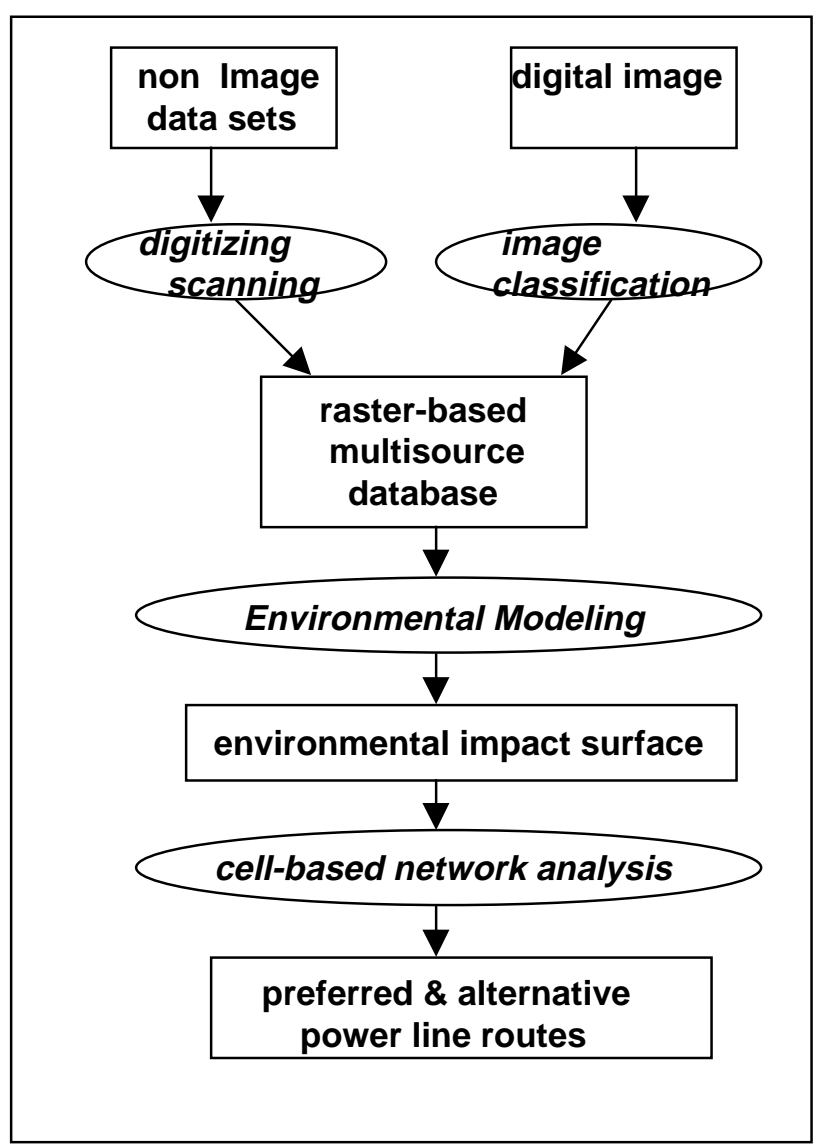

making it is important to be able to generate outcomes in as efficient a manner as possible. Invariably such decision making involves numerous and significant impact assessments, non-commensurate terms, and conflicting objective tradeoffs. For a number of reasons outlined later in this work SMA would appear to provide an efficient mechanism by which to identify and evaluate routing scenarios based on specified criteria.

Secondly, while cell-based methods which can easily incorporate remote sensing images are used in GIA routing projects, they are much more powerful when incorporated within an SMA approach. A raster dominated multi-source database can be built more efficiently via digital image automated processing techniques (Figure 3). Such an approach avoids potential errors in empirical human interpretation, mapping, and digitizing of traditionally vector-based data required by GIA. The direct utilization of remote sensing technology within SMA may also alleviate much of the cost and time 


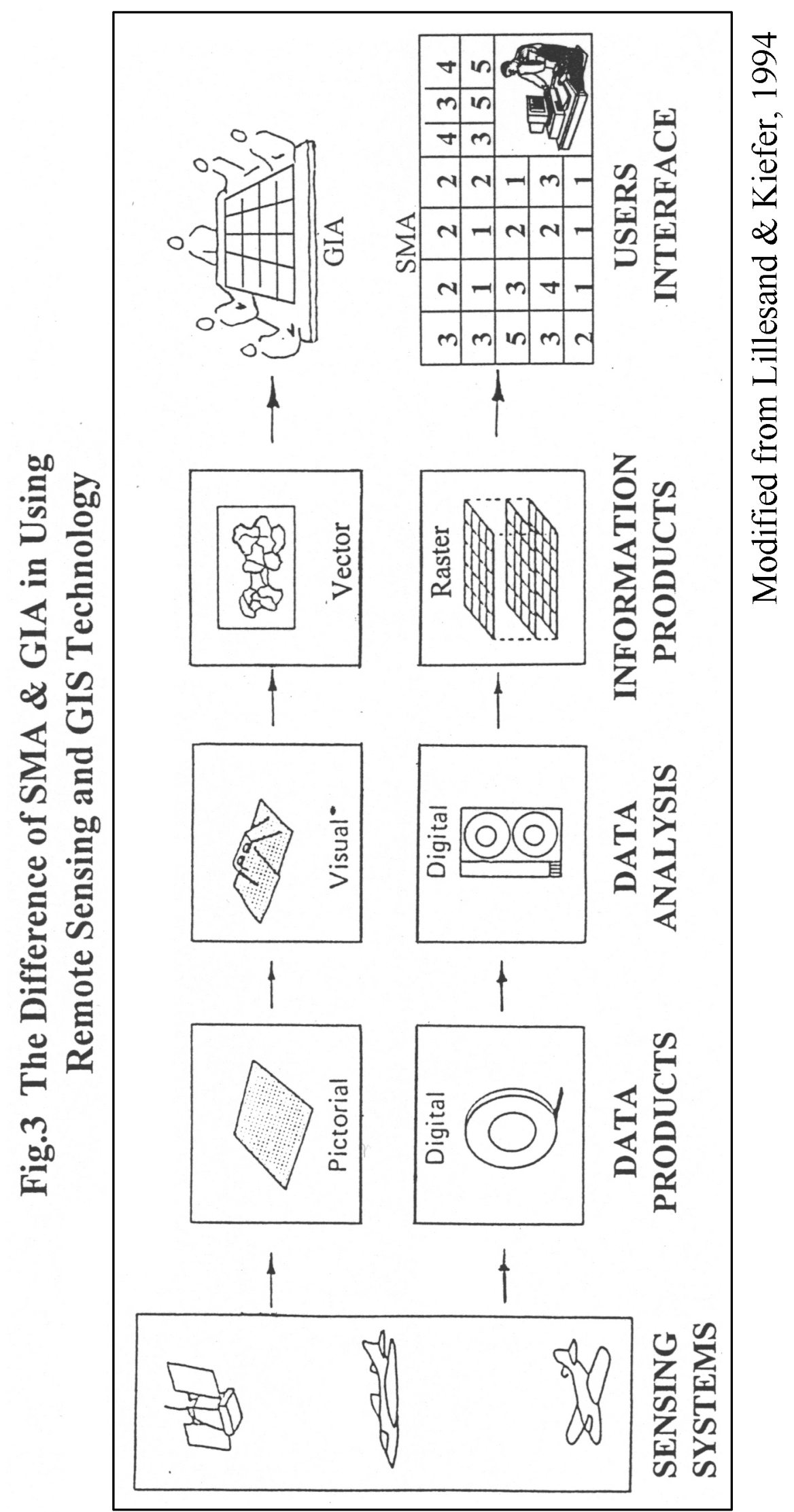


constraints associated with the development of large graphical vector databases. Not least, it facilitates an automated routing process, especially in areas where only limited maps or information is available. Thus, SMA could be argued to provide not only a more rigorous route selection methodology but also one which can effectively utilize the many advantages and benefits of digital satellite data.

Thirdly, by understanding the process by which decisions regarding least impact corridors are identified using constraint maps and visual analysis within the traditional analog and GIA method, many rule sets or rule-based models can be developed as knowledge representations which can be replicated in a computer-usable format by other users. Efforts to develop such a knowledge-based SMA could provide a powerful solution to a wide range of routing problems for graphically oriented designers, not least by supporting them with alternatives at the preliminary design stage of siting linear facilities.

\subsection{Dealing with Uncertainty in Semi-automated Modeling for Route Selection}

As stated earlier, most computer or GIS based modeling approaches to route-selection can be regarded as one of finding a path between a given origin and a destination which optimizes an objective function based on engineering construction cost, environmental impact, or possibly socioeconomic benefits (Goodchild, 1977). Usually, three steps are involved (Giles et al, 1976; Huber \& Church, 1985; Church et al., 1992): (1) a study area is defined in readiness for data collection and a multi-source database is constructed using available analog or digital data such as remotely sensed data sets; (2) a base suitability score is calculated and a routing network constructed; (3) a modified shortest path algorithm is applied to the raster defined network working from an origin cell to a destination cell such as to locate a string of contiguous cells that in sum have the least cumulative cost scores or maximized suitability score.

The above phased methodology utilizing a shortest path analysis seems to form the basis for what should be an equitable method for locating utility corridors. However, it also 
raises many questions, which have been examined and tested by Hopkins (1973), Goodchild (1977), Huber et al. (1985), Lombard et al. (1993), and Dean (1997). Logically, problems result from the process of constructing the initial cost surface and applying a shortest path algorithm to linear routing in a restricted network defined by grid-cells. More specifically, the effectiveness and efficiency of the modeling approach is significantly influenced by a number of factors including inaccurate database creation; an infinite spatial resolution selection potential; subjective base suitability score assignments; infinite permutations of directional moves for routing in a discrete lattice surface; and limited solutions to multi-objective and dynamic routing problems in planning practice.

\subsection{Improving Routing Accuracy in Using Semi-automated Modeling Approach}

In this work some problems associated with semi-automated approaches to route selection are pursued and solutions to the problems are proposed. The study addresses the manner in which the fundamental cost surfaces are constructed, including the identification of an optimal cell size and base suitability score assignment. Usually, computational cost is a major criteria in cell size determination, and large cell sizes are favored for use in vectorto-raster data conversion so that modeling is feasible for a large study area. This can be problematic for severe inaccuracies may result due to the loss of important spatial information at finer resolutions such as residential units, historic sites, and similar small features. Sensitivity analysis is thus suggested here as an additional rule to be added to cope with routing uncertainty caused by arbitrary cell size determination.

Linear cumulative models are commonly used to assign base scores for each cell of a lattice surface after a subjective weighting and scoring schema has been applied. There seems to be many reasons to explore the possibility of building different evaluation models (EM) that can reflect complex interrelationships among the various variables, which are ignored by the traditional cumulative models. Six discrete index models are reviewed and evaluated on the basis of difference and similarity in their behavior and the resultant friction surfaces which are generated. Also, a combination theory based aggregation 
algorithm is suggested in order to explore the potential of using data aggregation functions in the construction of cost surfaces.

Although many algorithms have been developed for solving the shortest path problem (SPP), only three algorithms are analyzed here: the Dijkstra Algorithm (Dijkstra, 1959), the Bellman-Ford Algorithm (ESRI, 1997), and the Eastman Pushbroom Algorithm (Eastman, 1997). These three algorithms have been selected based on their computational efficiency and because they all support cell-based linear route modeling within Arc/Info and IDRISI currently the most popular GIS software on the market. As their effectiveness is an important but unproven issue, the sensitivities of the algorithms to different directional moves, spatial resolutions, and positional accuracy are tested through the use of a simulated data set before any of the algorithmic approaches are actually applied to linear facility siting in the real world.

Finally, the many uncertainties inherent in the methodology of SMA cast some doubt on the ability to find the optimal path with a single application of a shortest path algorithm. It is thus necessary to undertake a systematic and iterative search for routing alternatives in using such a modeling approach. For example, changes in the suitability score calculations of multiple variables or objectives can unintentionally alter the alignment of the "optimal" least cost path, and some sub-regions within a study area can change their relative importance over time and become new barriers to routes modeled at the initial onset of a routing process. Hence, a successful modeling approach should be able to reflect these multi-objective and dynamic routing problems. In so doing, an ordered weighted combination modeling approach and a well known gateway algorithmic approach have been designed and introduced to address these real problems.

\section{4. Research Objectives}

\subsubsection{Overall Research Objective}


The overall objective of this research is to model and identify transmission line corridor routes based on digital environmental cost surfaces through the use of an algorithmic semiautomated approach within a GIS. The study then seeks to compare the relative advantages and disadvantages of a semi-automated modeling approach (SMA) with that of a graphical intuitive approach (GIA) in defining such routes.

\subsubsection{Specific Research Objectives}

Five specific research objectives concerning route identification using SMA are posed and addressed in this study:

1) To undertake a semi-automated modeling approach to a $765 \mathrm{kV}$ power line route selection.

2) To examine the most well known shortest path algorithms and their searching techniques in undertaking linear routing in a discrete lattice surface. This poses the question as to whether significant instability exists dependent on the use of different algorithms, resolutions, and directional links.

3) To assess the effect of modeling environmental phenomena via cost surfaces generated from varying interpretations and scores of environmental impact.

4) To test how routing outcomes are influenced by varying cell size as well as by employing different rasterization techniques. In particular, what is a suitable spatial resolution for modeling $765 \mathrm{KV}$ transmission line corridors when the base data is captured from 1:24,000 scale topographic and thematic maps.

5) To compare a SMA with a GIA in terms of their resulting corridor placement(s) and cumulative environmental impacts. To what extent can human intuitive judgment be digitally modeled for solving multi-objective and dynamic routing problems.

\subsection{Methodology}

Although GIA has been a very effective method to locate utility corridors in the real world, it is argued here that, as spatial information technologies and digital data sets become more widely available, GIS-based SMA is going to be utilized increasingly for addressing linear 
facility location problems. The main focus of this work is to identify potential power line corridor routes using a cell-based modeling approach within ESRI's Arc/Info software. Although remotely sensed digital data would greatly facilitate the database development for such a purpose it is not pursued here because it lies outside the primary focus and scope of this work. It would however, be a rational contribution to SMA development.

The structure of the thesis is such that it provides an overview of the literature on general approaches to linear facility siting in Chapter One, in which three methodologies are identified: traditional analog system methods, graphical intuitive approaches, and a semiautomatic modeling approach. In spite of the availability of improved pathway analytical functions provided by current GIS and remote sensing products, as well as other software packages, many problems still exist in the computerized corridor location modeling, especially in cell-based SMA where the area under study is divided into equal sized grid cells and corridor selection is based on routing in a raster defined network. Major errors or uncertainties with SMA are reviewed in detail in Chapter Two, most of them are related to cost surface generation and the application of modified shortest path algorithms to routing in a restricted network.

In Chapter Three possible solutions to the problems raised in Chapter Two are proposed and tested based on a review of current research and development in the field. The first issue concerns the determination of a suitable cell size for vector-to-raster data conversion. Usually, the selection of a suitable cell size is determined based on computational cost and multi-source data accuracy. It is suggested here that cell resolution sensitivity analysis is particularly useful in maintaining an effective and efficient model. Secondly, based on concepts of multi-criteria evaluation (MCE) widely used in spatial decision-making in GIS, six kinds of impact index models are compared based on their different focus and behaviors, and three of them are selected as Evaluation Models (EM) for use in generating cost surfaces supporting transmission line routing. Furthermore, a combination theory based aggregation algorithm is introduced to build three additional EM or reclassification models. Thirdly, in pursuing an efficient algorithmic approach to the shortest path 
problems, I focus on the Dijkstra's algorithm (1959), the Bellman-Ford algorithm (Dreyfuss, 1969; Lawler, 1976), and the Eastman Pushbroom algorithm (1989), all of which are currently used to support cell-based linear route spatial analysis within Arc/Info and IDRISI software. Their effectiveness is also tested by means of a sensitivity analysis using a hypothetical data set, so that the modeling process within the GIS software can be fully understood and evaluated, and confidence in the approach can be assessed by building on the detailed examination of possible routing uncertainties.

Based on the theoretical analysis and the extensive exploration of the issues in Chapters Two and Three, a case study is conducted in Chapter Four to actually model a proposed $765 \mathrm{kV}$ power transmission line route between two stations straddling the states of West Virginia and Virginia. The general process involves three stages: 1) performing a vector-to-raster data conversion using POLYGRID command within Arc/Info; 2) assigning an integer number for each of the environmental constraints to represent its relative environmental importance and to use data aggregation techniques and EM to generate environmental cost surfaces; and 3) to generate a least-cost power line corridor with the CORRIDOR command and delineate the least cost path using the COSTPATH command within Arc/Info.

It has been proven in the APCo project over the past eight years that large linear facility location must deal not only with multi-objective goals but with dynamic routing problems. Many features in the study area have changed their relative importance over time and can become additional barriers, permeable or impermeable, to routing the power line corridor. For example, the new housing is constructed, rare and endangered species migrate, historical structures become eligible for historical preservation status, and the Wild and Scenic River status of the New River is extended further upstream. Therefore, it is important to be sensitive to the dynamic nature of the region and the 'problems' that this entails in developing a modeling framework. Indeed, as the APCo study has demonstrated, a proposal to build a power line through this region has actually acted as a catalyst spurring groups to determine and adopt preservation status on both cultural and environmental features. A dynamic database and model should thus be considered the 
norm, and not the exception. In Chapter Five, by further pursuing the power line route selection as an example, the effectiveness of SMA in practice is tested based on route simulations. To this end, several ordered weighted linear combination models (OWC) are applied to the power line siting model in order to examine routing sensitivity within the multi-objective decision space. Furthermore, a gateway approach is similarly tested. By so doing, the roles of knowledge-based intuitive judgment used within GIA can be expressed by changing the relative weighting in the modeling process and the effectiveness of SMA assessed in a broader context. This finally leads to an application-oriented comparative study for evaluating the relative powers between the algorithmic approach and the graphical intuitive approach to linear route selection with GIS over a large area. 


\section{CHAPTER 2: ISSUES ASSOCIATED WITH A \\ SEMI-AUTOMATED MODELING APPROACH}

\subsection{Network Models For Route-Location Problem}

Route-location problems typically involve defining a path between a given origin and destination that minimizes cumulative costs, whether economic or otherwise, or optimizes a specified objective function (Hopkins, 1973; Ostresh, 1973; Goodchild, 1977; Wilf, 1986). Both vector and raster defined network models have been used to address optimal linear route siting by postulating them as a) shortest-path problems (SPP), b) least-impact problems (LIP), or c) the least-cost problem (LCP). In graph theory, a weighted directional graph is a typical vector network model used to solve the shortest path problem (SSP). As

\section{Figure 4: A Classical Vector Network Model}

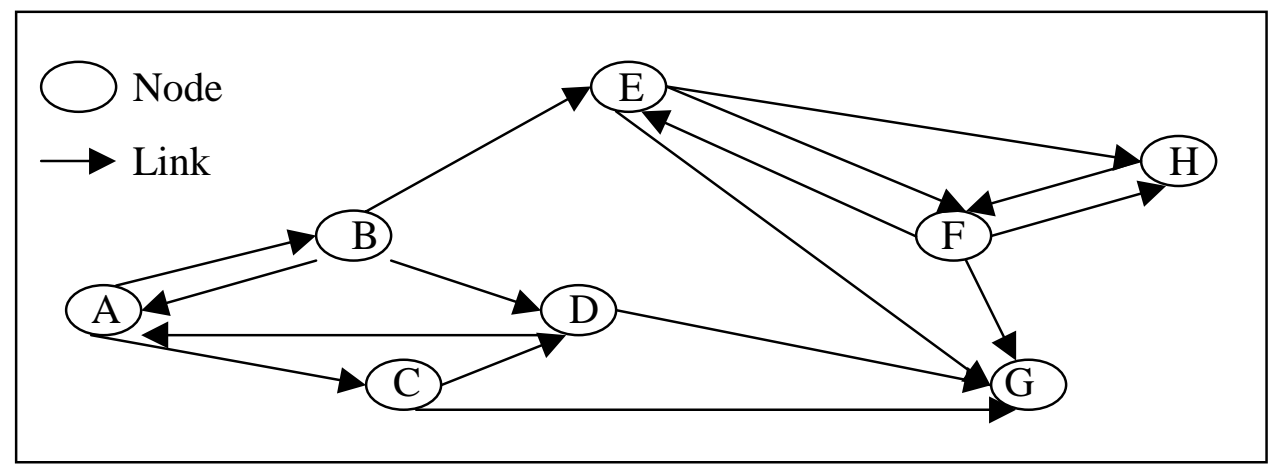

shown in Figure 4, this model is composed of punctual nodes and linear weighted directional links between the nodes. Dijkstra (1959) designed a widely used algorithm to find a set of shortest paths from a specific location to all other locations in the network, in which spatial nodes are connected by weighted links that can represent physical distance, environmental impact, economic cost, or traveling time incurred in moving between adjacent nodes. 
In the area of geographical analysis, two different approaches have been suggested for identifying shortest path based on two different definitions of an underlying network. The first general approach has been used by Angel and Hyman (Lombard \& Church, 1993), and Smith et al. (1989). It rests on the development of a network structure that is based on the polygonal layout on which a route is viewed as the path that represents a series of arcs on the network. It defines a path such that that an optimal path will change direction only when it crosses the boundary of a polygon that represents a homogeneous area. Thus, the underlying structure in which an optimal path can be found is a network consisting of all nodes on polygon boundaries as well as the set of links among the nodes. Smith et al. (1989) further simplified this view by reducing the set of potential nodes from an infinite number to a discrete number of points along each boundary.

The second approach solves the route-location problem by finding a path through a lattice surface or a raster defined network via the use of a modified shortest-path algorithm (Hopkins, 1973; Giles et al., 1976; Goodchild, 1977; Huber \& Church, 1985; Eastman, 1989; Lombard \& Church, 1993). In this, polygonal data are converted into grid cells and each node is considered as being the centroid of a cell. Arcs are the links which connect the nodes. The least-cost linear route siting problem is thus approximated firstly by representing the study area as a rectangular lattice, and then by finding the shortest-path via a series of moves or links through the cell-based network. Most corridor location models employ the raster defined network model for linear facility placement across a landscape (Lombard \& Church, 1993), because there are several advantages to this approach; for example, it places no restrictions on the distribution of cost over the study area, introduces an explicit level of spatial resolution to the study, and makes the problem finite and tractable (Goodchild, 1977).

However, many problems also exist in such a grid cell-based modeling approach which are primarily related to the construction of the lattice-defined discrete cost surface and the fact that most modified shortest-path algorithms were originally developed to operate within a well defined vector, not raster, network. In the sections that follow, these and other 
uncertainties in the use of SMA are reviewed and discussed. These uncertainties are crucial because they significantly influence the outcomes of a semi-automated approach. They include the arbitrary determination of cell size, the orientation of the rasterization that can result in inaccurate database creation, infinite spatial resolution selection potential in the cost surface generation, subjective base suitability score assignments to cell-links, infinite directional moves to routing in a raster defined network, and limited solutions to multi-objective and dynamic problems in routing practice.

\subsection{Parameter Ambiguity In Data Rasterization}

Although some cell-based source data, such as remotely sensed digital data, provide the opportunity for direct use within a raster-defined routing network, much of the information available occurs in the form of maps. Most of these maps are in vector form, and have to be converted into a raster data format for use in a cell-based SMA. Because vector and raster data models use quite different concepts of "object-based" and "field-based" space to represent spatial information about the world (Walsh, 1987; Lunetta et al, 1991), several parameters have to be identified to facilitate vector-to-raster data conversion. These include cell size, orientation, and the method of rasterization (Carver \& Brunsdon, 1994).

Several earlier empirical studies have noted that increased cell size has a significant effect in reducing map accuracy (Nicols, 1975; Hord \& Brooner, 1976; Van Genderen \& Lock, 1977). Muller (1986) demonstrates that the relationship between the misclassified area on raster maps is linearly related to cell size. A recent experimental study on landuse map rasterization also shows that cell size has a considerable impact on the quality of the resultant raster database. Therefore, many uncertainties or possibilities in determining cell size have the potential to result in varying and possibly 'inaccurate' database creation which is compounded by the possibility of an infinite spatial resolution selection for use in lattice surface construction. 
Inappropriate orientation determination also has a significant influence over routing results. Common practice is for the raster grid to be orientated parallel to the coordinate system of the source data (Huber \& Church, 1985; Carver \& Brunsdon, 1994) This universal alignment is actually arbitrary and can result in a geometric distortion of the routing process. Huber et al. (1985) defined such routing errors caused by grid orientation as 'orientation distortion' - one of many possible geometric distortions associated with the identification of a corridor route through the use of a lattice grid.

The method of rasterization also exerts other important controls over the rasterized vector map. Two basic approaches dominate current rasterization procedures and these are 'central point' and 'dominant unit' (Eastman, 1997; ESRI, 1997). Furthermore, resampling is also frequently used to regenerate data in a raster format. All of the rasterization methods are challenged by the complexities of different mapping scales and mapping accuracy, and the diversity of polygon shapes within multi-source databases required by the SMA.

\subsection{Subjective Suitability Score Assignment}

Vector routing networks are specifically determined by arc attributes and the directions of these arcs are generated by a variety of means within a cell based lattice surface. Routing processes begin by assigning suitability scores to cells through which arcs are directed. Invariably these cell scores are generated through a weighted combination representing a numerical value of suitability, dollar cost, or environmental impact. Therefore, objectively assigning a score to each cell directly will affect the quality of the raster defined network and the resultant linear route placement.

Many methods and techniques have been designed for use in environmental impact assessment (EIA) or suitability analysis. They include ad hoc approaches, overlays, checklists, matrices (McHarg, 1968; Sondheim, 1978; Rosemarin \& Wilson, 1976; Bisset, 1978; Jackson \& Hudman, 1978; Shopley, 1984; Conn \& Phil, 1986; Geertman et al., 
1995), and neural networks (Zhou \& Civco, 1996; Singh \& Treleaven, 1997). Among them, digital map overlays, weight-scaling checklists, and mathematical matrices have been commonly used in EIA. The checklists and matrix techniques contain common means whereby the extent and magnitude of environmental impacts can be identified and organized arithmetically for the comparison of seemingly incomparable and noncommensurate factors. The overlay method can be utilized to produce a suitability map from a series of Boolean operations and is very similar to the approach used in GIS.

Based on the concepts and techniques outlined above, a multi-criteria evaluation (MCE) approach has been used and integrated into a GIS for spatial decision-making (Voogd, 1983; Carver, 1991; and Eastman, 1997). Steps within MCE typically represent the major

Figure 5: General Model Of MCE

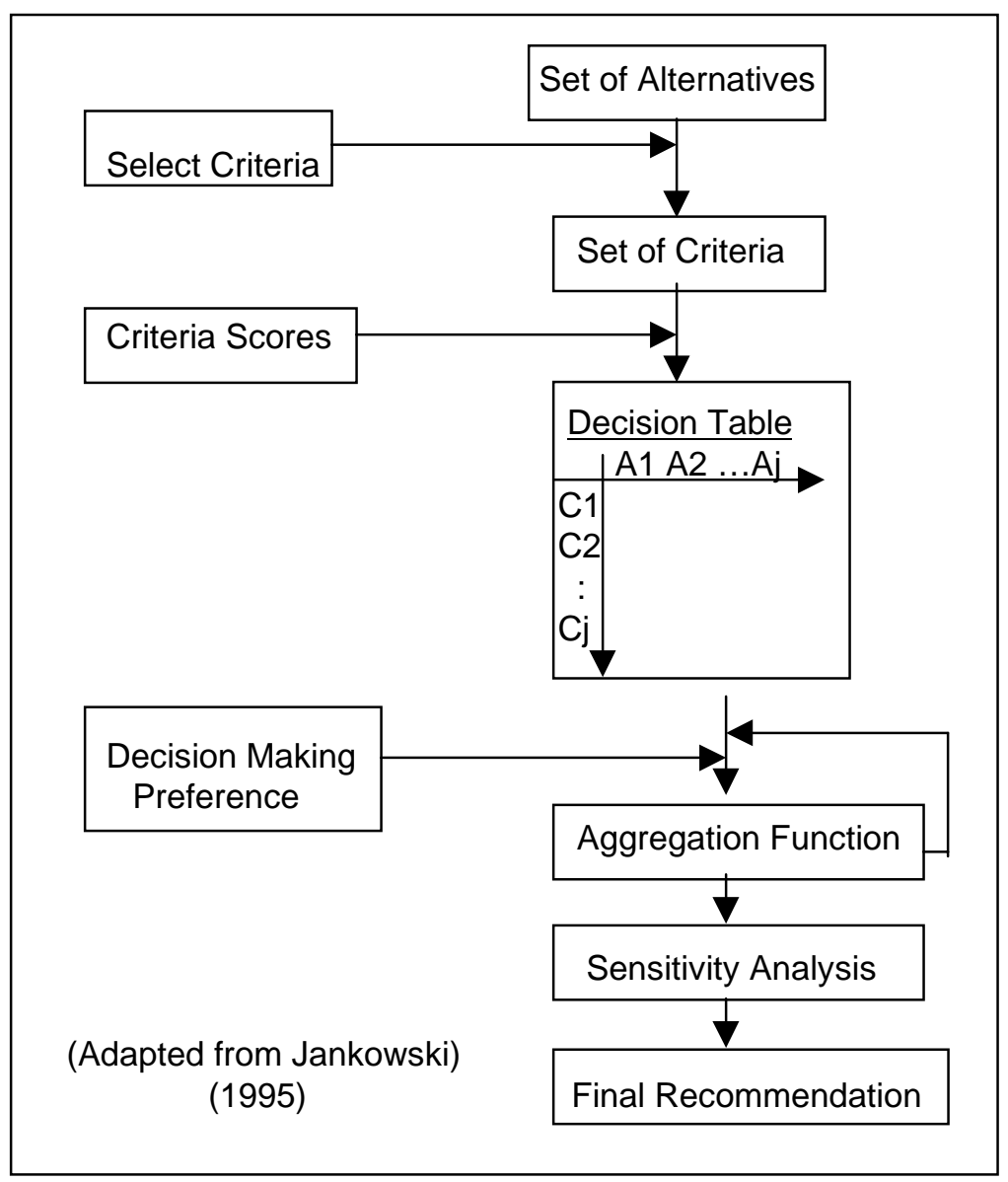


stages of current quantitative EIA. Jankowski (1995) gave a general model of MCE (Figure 5) in which a set of criteria is selected according to the alternatives under consideration. After all the relevant criteria have been identified, the criterion scores, which indicate for each alternative the impacts on each criterion, are then determined. The importance of each criterion is usually evaluated by means of a weighted score. Finally, the weighted criteria scores are combined to produce a final impact or suitability result.

Decisions as to which environmental factors or constraints are to be considered cannot be made without reference to some framework of environmental and socioeconomic values. The differing value systems of project developers, environmental experts, and local communities tends to lead to differing selections of criteria, weights, and scores.

\subsection{Infinite Directional Moves To Routing In A Lattice Surface}

In a cell-based modeling approach to linear route siting, raster defined networks consist of nodes and arcs where all nodes are assumed to be the center of cells and all arcs linking the nodes define moves permitted on the cell-based discrete lattice surface. Huber and Church (1985) specifically defined a R-valued system based on the numbers of linking nodes. As shown in Figure 6, $\mathrm{R}$ is equal to zero when only four adjacent closest nodes are linked (6a). When eight adjacent closest nodes are linked together then $\mathrm{R}$ is equal to one (6b). A higher $R$-valued system is defined by linking 16 nodes $(R=2)(6 c), 32$ nodes $(R=3)(6 d), 64$ nodes $(\mathrm{R}=4)$, or even more nodes $(\mathrm{R}>=5)$. Obviously, orthogonal links $(\mathrm{R}=0)$ only represent the set of moves a rook can take on the lattice surface, while queen's and knight's move are permitted after diagonal links $(\mathrm{R}>=1)$ are included to construct the routing network on lattice surface.

As $R$ increases, especially by linking non-adjacent closest nodes $(R>=2)$, the total number of directions available to move from a cell also increases. Intuitively, this increase in directional possibilities leads to an increase in the number of arcs that represent the network defined about the grid, and should result in a more accurate linear routing process 
Figure 6: Different Cell-Based Links

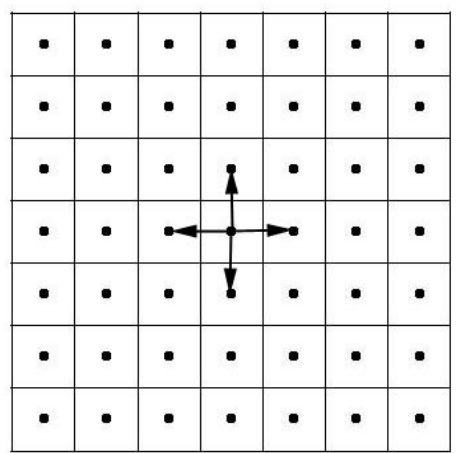

6a.4-cells linking

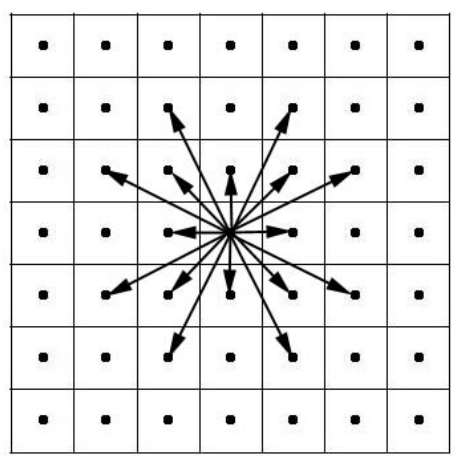

6c.16-cells linking

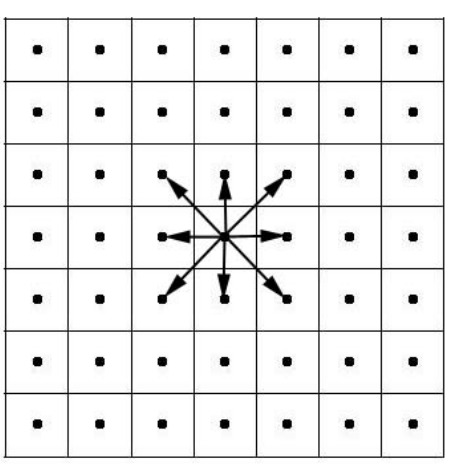

6b.8-cells linking

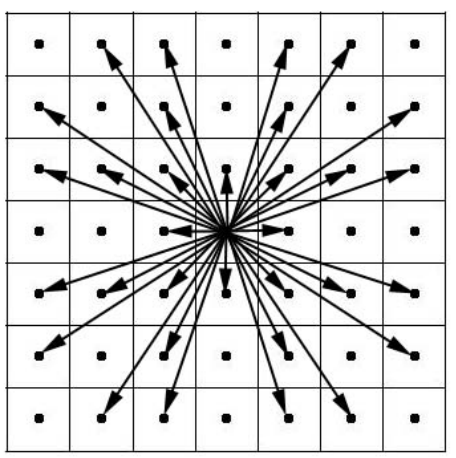

6d.32-cells-linking 
Huber \& Church (1985) demonstrate the improvement of routing accuracy with the inclusion of diagonal links, based on elongation error, which is mathematically defined as the ratio of the cost of the calculated least cost path to the true least cost path (Goodchild, 1977). Given a R-valued routing system, the maximum possible elongation error can be expressed wholly as a function of $R$, i.e., $E(R)=2 r[(1+R) /(r+R)]$, in which $r=R /((R+1)$ $+\mathrm{R})$ and $\mathrm{R}$ is an integer greater than zero. In this case the different links permitted result in the following elongation errors $\mathrm{E}(\mathrm{R})$ (Huber \& Church, 1985):

$$
\begin{array}{ll}
\mathrm{R}=0(\text { ( } 4 \text { cell links) } & \mathrm{E}(0)=41 \% \\
\mathrm{R}=1(\text { ( } 8 \text { cell links) } & \mathrm{E}(1)=8.2 \% \\
\mathrm{R}=2(16 \text { cell links) } & \mathrm{E}(2)=2.79 \% \\
\mathrm{R}=3 \text { (32 cell links) } & \mathrm{E}(3)=1.3 \% \\
\mathrm{R}>3(48 \text { cell links) } & \mathrm{E}(>3)=<1 \%
\end{array}
$$

The above indices indicate that four neighboring cells linking $(\mathrm{R}=0)$ produces the greatest geometric distortion. By adding four adjacent diagonal links $(\mathrm{R}=1)$ to the orthogonal links based network $(\mathrm{R}=0)$, the elongation errors can be reduced dramatically. The errors can be minimized substantially after eight non-adjacent diagonal links $(\mathrm{R}=2)$ are added. While the geometric accuracy increases rapidly with the inclusion of eight non-adjacent closest linkcells, the error decreases only slowly for additional higher ordered routing systems $(R>3)$. More importantly, geometric distortion such as elongation error can never be reduced to zero because on a hypothetical lattice surface, the possible links are infinite and a significant price in computational resources is paid to eliminate all elongation errors.

\subsection{The Multi-objective Dynamic Routing Problem}

In most location-planning for large linear facilities, the decision-making process usually involves possible conflicting issues such as economic growth demand and environmental protection associated with geo-politics in a democratic society. Route selection is usually a multi-objective planning process, in which possible conflicting objectives co-exist. Even 
with a single objective, for example minimizing environmental impact, many different viewpoints of environmental protection, represented by different special interest individuals or groups, can be found. Within the context of the multi-objective planning problem, the simultaneous optimization of several objectives or sub-objectives, such as maximizing economic profits and minimizing environmental impact, can be required. However, routing procedures can only be regarded as being at best limited searches toward a sub-optimal solution in a multi-objective decision space, because the conflicting objectives force the selection of a non-inferior solution and pareto-optimality (Church et al., 1992). Because objective measurements such as economic cost and environmental impact are usually estimates, and reaching consensus on the criteria for the multiple objective planning problem can be difficult, seeking 'optimality' in route selection becomes a quest which is rarely completely achieved in reality.

On the other hand, public opinion regarding environmental protection are not only critical to route selection but usually dynamic in that they can change over time as economies, technologies, or values change. As a result, the selection of routes could be invalidated by the passage of time and the formalization of evolving societal values by the implementation of regulations and statutes which change the relative ranking of environmental criteria used in a routing project. Moreover, alternative routes may be preferred and pursued by the public, politicians, project developers or regulatory bodies. Both situations indicate that an 'optimal' solution may be viewed in many ways other than as the result of a multi-objective function. 


\section{CHAPTER 3: SOLUTIONS TO ROUTING UNCERTAINTY WITH SMA}

\subsection{Suitable Cell Size Determination}

Accurate vector-to-raster data conversion plays an important role in creating a high quality database for use in a raster defined SMA study. An inappropriate choice of cell size may result in proximity geometric distortion (Huber \& Church, 1985), which is caused by arbitrarily assigning different friction values to neighboring cells that define the same feature on the ground. Cell size determination is, however, a rather arbitrary process and is invariably dependent on user judgment and a desire to balance database accuracy, database size, and processing time. The selection of cell size rarely 'captures' the cartographic accuracy of the original source data because a multiple source database often includes numerous source data sets captured at different mapping scales, spatial resolution, and positional accuracy.

Given these constraints, a researcher can only hope to find a way by which a suitable cell size is identified. Some specific rules have been proposed, for example, matching the raster size to the spatial resolution of the source data (Meyers et al., 1974); selecting a raster size in which $50 \%$ of the space is occupied by the smallest polygon; and considering the width of the zone of influence on either side of the corridor (Goodchild, 1977; Huber \& Church, 1985; Lombard \& Church, 1993). Cell resolution sensitivity tests were used in this study to select suitable cell size(s), and were based on incorporating the above three rules to define the possible range of cell size.

\subsection{Environmental Quantification And Evaluation}

Although assigning weight values to the grid cells is the most subjective and controversial step in modeling linear routes, as mentioned in Chapter 2.3, some techniques can be used to reduce some of the subjectivity involved in these decisions. These techniques can involve the use of a team of multidisciplinary experts to perform 
environmental evaluation and incorporate public opinions into the evaluation process, including constraints identification, scores assignment, weights determination, and combination function selection.

\subsubsection{Scoring \& Weighting}

Several techniques have been identified to quantify of environmental impacts. The most widely used quantification methods in environmental impact assessment (EIA) include scoring and weighting approaches such as the Delphi technique (Margaret \& Schofer, 1973); the normalization technique (Dobson, 1979; Voogd, 1983; Huber \& Church, 1985); and the Analytical Hierarchy Process (Eastman, 1997; Warner \& Diab, 1997). The Delphi technique is an integral part of the weight-scaled checklist method which was originally designed to derive commensurate impact scores for the comparison of project alternatives. Although alternatives are ranked in order of total impact scores, the intermediary judgments supporting the final order are available for inspection, debate, and possible amendment. In other words, the impact weights and scaling functions are explicit in this approach.

The 'precision' and 'accuracy' of these score and weight assignments can also be improved by applying normalization techniques to deal with the different scales upon which features are quantified. Voogd (1983) reviews a variety of procedures for normalization such as the linear scaling function and the fuzzy set membership function. The former uses minimum and maximum values as scaling points while the latter provides a range of fuzzy sets for the standardization of constraints. Huber \& Church (1985) particularly recommends another normalization technique to calculate a suitability score matrix: the nominal group technique. This technique involves a four step process in which each step involves a value judgement by all the participants in the study, and the final impact indices and importance weights are quantified on a scale of 0-10.

Another promising quantification technique is the Analytical Hierarchy Process (AHP) method, in which weights are derived by taking the principal eigenvector of a squared 
reciprocal matrix of pairwise comparisons between the criteria (Eastman, 1997; Warner $\&$ Diab, 1997). The comparisons concern the relative importance of two criteria involved in determining suitability for the stated objective. Ratings are provided on a nine-point continuous rating. The advantages of this method are that an individual or group can compare every possible pairing and enter the ratings into a pairwise comparison matrix of weights. The degree of consistency used in developing the ratings can be computed to reevaluate the matrix because the complete pairwise comparison matrix contains multiple paths by which the relative importance of criteria can be assessed. In fact, the matrixbased procedure proposed for scaling attitude scores about environmental impacts is particularly suited for gauging and structuring public opinion for environmental impact analysis.

\subsubsection{Evaluation Models}

After determining a scoring and weighting schema, an evaluation stage is necessary in order to combine or integrate the impact indices of all constraints into a simple cumulative impact index value. This index value can be based on selected aggregation functions or evaluation models. By way of example, consider the study area (SA) as a raster data model defined 2 dimensional digital space CELL(i) $[i=1,2, \ldots, n]$, which supports linear route siting with SMA in a Euclidean environmental space, and assume:

$$
\mathbf{S A}=\sum_{i=1}^{n} C E L L(i)=\operatorname{CELL}[\text { row }][\text { column }] \quad(\mathrm{n}=\text { row } * \text { column }, \mathrm{n}: \text { integer })
$$

Let $\mathrm{m}$ donate the number of environmental constraints or categories, and $\boldsymbol{X}$ environmental constraint values assigned. Then, an environmental friction surface $\mathbf{A}(\mathrm{i})[\mathrm{i}=1,2, \ldots, \mathrm{n}]$ can be expressed as a mathematical combination of all environmental constraints, i.e.,

$$
\mathbf{A}(\mathrm{i})=\vec{X}=\{X i j\} \quad(\mathrm{i}=1,2, \ldots, \mathrm{n}) \&(\mathrm{j}=1,2, \ldots, \mathrm{m})
$$


Four approaches can be used to explore relationships among constraints shown in formula (1). These, in turn, result in four types of aggregation functions or evaluation models (EM) that can be used to calculate total impact index value (TIIV) for every cell in the image CELL(i). The first approach is expressed in formula (2) and (3), in which TIIV is represented by the maximum constraint value or the product of all constraints:

$$
\begin{array}{ll}
\text { EM1: Ai }=\operatorname{Max}\left\{X_{i j}\right\} & (\mathrm{i}=1,2, \ldots, \mathrm{n}) \&(1 \leq \mathrm{j} \leq \mathrm{m}) \\
\text { EM2: Ai }=\prod_{j=1}^{m} X_{i j} & (\mathrm{i}=1,2, \ldots, \mathrm{n}) \&(1 \leq \mathrm{j} \leq \mathrm{m})
\end{array}
$$

As shown in formula (4) and (5), the second approach adopts a well-known weighted linear combination model (WLC), where continuous criteria (or constraints) are standardized to a common numeric range and are then integrated into a weighted linear combination model:

$$
\begin{array}{ll}
\text { EM3: } \mathrm{Ai}=\sum_{i, j=1}^{m} X i j * W j & (\mathrm{i}=1,2, \ldots, \mathrm{n} \text { and } W j<1) \\
\text { EM4: } \mathrm{Ai}=\sum_{i, j=1}^{m} X i{ }^{*}{ }^{*} W_{j}, & \left(\mathrm{i}=1,2, \ldots, \mathrm{n} \text { and } W j^{\prime}=1\right)
\end{array}
$$

The third approach is an ordered weighted combination (OWC) method (Liu et al., 1991; Eastman and Jiang, 1996). As shown in formula (6), the ordered weights $\boldsymbol{V}$ only apply to those factors as determined by their rank ordering or ordinary criterion weights $W \mathrm{j}$ achieved in the normal weighting step:

$$
\text { EM5: } \mathrm{Ai}=\sum_{j, l=1}^{m}\left(X_{i j} * \mathrm{~V} x i l\right) \quad(\mathrm{i}=1,2, \ldots, \mathrm{n})
$$


The fourth approach is a nonlinear square summation approach (Liu et al., 1991), expressed in formula (7). Here the features with the highest indices will be incremented in a nonlinear fashion while those features with low values are relatively dampened in the aggregation function:

$$
\text { EM6: } \mathrm{Ai}=\sum_{j=1}^{m} X_{i j}^{2} \quad(\mathrm{i}=1,2, \ldots, \mathrm{n})
$$

Among these models, WLC appears to offer good tradeoff qualities. A very poor quality can be compensated by having a number of very strong qualities and this represents a better method than either formula (2) and (3) that just represent AND \& OR operations. Furthermore, the method is positioned between the extremes of complete pessimism and complete optimism. In OWC, the degree of trade-off is further influenced by the relative distribution of weights among the ranked environmental constraints, and the decision rules can be manipulated into a triangular decision strategy space (Eastman, 1997). In formula (7), some important relationships among the constraints can be implemented, including non-linear and interdependency relationships.

With their unique aggregation functions, different EM will result in the formation of different friction surfaces, even though the environmental constraints are quantified in the same manner. This situation not only leads to alternative scenarios and greater diversity of surface response, but it also reflects more complex interpretations of environmental phenomena. This is similar to the manner in which different bands TM digital image are used simultaneously to capture ground objects within a same area of interest (AOI). Liu et al. (1991) designed a combination theory-based aggregation algorithm that seeks to generate a set of theoretical thresholds for each of the EM used in the ecological classification of land resources, such that comparative recommendations can be made for land development based on varying assessments of land quality. By adopting the aggregation algorithm into an environmental friction surface, different friction surfaces arise based upon varying interpretations of environmental impact. These can also be 
regenerated into simple comparative friction surfaces in which total environmental cost could be estimated on a comparative basis. Meanwhile, a simple friction lattice surface with smaller range of integer number always takes less storage space and computational time in routing process.

\subsection{Efficient And Effective Algorithmic Approaches}

Dreyfus (1969) reviewed many algorithms for finding the shortest path between two given nodes, and the Dijkstra algorithm (1959) was identified as the most efficient and typical algorithm to address the shortest path problem (SPP). The Bellman-Ford algorithm and Eastman Pushbroom algorithm have also been developed in cell-based modeling approaches to linear route siting within Arc/Info and IDRISI software, respectively.

\subsubsection{Dijkstra's Shortest Path Algorithm}

The Dijkstra algorithm is the most common algorithm in graph theory used to find the shortest-path on a vector network model (Dreyfus, 1969; Ostresh, 1973; Goodchild, 1977). Four specific steps are involved in executing this algorithm:

1) Label the origin node 'reached' and set its minimum path cost to zero. Label all other nodes 'unreached'.

2) Examine all links which directly connect 'reached' nodes to 'unreached' nodes. In each case add the link cost to the minimum-path cost at the 'reached' node to obtain a temporary minimum-path cost at the 'unreached' node.

3) Find the minimum temporary path cost in the network, label the corresponding node 'reached', and make the path cost permanent.

4) If the new 'reached' node is not the 'predetermined' destination, return to step 2.

This approach has been applied to linear route siting on raster defined digital surfaces and two assumptions are made to allow a cell-based discrete surface become similar to a graph (Gile et al., 1976; Economides \& Sharifi, 1977; Goodchild, 1977; Xu \& Lathrop, 1995). The first assumption is that each cell is 'shrunk' such that its center becomes a punctual 
node. Secondly, that the connections between the centers are assumed to be graph links. As a result of these two assumptions, two potential economies are obtained when routing on a lattice surface. First, the links need not be identified explicitly because they occur systematically. Second, it is likely that ties will occur between temporary path costs. Thus, step 3 can be executed repeatedly without returning to step 2 .

\subsubsection{The Arc/Info Approach}

Several specific modules have been designed within Arc/Info to address linear routelocation problems. These include COSTDISTANCE, COSTPATH, and CORRIDOR. Overall, only COSTDISTANCE does actual "cost path distance" mapping on node/link cellbased network representations. COSTPATH just uses the results of COSTDISTANCE to find the least-cost paths by traversing along the back-link move direction surface (eight neighboring links), while CORRIDOR only adds two distance grids with different origination(s).

The algorithms used in COSTDISTANCE for the path distance mapping include both Dijkstra's tree-building algorithm and Bellman-Ford's matrix algorithm. The combination of these two algorithms contributes to program efficiencies when applied to both small and large data sets (Zhan et al., 1993). Although the Dijistra shortest path algorithm usually works better with larger grid data sets and the Bellman-Ford algorithm with small grid data sets, there is no set threshold size at which to switch between them, all depend on the memory available in the machine, the data size, and the parameters selected in the COSTDISTANCE function.

As long as the origination and friction surface do not change, the COSTPATH function is efficient in running as many delineation as desired, with as many different destinations. More importantly, the lowest cumulative cost for each cell to an origin is identical, because the least-cost distance is calculated from each cell in the analysis window (ESRI, 1997). Thus, COSTPATH can effectively produce an output grid that records the least-cost path(s) from any selected cell(s), including gateway point(s), and destination to the closest source 
cell(s) including the origin. The CORRIDOR function gives an additional routing choice by generating the least-cost corridors through the use of a specified threshold determined by a user-defined conditional instruction.

\subsubsection{The IDRISI Approach}

In IDRISI, linear route siting is achieved by running COST and PATHWAY modules (Eastman, 1997). Given a friction surface and two points, the former generates a cumulative cost distance surface while the latter specifically identifies the least-cost path between two points on the cost distance surface. Here, distance is measured in terms of the least effort or cost involved in moving over a friction surface according to the minimum number of cells that must be traversed. By default, the maximum possible movement is in eight directions or eight adjacent cell links from any cell.

There are also two algorithms within the COST module which allow for the determination of cost distances: the pushbroom algorithm and the growth algorithm. The pushbroom algorithm is considered more efficient than the growth algorithm when applied to a large digital surface (Eastman, 1989), but does not work well with complex digital surfaces with street-like barrier patterns. In addition, the barriers can only be assigned by very high friction values which causes the base suitability score assignments to be more subjective and limits its utility when dealing with distributed constraint data sets that are not well distributed.

The PATHWAY module is used in conjunction with $\operatorname{COST}$ to determine the cost distance by moving over the friction surface from the point of origin. Usually, the point with the lowest value on the cost distance surface represents the destination used in the PATHWAY module. By working with the cost distance surface, PATHWAY can effectively identify the cheapest route, by following the steepest downhill route until no further movement is possible.

\subsubsection{Sensitivity and Effectiveness Testing}


Few comparative studies have been conducted to address the relative effectiveness of modeling linear routes with the Arc/Info and IDRISI approaches. Several specific questions, such as modeling sensitivity and accuracy, must be examined before the two approaches are used to simulate linear route siting in the real world. The following experiment seeks to examine the effectiveness and sensitivity of the two approaches using a controlled hypothetical spatial data set (Figure 7). The simulations focus on different algorithms, links, and spatial positional accuracy.

Algorithms: Based on the friction surface with 100 meter cell size (Figure 7), four shortest path algorithms are used in the routing sensitivity analysis. These include:

1) the Shortest path algorithm (Huber \& Church, 1985)

2) the Dijkstra-Lombard Gateway Algorithm (Lombard et al., 1993)

3) the Bellman-Ford algorithm (Arc/Info, 1997)

4) the Eastman Pushbroom Algorithm (IDRISI, 1997).

The routing results (Figure 8) illustrate that only the Dijkstra-Lombard Gateway algorithm generated a unique path, and the remaining three algorithms produce three spatially closed paths. This demonstrates that different algorithms themselves do not guarantee to generate spatially different least-cost paths.

Links: Huber (1985) tested the sensitivity of $k^{\text {th }}$ shortest path algorithm to different celllinking, and this included 4-neighboring cell links (orthogonal link, $\mathrm{R}=0$ ), 8-neighboring cell links (diagonal link, $\mathrm{R}=1$ ), 16-neighboring cell links (diagonal link, $\mathrm{R}=2$ ), and 32neighboring cell links (diagonal link, $\mathrm{R}=3$ ), using the same friction surface as above. As illustrated in Figure 9, the shortest path generated from the higher order system $(R=2$ and $\mathrm{R}=3$ ) are substantially different from the shortest paths on the lower ordered systems $(\mathrm{R}<=1)$. With the same friction surface, both the Arc/Info approach and the IDRISI approach surprisingly generated two routes that are very similar to those within the higher ordered systems $(\mathrm{R}>=2)$, even though only 8-neighboring cell links were included within Arc/Info and IDRISI approaches. 
Figure 7: A Hypothetical Data Set For Routing Process Simulation (Huber et al., 1985)

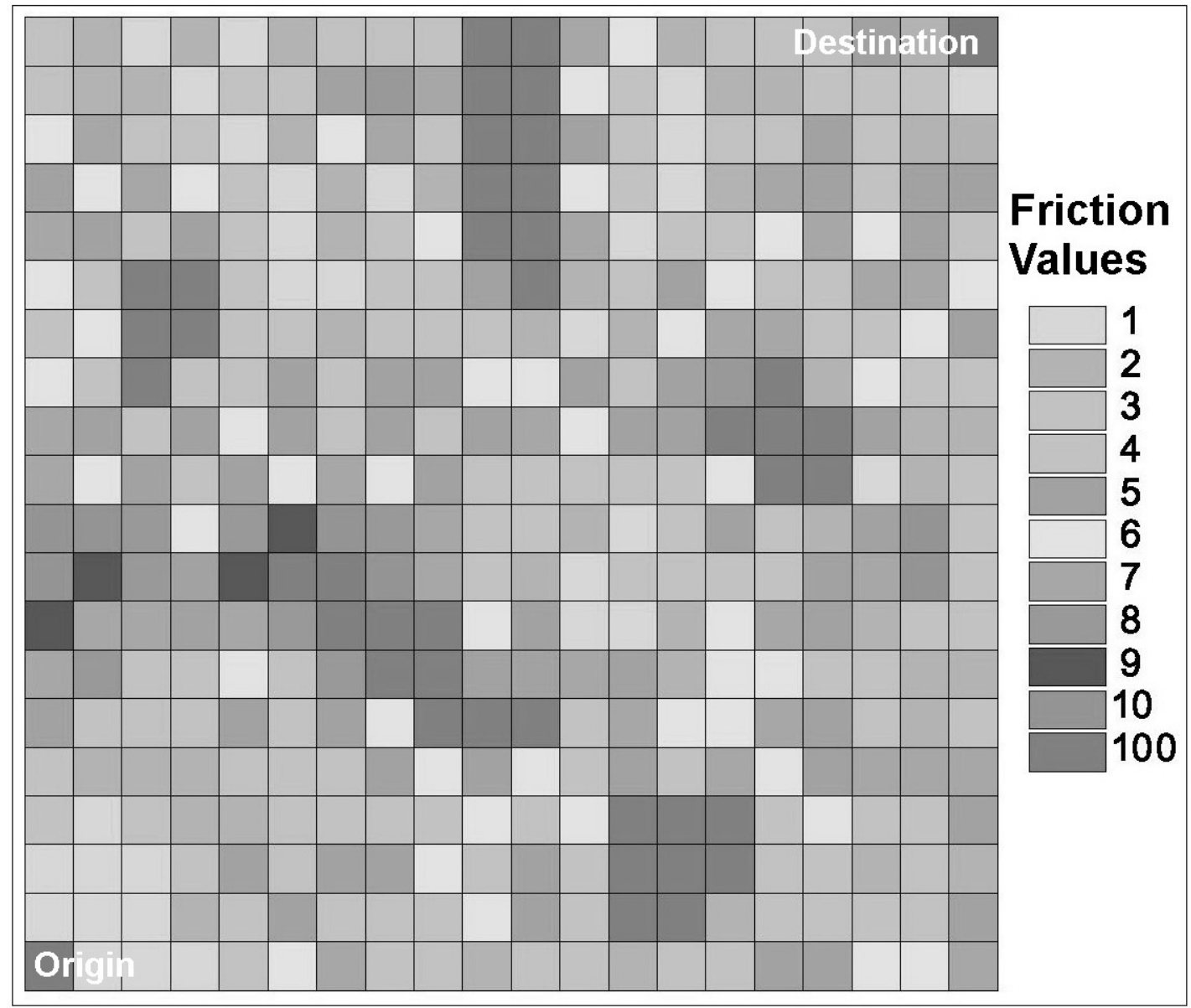




\section{Figure 8: Routing Sensitivity To Different Shortest-path Algorithms}

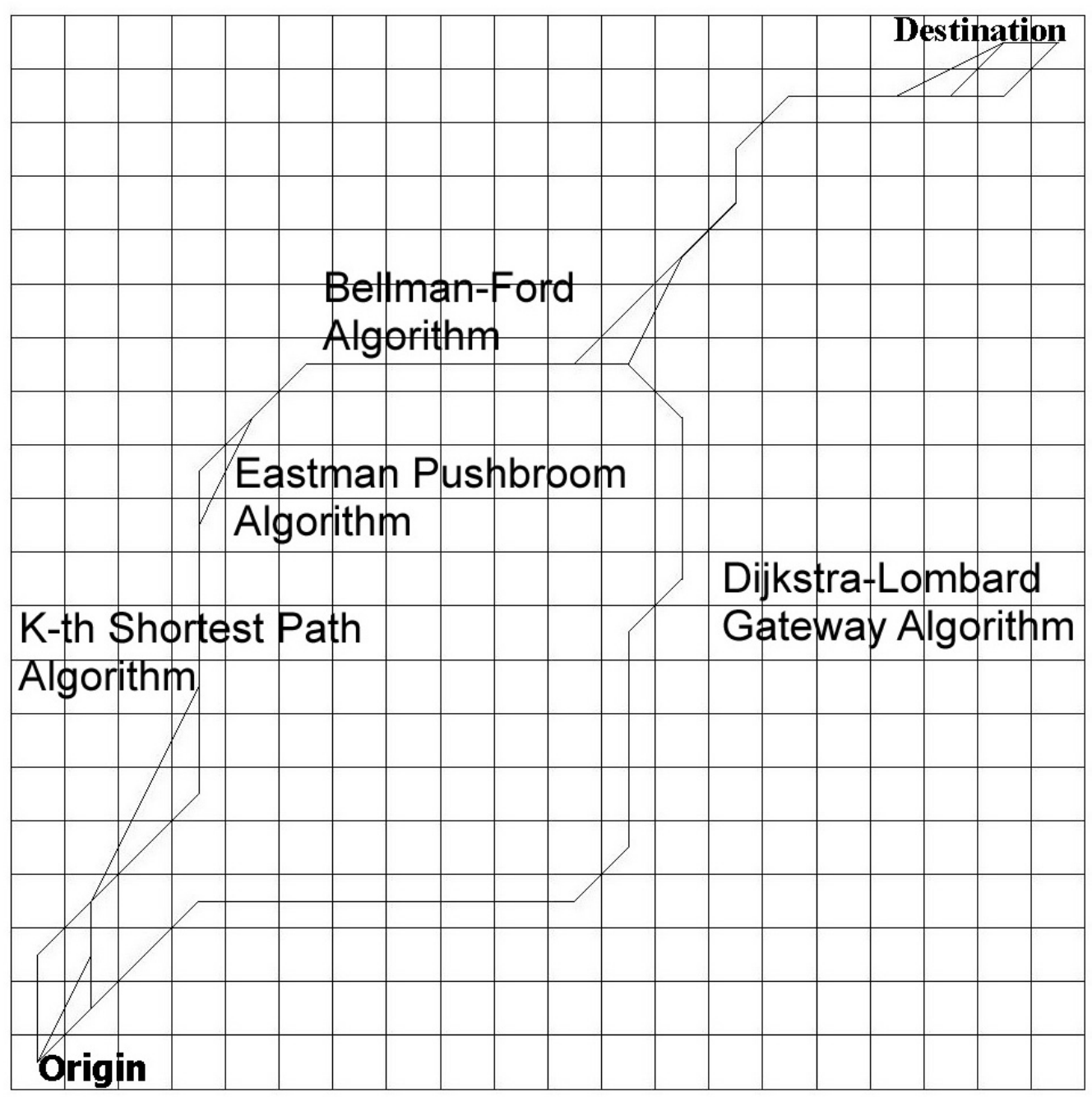


Figure 9: Routing Sensitivity To Different Cell Links

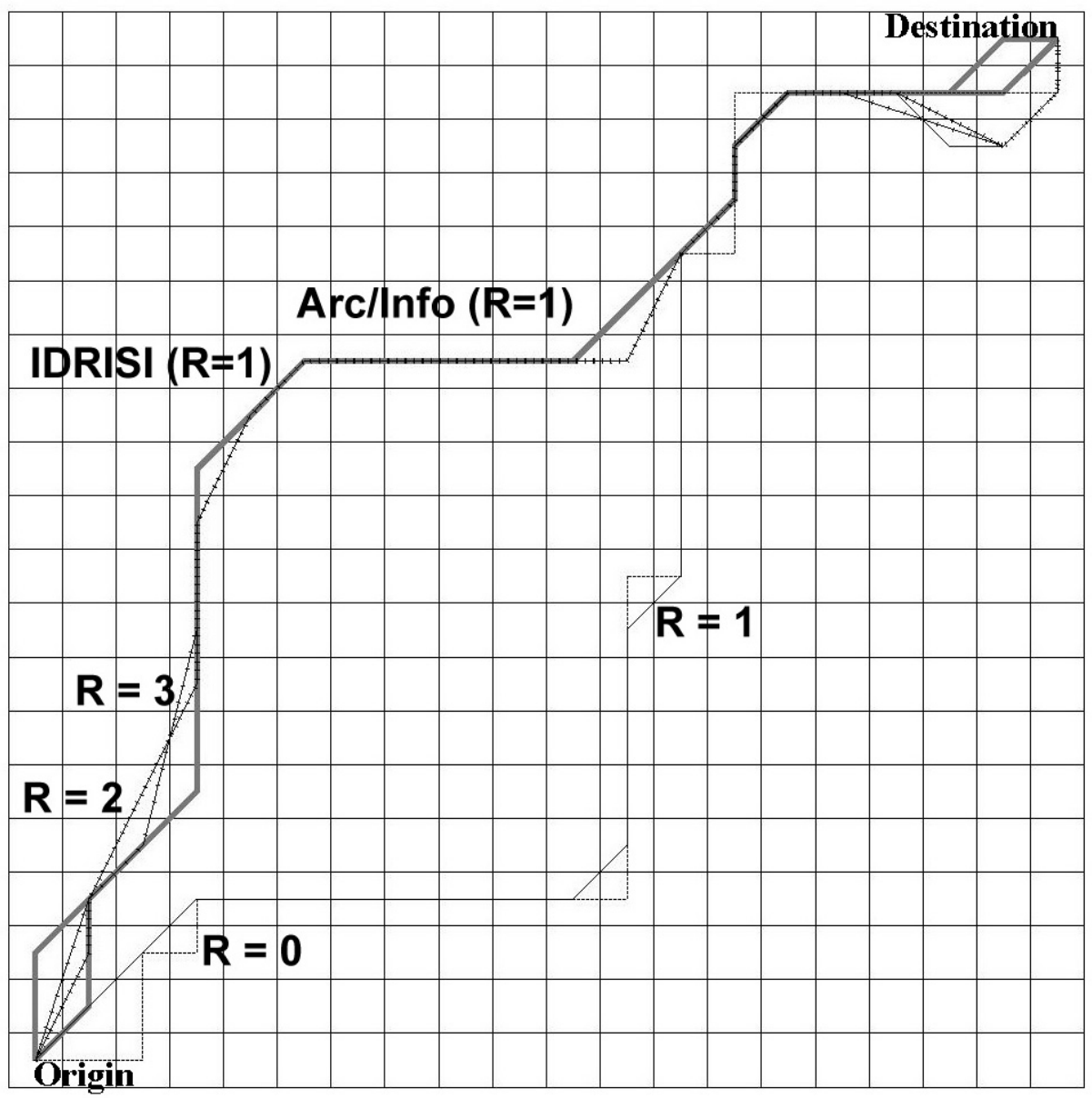


Spatial Resolution and Positional Accuracy: The quality of database regeneration can be improved by selecting a finer spatial resolution in the data conversion process. This may result in slight improvements in the corridor location by narrowing and smoothing the corridor route, as shown in Figure 10 (10a, 10b, 10c, 10d). However, the spatial position of both origin and destination points, commonly defined by their nodes or cell centroid, are also changed as the spatial resolution changes. Because the positions of the two points are a major input into the costdistance surface generation as well as costpath generation, it is unclear how sensitive the Arc/Info and IDRISI approaches are to spatial positional accuracy. This can be simulated by moving two point positions associated with changing spatial resolutions. In so doing, the same simulated vector data set is converted into five raster data sets with $1,5,25,50$, and 100 meters spatial resolution, respectively, and the two end points are always assumed to be the center of cells. The results (Figure 11) show that the IDRISI approach generates five shortest-paths, all are within a single corridor. By compression, the Arc/Info approach simulates two spatially different corridors that are dependent on spatial resolution (Figure 12). The Arc/Info approach thus seems to be more sensitive to spatial positional accuracy and effectively reflects the different routing process resulting from choosing different spatial resolutions.

\subsection{Modeling Alternatives}

Many approaches have been developed and used to identify both good and spatially different alternative routes (Lombard and Church, 1993). These include the $k^{\text {th }}$ shortest path and goal programming; the gateway path generation method; the iterative-penalty method; the difference maximization method; and the multiobjective optimization method. Among these, the gateway path generation and the multiobjective optimization techniques are particularly useful for modeling route alternatives.

\subsubsection{Multiobjective Optimization Method}

Given a network representation of the routing problem where arc attributes contain measures of route suitability, route cost, and environmental impact, a shortest path 


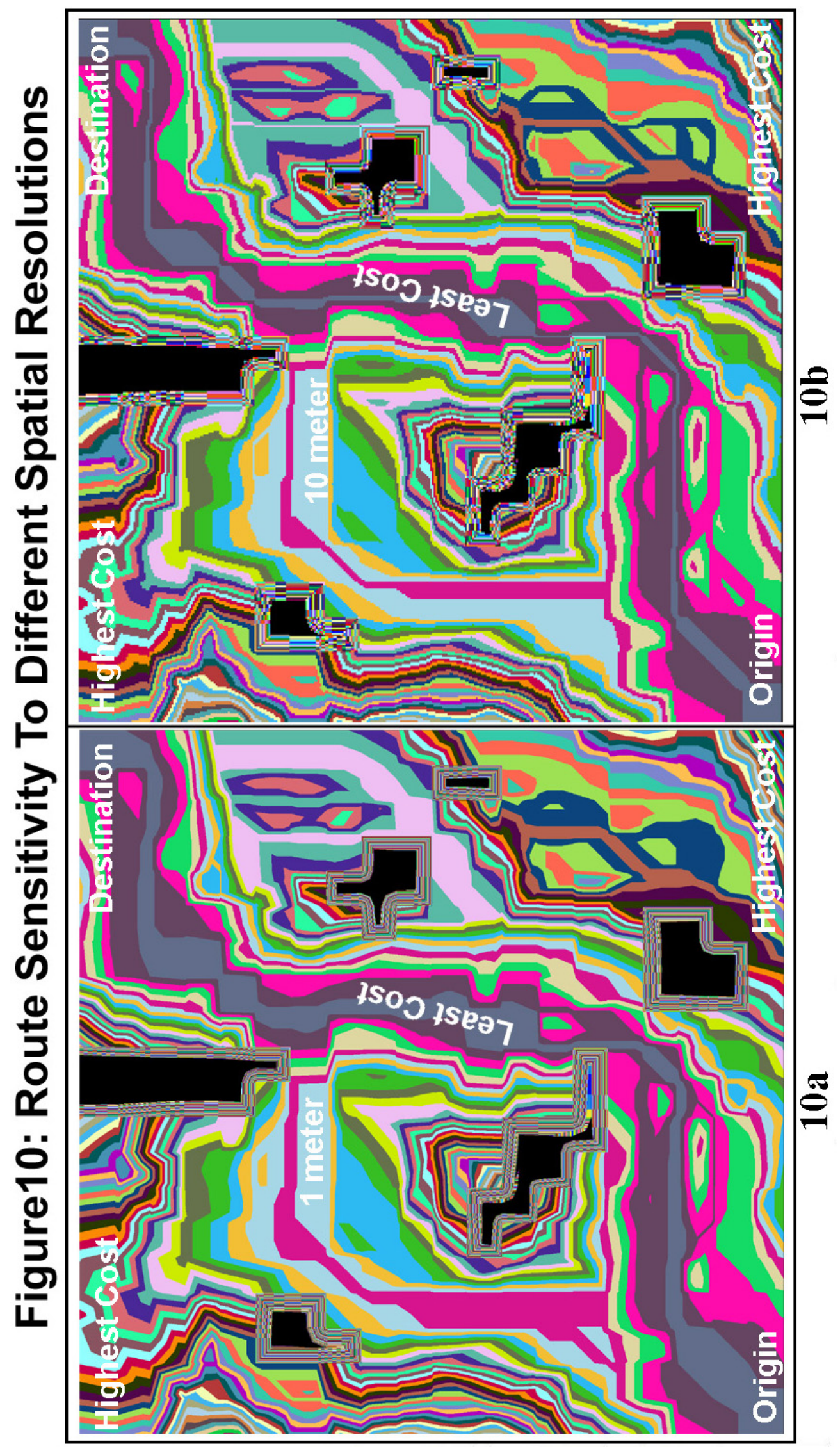




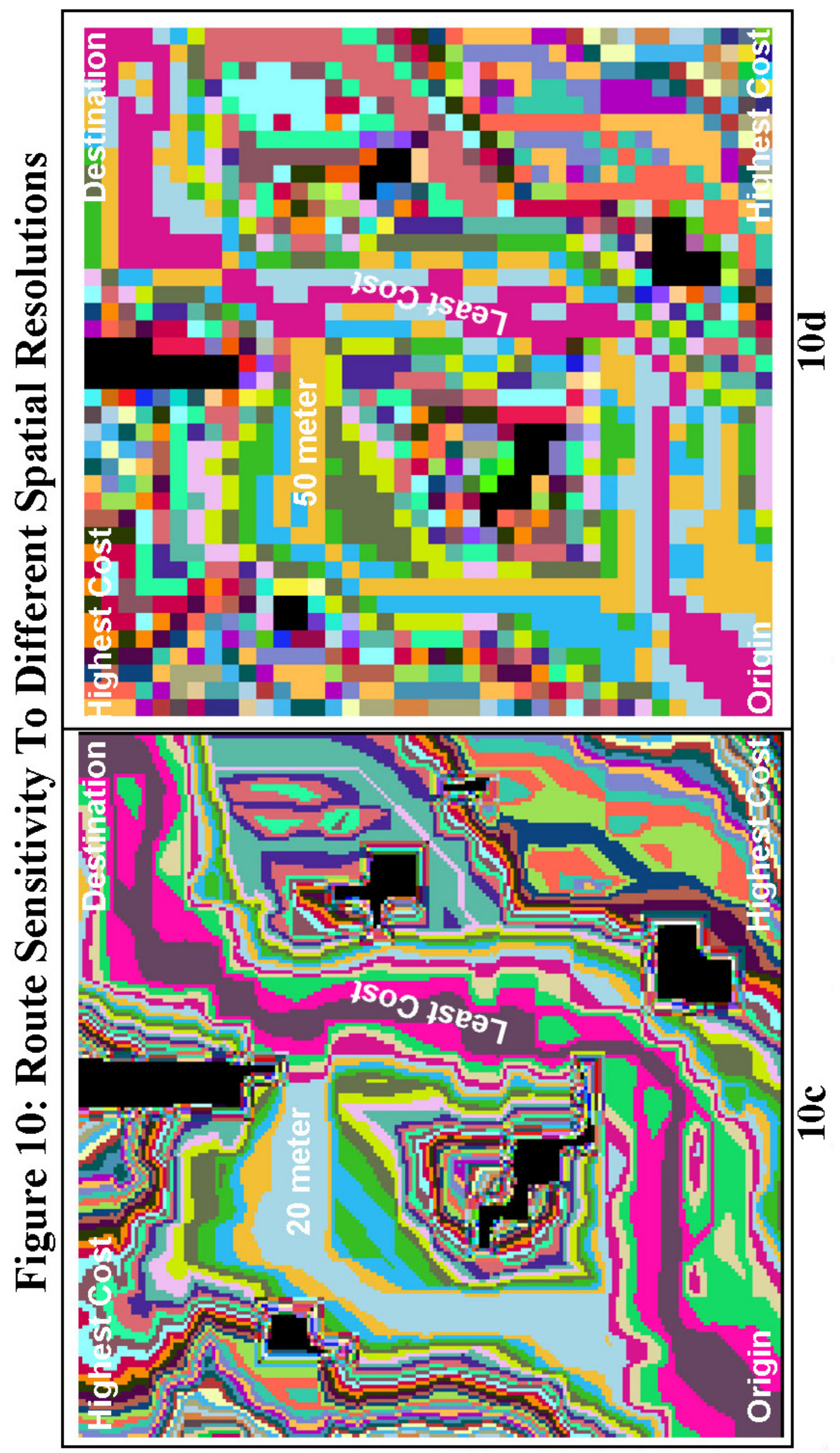


Figure 11: Routing Sensitivity Of IDRISI To Spatial Positional Accuracy

\begin{tabular}{|l|l|l|l|l|l|l|l|l|l|l|l|l|}
\hline & & & & & & & & & & & & \\
\hline
\end{tabular}


Figure 12: Routing Sensitivity Of Arc/Info To Spatial Positional Accuracy

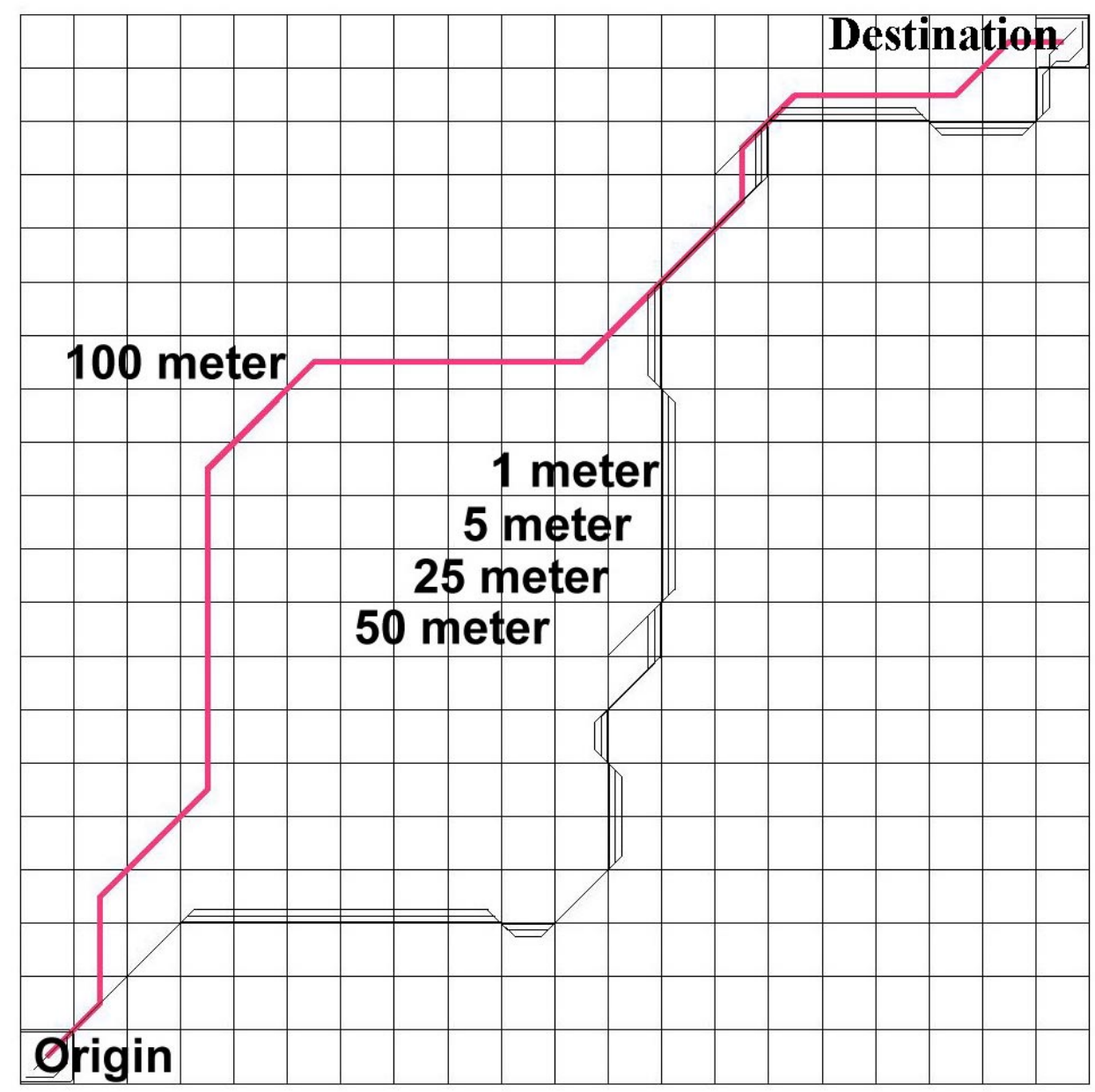


algorithm can be used to find a least cost path between a specified origin and destination. Typically, suitability and impact measures range from zero (very acceptable or no impact) to a large number (not acceptable). The 'cost' of the path then represents some weighted combination of the various attribute measures. If one considers each of the major attributes as a separate objective measure, then the routing problem can be viewed as a multiobjective shortest path problem (MSPP).

There are two approaches designed solve a MSPP: the weighting technique and the Weighted Tchebycheff Distance Metric (WTDM) (Solanki, 1991; Church et al, 1992). Both procedures can be used to identify non-inferior solutions that are part of the tradeoff between various objectives by means of changing or modifying objectives or adding new terms to the objective function.

Specifically, by varying the weights of the various arc attributes, one can solve for a range of routing alternatives that trade off the various impact objectives. Counterbalancing the simplicity and ease of implementation accruing from the weighting method, three major concerns are raised by Schenkerman (1991) concerning ambiguity and misunderstood weights; non-commensurable terms and non-normalized weights; and the observation that all given sets of weights may miss the decision-makers most preferred alternatives. However, a well-informed and cautious user can quickly obtain useful insights into the tradeoffs between a few alternative solutions.

\subsubsection{Gateway Path Generation Method}

The gateway model was designed to site alternative linear routes that are constrained by some intermediate target(s) (ESRI, 1991 \& 1992; Lombard \& Church, 1993; Dean, 1997) or prespecified node(s). In these cases the selected crossing points or gateway points can force a selected path to travel through different regions or veer away from the 'optimal path' selected. This approach can generate spatially different alternatives by modifying an existing constraint or adding new constraints. It can efficiently search for spatially different alternatives only by passing through the pre-selected gateways. 


\subsection{Optimal Analysis For Preferred Route Selection}

After a larger set of alternative paths are selected, it is necessary to choose a final preferred path and several alternative paths among them. Such traditional optimization techniques as linear programming, integer programming, and dynamic programming can be used to identify a set of final routes. K-shortest paths and goal programming approaches were also utilized in combination to address power line route selection. Furthermore, segment-based impact matrix analytical techniques are often used in the real world while a cell-based heuristic solution are designed to generate theoretically a optimal route among all potential routing patterns.

\subsubsection{Impact Matrix Manipulation}

Segment-based impact index matrix manipulation techniques have been used to select preferred corridors. Howlett (1976) and Harris et al. (1991 \& 1997) used a traditional impact matrix visualization approach to select the preferred and the alternative corridors in their transmission line route selection studies. By keeping the original environmental impact information in a multidimensional matrix, segment-based alignment impact profile (Howlett, 1976) or route impact index (Harris et al., 1991 \& 1997) can be output as a diagrammatic link route map, with the real impact of any link proportionate to its width. Output in these forms has great potential not only for a professional-technical review but also for good public dissemination and understanding of the decision making and route selection process.

An impact scalar matrix manipulation method was also designed by Massam (1982) to select the optimal route between two towns. It has a set of multiple criteria procedures for identifying the best routes based on a mathematical comparison of all alternative routes linking two end points. The method uses a modification of the concordance index to derive a dissimilarity matrix. This matrix is analyzed using multi-dimensional scaling to give a classification of all alternative route segments with respect to a hypothetical best 
route segment. A shortest path algorithm is used to find the combination of a subset of segments to produce a continuous route which has the least cost. The solution appears to be insensitive to changes in weighting for the multi-criteria used to construct impact index matrix. In a series of ten experiments conducted using five weighting schemes and two alternate methods for defining the hypothetical best, Massam (1982) identified the same route as being the best in all instances.

\subsubsection{Heuristic Approach}

Dean (1997) developed a branch evaluation approach to solve heuristically multiple target access problem (MTAP). This approach first generates a list of all possible route branching patterns for the desired number of targets or prespecified nodes, and then uses an approximation technique to compute an estimated routing cost for each possible branching pattern. Once the routing costs for all possible branching patterns have been developed, the branching pattern producing the lowest total routing cost is chosen as the final accessing technique. This technique is not completely optimal because it only includes those points identified by the heuristic used in branch evaluation. Complete enumeration extends the branch evaluation method to include all possible branching points for each branching pattern. This approach produces the most optimal solutions possible, but it requires more time to find solutions than branch evaluation. 


\section{CHAPTER 4: TRANSMISSION LINE ROUTE SELECTION USING SMA}

\subsection{Research Background}

\subsubsection{Background To The AEP Project}

For a number of reasons American Electric Power (AEP) desires to build a high power $765 \mathrm{kV}$ transmission line between the Wyoming substation in Wyoming County, West Virginia, and the Cloverdale substation in Roanoke County, Virginia (AEP News Communication, 1990 and 1996). A Universities Study Team (UST) comprising researchers from West Virginia University and Virginia Polytechnic Institute and State University were requested by AEP to identify and evaluate a least environmental impact route between the Wyoming and Cloverdale substations. The project has evolved through various stages in response to local, State, and Federal requests and essentially covers some 77 1:24,000 USGS topographical quads. The UST routing criteria selected covered physical, ecological, cultural, and visual aspects of the landscape. A graphical intuitive approach was used.

\subsubsection{Research Area And Data Selection}

In order to explore the SMA approach to route selection, part of the overall AEP project study area was chosen for study (Figure 13). Several corridor routes were selected in this area by the UST using a GIA and this provides an excellent comparative basis for the SMA generated routes. Within the study area, 48 types of environmental constraints, as shown in category III of Table 1, were selected from the UST multi-source database. All of the constraints are in form of the vector-based GIS layers, which represent a comprehensive and exhaustive spatial database of the study area. The digital information collected came from a variety of sources, including state and federal agencies, digital data repositories, and from field survey. The data was also collected at a variety of data scales, depending on the source, but usually at a scale of 1:24,000 or larger whenever possible. For example, over ten thousand individual residences and buildings were identified directly from the USGS 7.5 minute quadrangle maps and current landuse was compiled from manual interpretation 


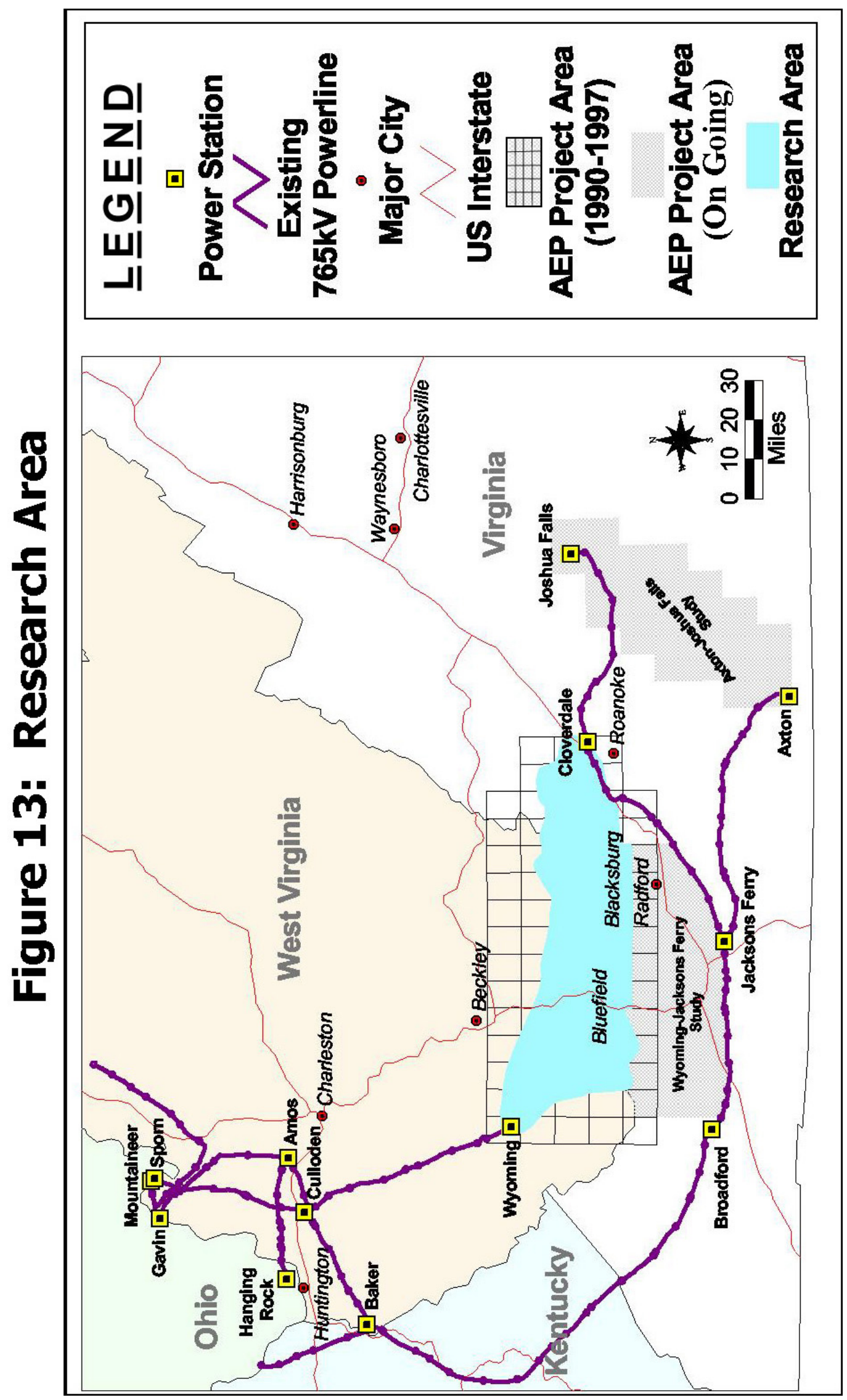


Table 1: Digital Landscape Dataset For Modeling Powerline

\begin{tabular}{|c|c|c|}
\hline CATEGORY 1 & CATEGORY 2 & CATEGORY3 \\
\hline \multirow[t]{10}{*}{ LANDUSE } & CURRENT LANDUSE & built-up \\
\hline & & agricultural land \\
\hline & & forest woodland \\
\hline & & water / reservoir \\
\hline & & transportation \\
\hline & FUTURE LANDUSE & industrial \\
\hline & & neighbourhood \\
\hline & & planned unit \\
\hline & & public \\
\hline & & residential \\
\hline \multirow[t]{10}{*}{ HUMAN } & MAN-MADE & airport \\
\hline & & AM-tower \\
\hline & & FM-TV-BE-ALL \\
\hline & & house \\
\hline & & school \\
\hline & & church \\
\hline & & cemetery \\
\hline & RESTRICTED AREA & agricultural / forest districts \\
\hline & & federal land \\
\hline & & exclusion zone \\
\hline \multirow[t]{5}{*}{ CULTURE } & HISTORICAL AREA & national register site \\
\hline & ПISIUNIUAL AREA & national register site eligible \\
\hline & & historic district \\
\hline & & historic district planned \\
\hline & & archaeology site \\
\hline \multirow[t]{8}{*}{ RECREATION } & APPALACHIAN TRAIL & property boundary \\
\hline & & shelter \\
\hline & & trail \\
\hline & PUBLIC REC. AREA & state parks \\
\hline & & campsites \\
\hline & & picnic areas \\
\hline & & scenic trail \\
\hline & KARST AREA & cave entrance \\
\hline \multirow[t]{5}{*}{ VISUAL } & FS VQOS & maximum modification \\
\hline & & modification \\
\hline & & partial retention \\
\hline & & retention \\
\hline & 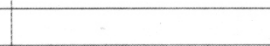 & preservation \& protection \\
\hline \multirow[t]{10}{*}{ ECOLOGICAL } & BIOTA & rare \& endangered species \\
\hline & FORESTED AREAS & motorized semi-primitive \\
\hline & & non-motorized semi-primitive \\
\hline & & roadless area \\
\hline & & wilderness area \\
\hline & & unfragmented forest \\
\hline & WETLAND & national wetland \\
\hline & HYDROLOGY & wild \& scenic river \\
\hline & & high quality rivers \\
\hline & & trout natural streams \\
\hline
\end{tabular}


of stereoscopic pairs of the 1:2,000 aerial photography.

The data generally includes such features as current and future landuse, human and cultural resources, recreational areas, visual quality objectives, and ecological sensitivity. The database also contains information on residential and workplace, major interstate and state roads, rare and endangered species, semi-primitive motorized and non-motorized areas in the Jefferson National Forest, wilderness and retention areas, existing and proposed historic sites, state parks and recreation camping areas, AM/FM/television towers, scenic trails and byways, and priority wetland areas and other highly sensitive ecological sites (Harris et al., 1991 \& 1997).

\subsection{Vector-to-Raster Data Conversion}

\subsubsection{Primary Cell Size Selection}

Because the SMA detailed here operates within a raster environment, any vector spatial data must first undergo a vector-to-raster data conversion process. In undertaking an SMA, cell size is an important parameter. Defining the primary cell size in this study is a difficult process and is dependent, among other factors, on a balance between the accuracy of the 'original' source data, and the final route widths proposed. Much of the source data came from 1:24,000 USGS topographic maps. The final rights-of-way (ROW) required by the proposed power line route consists of a corridor 200 meters wide. As such a 100 meter upper cell size limit was selected. Meanwhile, it is necessary to use as fine a spatial resolution as possible in order to capture features considered important to the study such as residential units and wetland areas. These are invariably less then $100 \mathrm{~m}^{2}$. Thus the raster cell size could range from 10 to 100 meters.

\subsubsection{Cell Resolution Sensitivity Analysis}

Given the large range of potential cell size it is difficult to avoid some uncertainty arising in the route selection caused by the actual selection of cell size and the impact on the resultant 'cost' values assigned to each cell. It is problematic to enumerate how cell size 
could affect the cost surface generated but an approach is explored here to seek some clarification, if not solution, to this problem. Specifically, the sensitivity of the linear routing process to the varying resolution of cell size is tested. To this end a vector land cover map of part of the study area, mentioned in Chapter 2.2, is used to conduct a routing cell resolution sensitivity analysis. In this, cost surfaces are generated from the vector land cover map using the same criteria but for a range of different cell sizes, including 10, 20, $30,40,50,60,70,80,90$, and 100 meters.

Interestingly, and as demonstrated in Figure 14, only minor changes in the routing location of the power-line were found as a result of the changing cell size. Some variations were noted for the 40 meters cell cost surface, which has an unique spatial distribution from all the others. Overall, however, it appears that route selection is relatively insensitive to differing variations of cell size between 10 and 100 meters. For cell sizes between 10, 20, and 30 meters almost no spatial differences can be discerned. The same situation is demonstrated in the case of cell sizes at 50, 60, 70, 80, 90, and 100 meters cell size. In other words, 30 and 100 meters cell sizes seem to be as representative as those cell sizes between 10-30 and 40-100 meters respectively in terms of the linear routing that arises. This study used 30 and 90 meters cell sizes because of the ability to resample the 30 meters cell size to 90 meters cells in order to test the degree to which the linear routing process is sensitive to differing methods of raster defined database generation.

\subsection{Constructing the Environmental Cost Surface}

\subsubsection{Quantifying the environment}

Environmental quantification in this study is the process of determining the relative importance of each of the 48 environmental factors via a numerical value, and the environmental impact posed by the proposed corridor routes. A group of fellow students, researchers, and faculty were asked to give their value judgments for each of the 48 criteria. Weighting was not requested at this time. The results can be regarded as a discrete environmental impact index with integer values ranging between 1 and 10 in 


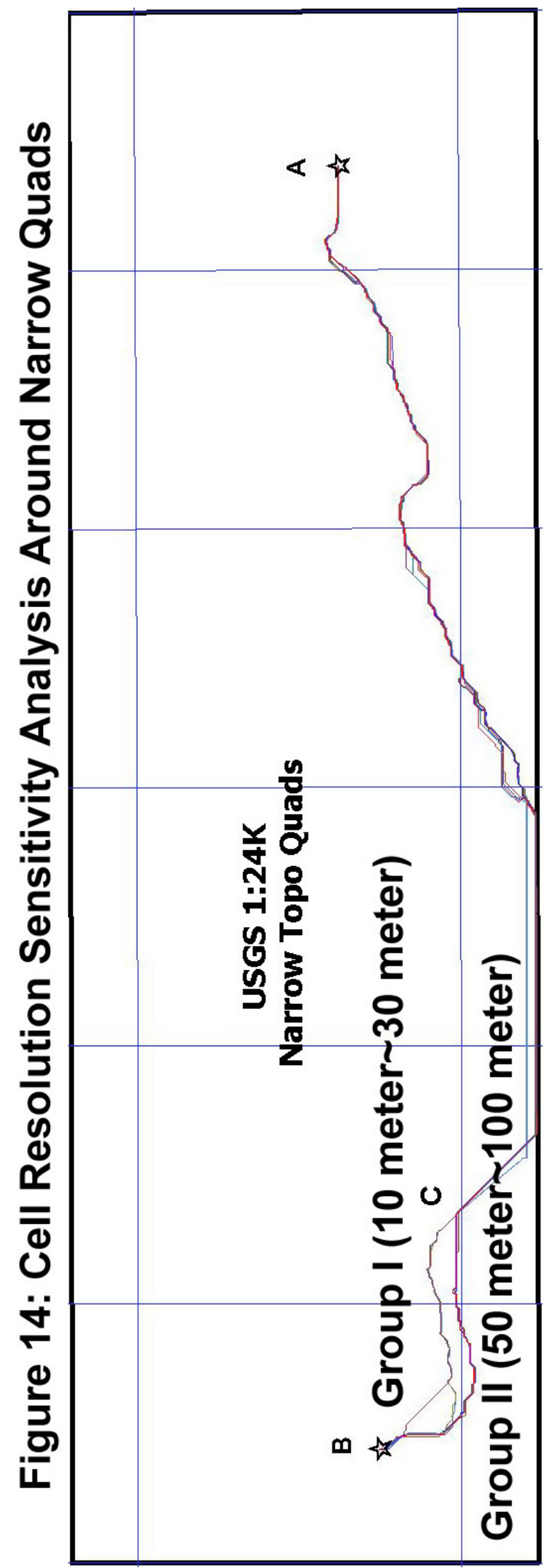


which 10 represents features considered most sensitive to a power line corridor and worthy of 'protection'.

Table 2: Environmental Constraints Quantification

\begin{tabular}{|c|c|}
\hline Value & Constraints \\
\hline 1 & agricultural land maximum modification \\
\hline 2 & $\begin{array}{l}\text { AM-tower archaeology site FM-TV-BE ALL Industrial wetland } \\
\text { future neighborhood planned unit future public future residential }\end{array}$ \\
\hline 3 & modification shelter \\
\hline 4 & forest woodland water / reservoir \\
\hline 5 & agricultural \& forest districts cave entrance \\
\hline 6 & $\begin{array}{l}\text { unfragmented forest } \\
\text { historic district planned motorized semi-primitive } \\
\text { national register site eligible partial retention roadless area scenic trail }\end{array}$ \\
\hline 10 & $\begin{array}{l}\text { airport built-up campsite church cemetery federal land } \\
\text { high quality rivers historic district house national register site } \\
\text { non-motorized semi-primitive picnic area property boundary } \\
\text { preservation \& protection retention rare \& endangered species school } \\
\text { state parks transportation trail trout natural streams } \\
\text { wilderness area wild \& scenic river }\end{array}$ \\
\hline
\end{tabular}

As shown in Table 2, very high values are assigned to such man-made features as settlements, schools, churches, cemeteries, recreation areas, and historic sites, which are considered as being most vulnerable to negative environmental impacts from the power line, and most worthy of 'protection' or avoidance. Agricultural land and future landuse were given the lowest values partially due to the ability to mitigate any impacts posed by the proposed power line.

\subsubsection{Cumulative Impact Modeling}

Most current environmental impact models used in corridor location studies are cumulative models in that they usually involve location decisions based on the cumulative impacts arising from several criteria selections and related weighting assignments. In seeking to understand the potential variations in corridor location that are bound to arise based on the varying weighting and scoring of the 48 criteria, an approach is used here which seeks to generate routes based upon differing emphases in the selection criteria. Initially the 48 
environmental criteria are grouped into six typical model variables $\mathrm{X}(\mathrm{i})$, where $\mathrm{X}(\mathrm{i})$ is specifically defined as the follows:

$$
\begin{aligned}
& \mathrm{X}(1) \in \text { Landuse } \\
& \mathrm{X}(2) \in \text { Human } \\
& \mathrm{X}(3) \in \text { Culture } \\
& \mathrm{X}(4) \in \text { Recreation } \\
& \mathrm{X}(5) \in \text { Visual } \\
& \mathrm{X}(6) \in \text { Ecology }
\end{aligned}
$$

Secondly, assume that the new variables $\mathrm{Y}(\mathrm{i}), \mathrm{i} \in[1,6]$, and $\mathrm{Y}(\mathrm{i})$ are proportional to $\mathrm{X}(\mathrm{i})$. The differences between $\mathrm{X}(\mathrm{i})$ and $\mathrm{Y}(\mathrm{i})$ are that $\mathrm{Y}(\mathrm{i})$ excludes zero indicating nondistribution of any constraints within the group over the study area, and that there is no cell with a value greater than 10 within $\mathrm{Y}(\mathrm{i})$. In so doing it is expected to smooth or eliminate possible large disparities in the suitability scores among neighboring cells.

Thirdly, three EM are selected to calculate total environmental impact. These comprise a linear combination model (EM4), an ordered weighted combination model (EM5), and a nonlinear square combination model (EM6). These are shown respectively in formula (5), (6), and (7) in Chapter 3.2. The weights used in EM4 are theoretically chosen as ordered positive integer numbers ranging from 1 to 6 (Liu et al., 1991).

Fourthly, a combination theory based algorithm (Liu et al., 1991) is used to generate three sets of theoretical thresholds $\operatorname{RCL}(j)[j=1,2,3]$ for further friction value aggregation, by reclassifying the results of each of the three EM selected above. Four steps are designed for executing the further aggregation algorithm:

1) Assume cell based TIIV is computed by

$$
\mathbf{A}(\mathrm{i})=\vec{X}=\{X i j\} \quad(\mathrm{i}=1,2, \ldots, \mathrm{n}) \&(\mathrm{j}=1,2, \ldots, \mathrm{m})
$$

and a tempory order or reclassification level $(\mathbf{K})$ is considered as

$$
\mathbf{K}(\mathrm{i})=\operatorname{Max}\{X i j\} \quad(\mathrm{i}=1,2, \ldots, \mathrm{n}) \&(\mathrm{j}=1,2, \ldots, \mathrm{m})
$$


2) Let $N_{K}$ denote the total number of theoretical combination of the impact index within the tempory order, and

$$
N_{K}=(\mathrm{m}+\mathbf{K}-2) ! /(\mathrm{m}-1) ! *(\mathbf{K}-1) ! \quad(\mathbf{K}=\mathbf{K}(\mathrm{i}))
$$

3) Compute all theoretical $\mathrm{A}$ (i) for the $N_{K}$ combinations within the tempory order, for each of EM selected.

4) Define a $A_{K}^{*}$ to minimize the subtraction of combinations percent for $\mathbf{A}(\mathrm{i})>A_{K}^{*}$ within the tempory order $\mathbf{K}$ and combinations percent for $\mathbf{A}(\mathbf{i})<=A_{K}^{*}$ within the order $\mathbf{K}+\mathbf{1}$.

The set of orders and their thresholds calculated for EM4, EM5, and EM6 are shown in Table 3.

Table 3: Theoretical Thresholds $\left(A_{K}^{*}\right)$ For Three EM Selected

\begin{tabular}{|c|c|c|c|c|c|c|c|c|}
\hline Order K & 1 & 2 & 3 & 4 & 5 & 6 & 7 & 8 \\
\hline $\operatorname{RCL}(1)$ & {$[6]$} & $(6,11]$ & $(11,14]$ & $(14,18]$ & $(18,21]$ & $(21,25]$ & $(25,28]$ & $>28$ \\
\hline $\operatorname{RCL}(2)$ & {$[21]$} & $(21,41]$ & $(41,58]$ & $(58,73]$ & $(73,89]$ & $(89,104]$ & $(104,120]$ & $>120$ \\
\hline $\operatorname{RCL}(3)$ & {$[6]$} & $(6,21]$ & $(21,39]$ & $(39,62]$ & $(62,91]$ & $(91,125]$ & $(125,164]$ & $>164$ \\
\hline
\end{tabular}

In order to demonstrate the influence of early data aggregation on the linear routing process, the data sets X(i) are used, but only input into EM4. As a result, seven specific discrete impact index models (IIM) are used to define cumulative environmental impact surfaces or continuous friction surface in the study. These are:

$$
\begin{aligned}
& \mathrm{IIM} 1=\mathrm{X} 1+\mathrm{X} 2+\mathrm{X} 3+\mathrm{X} 4+\mathrm{X} 5+\mathrm{X} 6 \\
& \mathrm{IIM} 2=\mathrm{Y} 1+\mathrm{Y} 2+\mathrm{Y} 3+\mathrm{Y} 4+\mathrm{Y} 5+\mathrm{Y} 6 \\
& \mathrm{IIM} 3=\mathrm{Y}_{1}^{2}+\mathrm{Y}_{2}^{2}+\mathrm{Y}_{3}^{2}+\mathrm{Y}_{4}^{2}+\mathrm{Y}_{5}^{2}+\mathrm{Y}_{6}^{2} \\
& \mathrm{IIM} 4=1 * \mathrm{Y} 1+6 * \mathrm{Y} 2+5 * \mathrm{Y} 3+4 * \mathrm{Y} 4+3 * \mathrm{Y} 5+2 * \mathrm{Y} 6 \\
& \mathrm{IIM} 5=\text { RECLASS }[\mathrm{EM} 4, \mathrm{RCL}(1)] \\
& \mathrm{IIM} 6=\text { RECLASS }[\mathrm{EM} 6, \mathrm{RCL}(3)] \\
& \mathrm{IIM} 7=\text { RECLASS }[\mathrm{EM} 5, \mathrm{RCL}(2)]
\end{aligned}
$$




\subsubsection{Cost Surface Generation}

As discussed in Chapter 3.3, cost surface generation is always conducted before actual linear route generation within Arc/Info. The cost surfaces here include a continuous friction surface, a cost distance surface, and a cost back_link surface (3S). All of these three surfaces must be generated if both corridor and center line need to be identified using Arc/Info.

Because any particular cost surface generation depends on both cell size and friction value, each of the seven IIM suggested above can generate different $3 \mathrm{~S}$ if varying cell sizes or friction values are input into it. Earlier in this study, three raster databases were regenerated by using two different data conversion techniques within Arc/Info. The first two databases were created by the POLYGRID module and are based on 30 and 90 meter spatial resolution respectively. The third raster database also has 90 meter resolution, but was created by using the RESAMPLE module. These three databases are input into the seven IIM which resulted in 21 friction surfaces. Some 42 cost distance surfaces and 42 cost back_link surfaces were created using the COSTDISTANCE module. The former represents the least cost route for each cell backing from the Cloverdale station or moving away from the Wyoming station. The latter illustrates the least-cost moving directions for each cell back to the Wyoming station from the Cloverdale station or back to the Cloverdale station from the Wyoming station.

Seven resultant friction surfaces with 30 meter spatial resolution are selected and shown in Figure 15. Each surface is labeled by the spatial resolution and impact index model used. The red tone indicates areas with higher friction values and environmental impacts while yellow patterns characterize those areas with low environmental impacts. Intuitively, there are very similar spatial patterns of impact distribution between the surface IIM2_30 (Figure 15b) and IIM5_30 (Figure 15e), the surface IIM3_30 (Figure 15c) and IIM6 


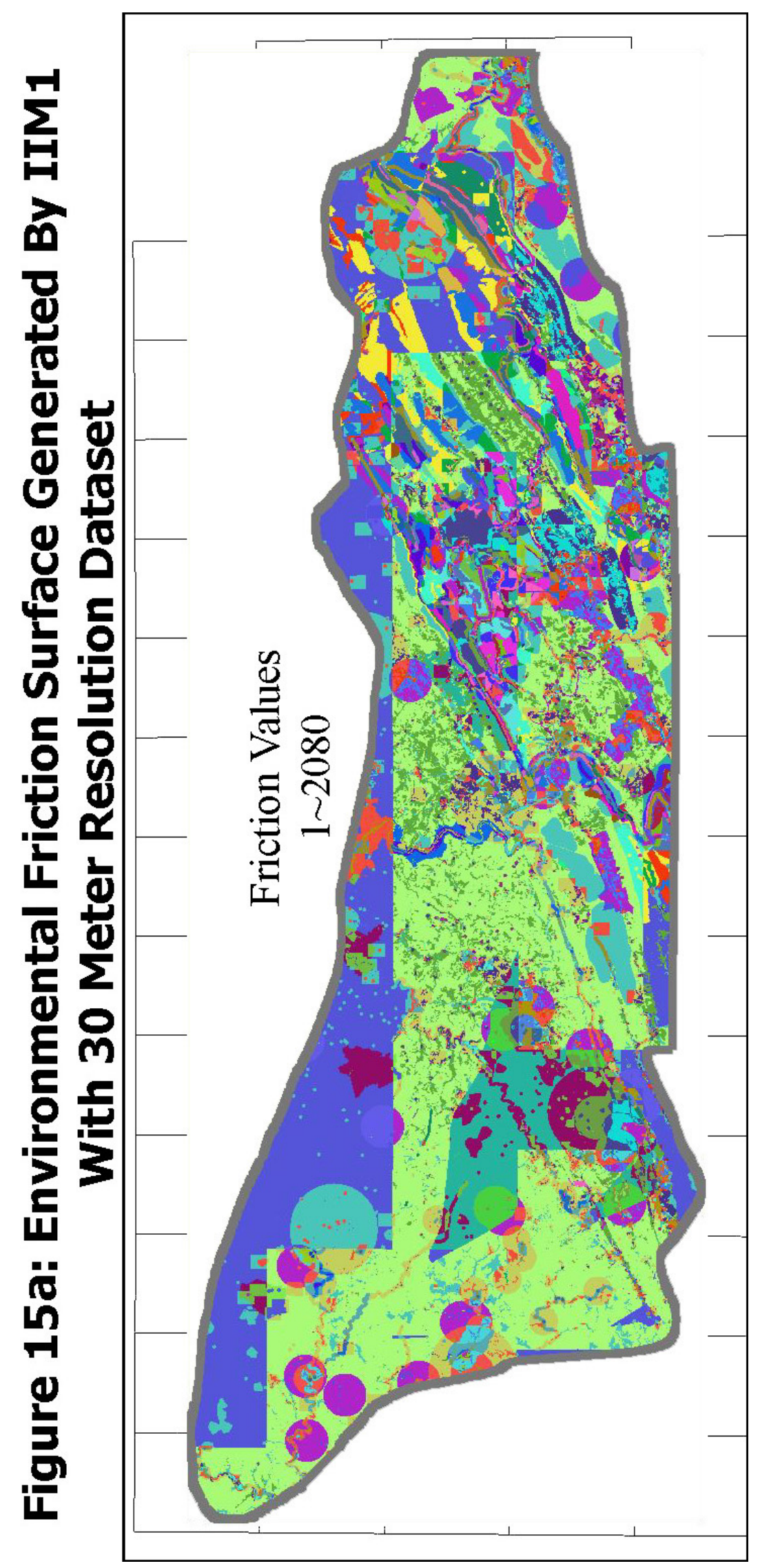




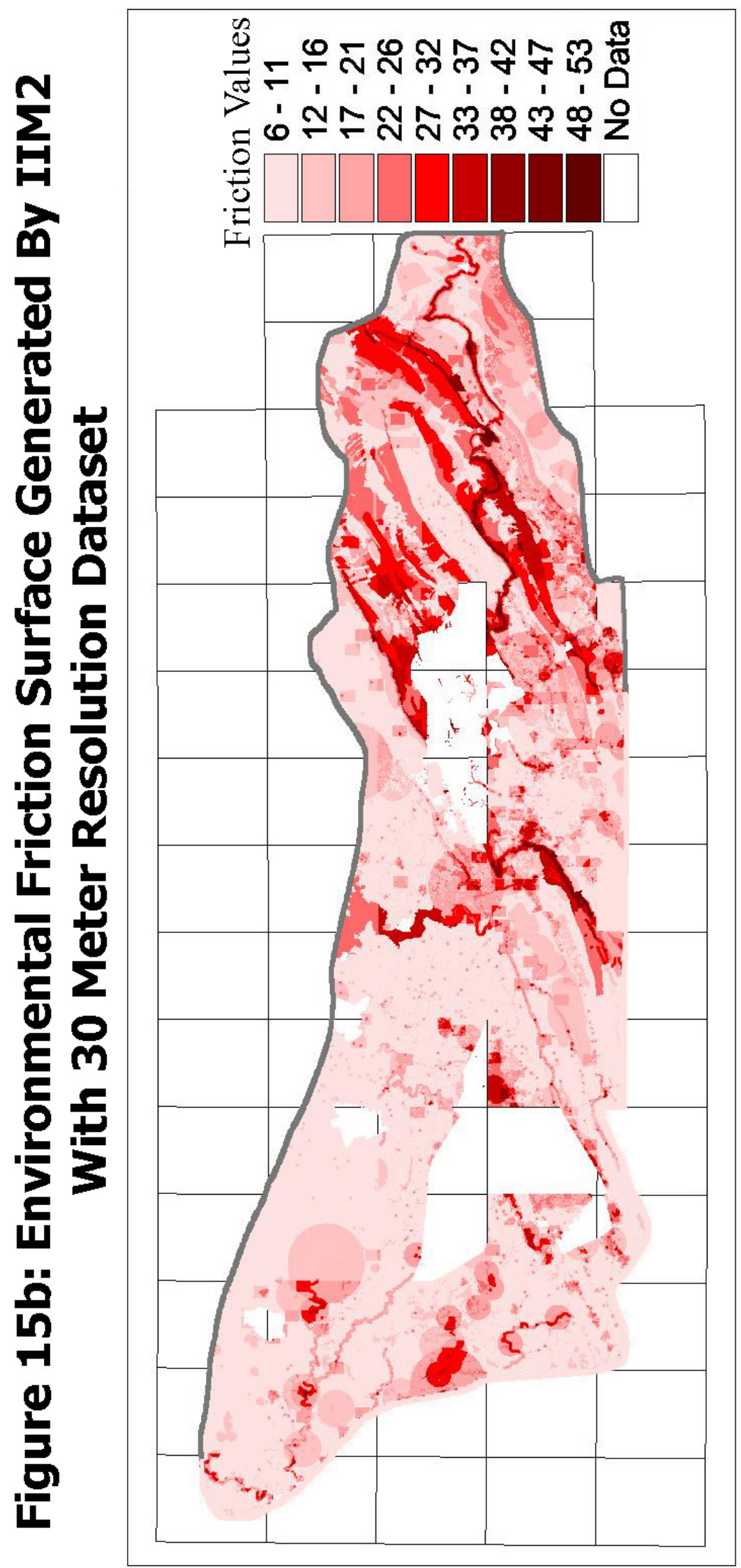




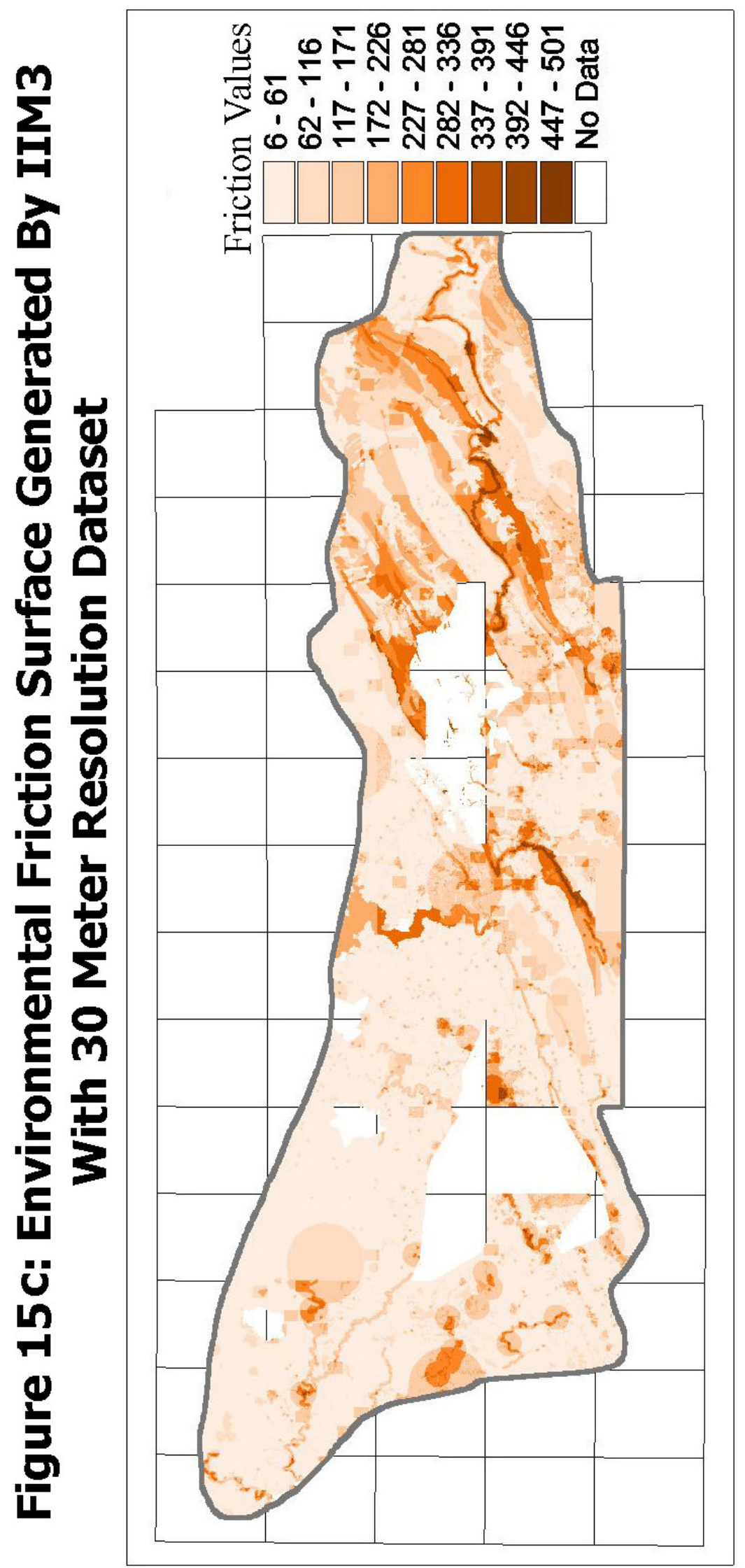




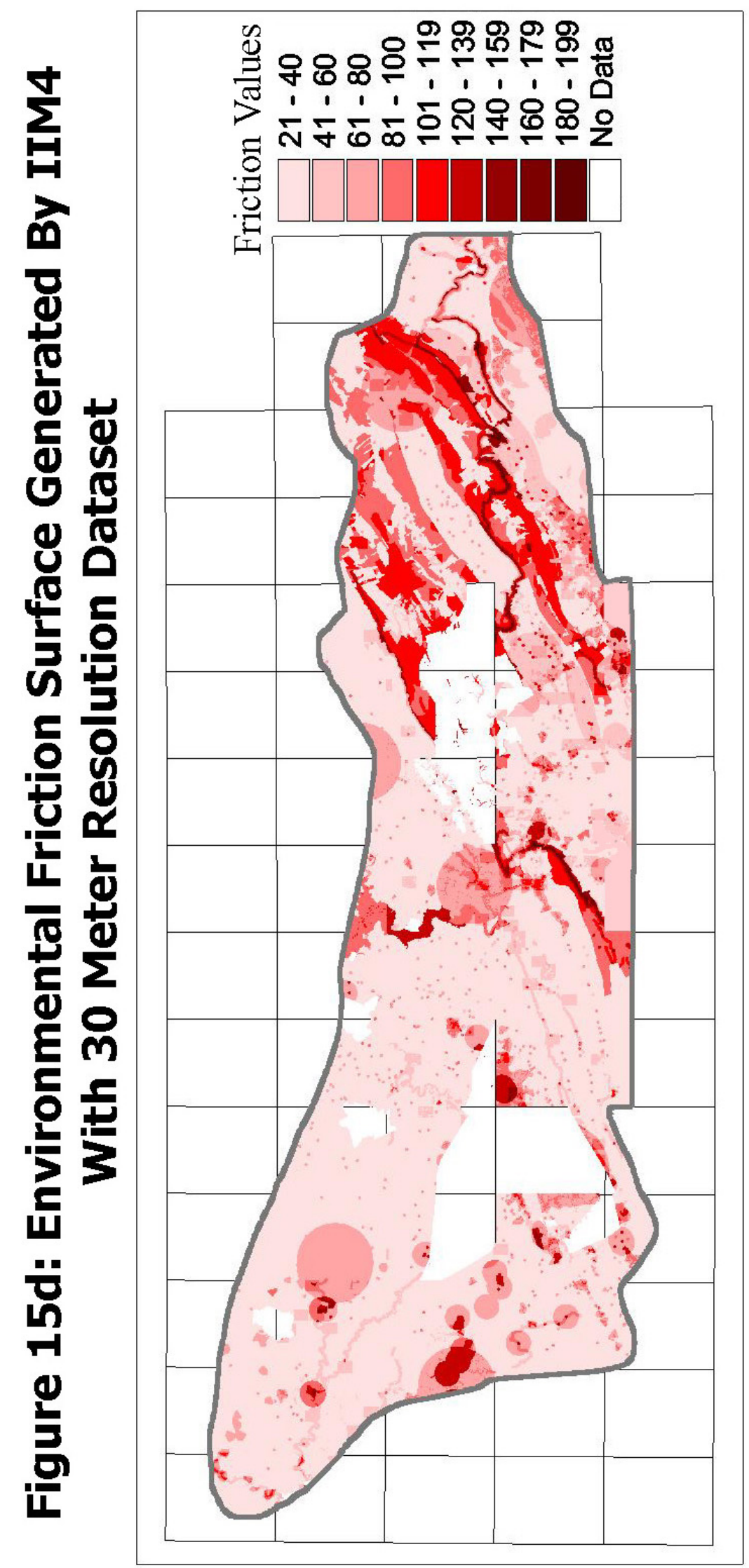




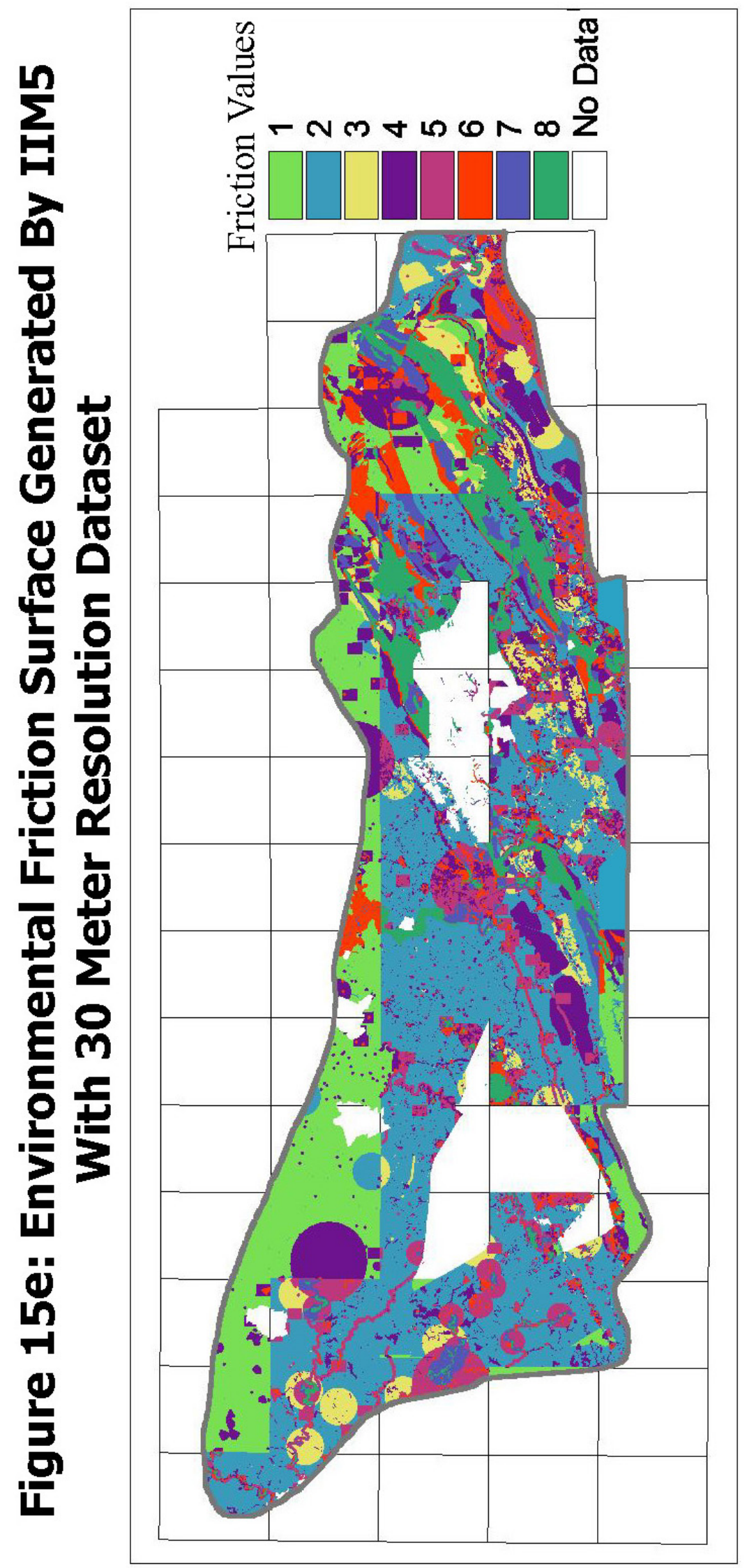




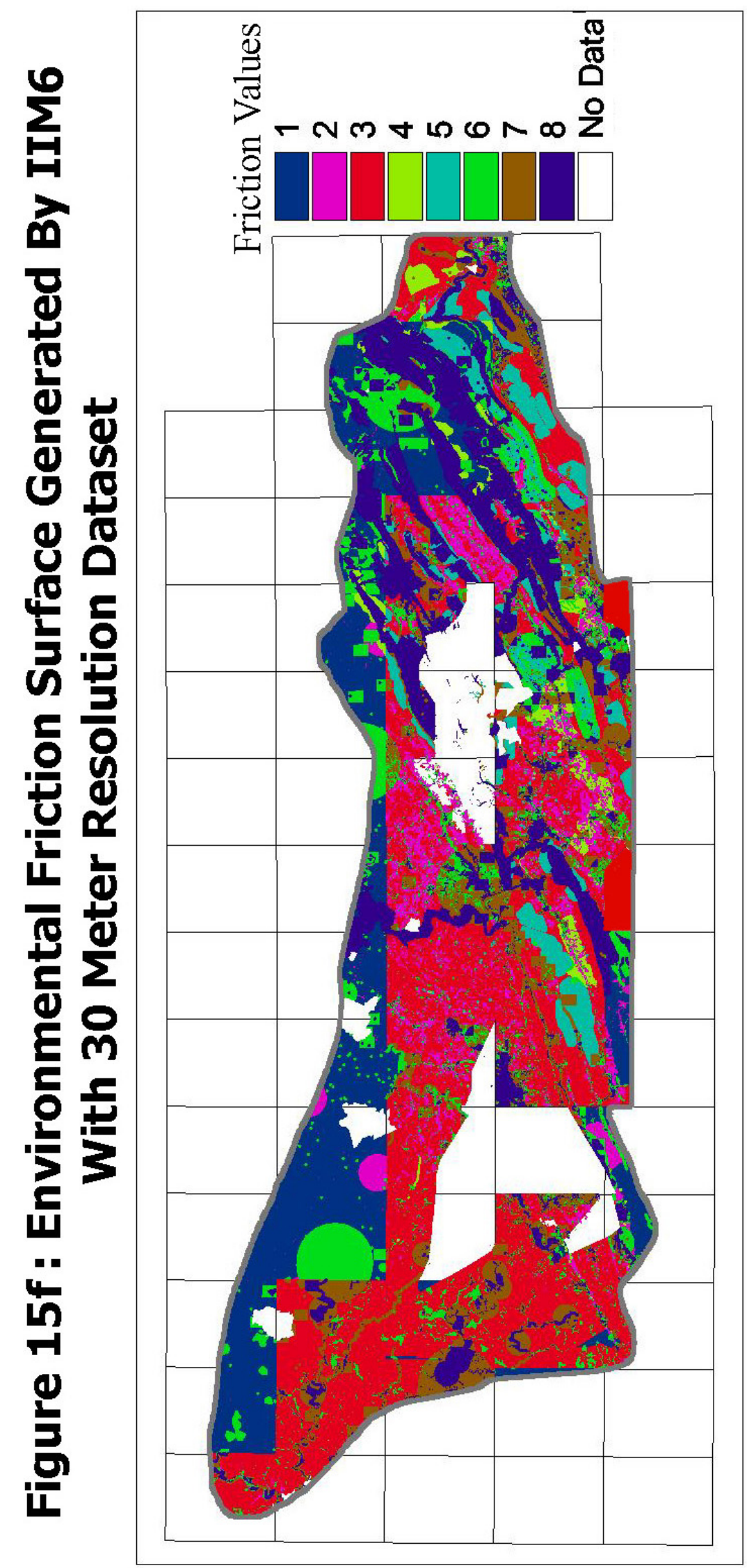




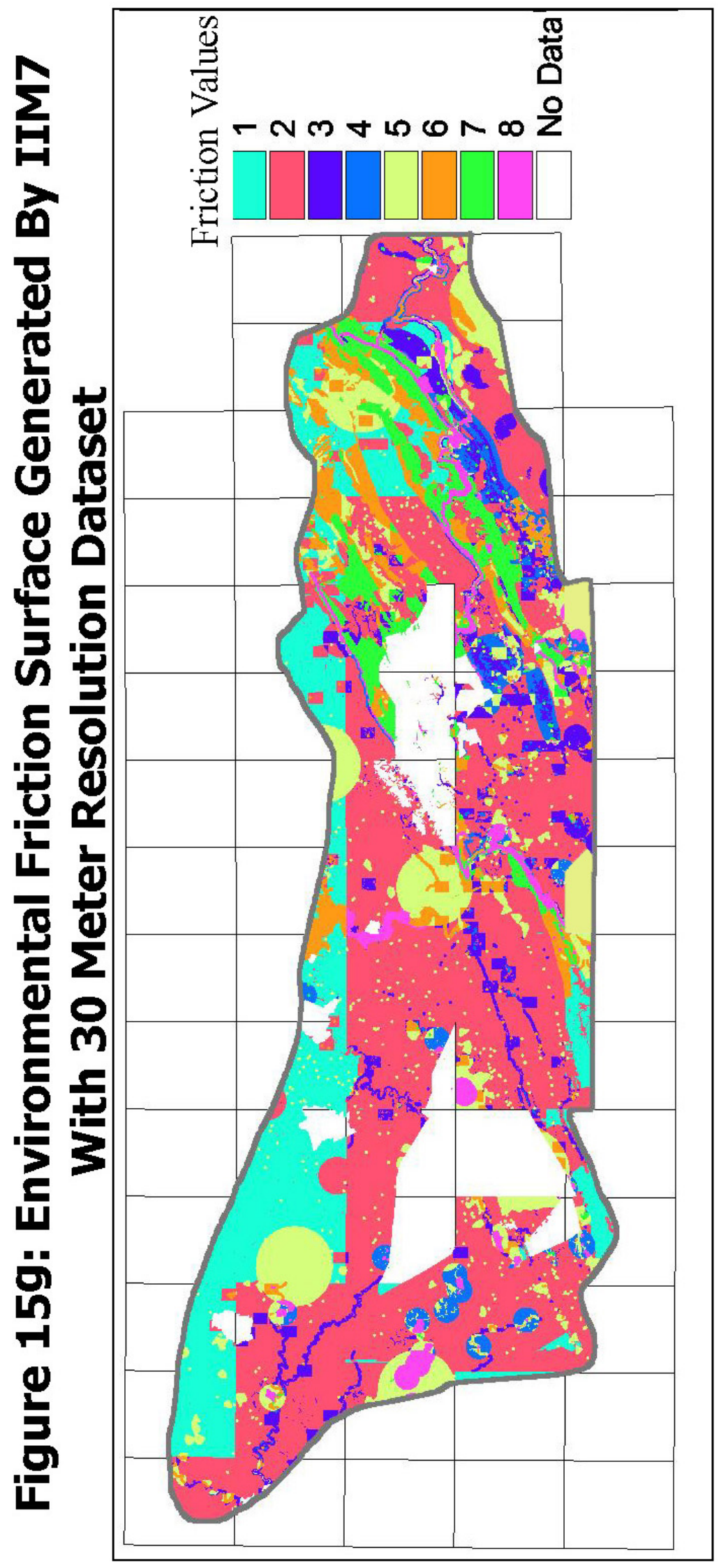


(Figure 15f), as well as the surface IIM5_30 (Figure 15d) and IIM7_30 (Figure 15g), although only a very small range of integer numbers from 1 to 8 are used to construct such friction surfaces as IIM5_30, IIM6_30, and IIM7_30. With all the friction surfaces determined, it is noticeable that urban and residential areas are exactly located in the highest impact regions while barren ground and agriculture land predominate within the least impact areas.

\subsection{Least Impact Power Line Route Siting}

\subsubsection{Corridor Location}

The least environmental impact corridors can be identified simply by adding two costdistance surfaces generated from the same friction surface or based on using the same IIM. In our particular case, one of the cost-distance surfaces represents cumulative environmental impact moving away from the Wyoming station while another is backing away from the Cloverdale station. Some 21 corridors were determined by adding the 42 cost-distance surfaces and these generally illustrate the least environmental sensitive areas connecting the two stations.

\subsubsection{Line Delineation}

While corridor locations generally represent areas incurring least environmental impact, the COSTPATH module within Arc/Info provides another opportunity for modeling potential corridor center lines. By assuming the Wyoming station or the Cloverdale station as a starting or end point, 42 least environmental paths are delineated based on 42 different cost distance surfaces and the cost back_link surfaces generated above.

Rasterization and resample techniques have no obvious influence on the resultant spatial distributions of the power line routes (Figure 16b, 16c). Compared to the routes generated using 30 meter raster data (Figure 16a), large route spatial deviation is only found in a small part of the routes generated using 90 meter raster data. Given the computational costs, it is suggested that 90 meter resolution is a suitable cell size for further use in cost 


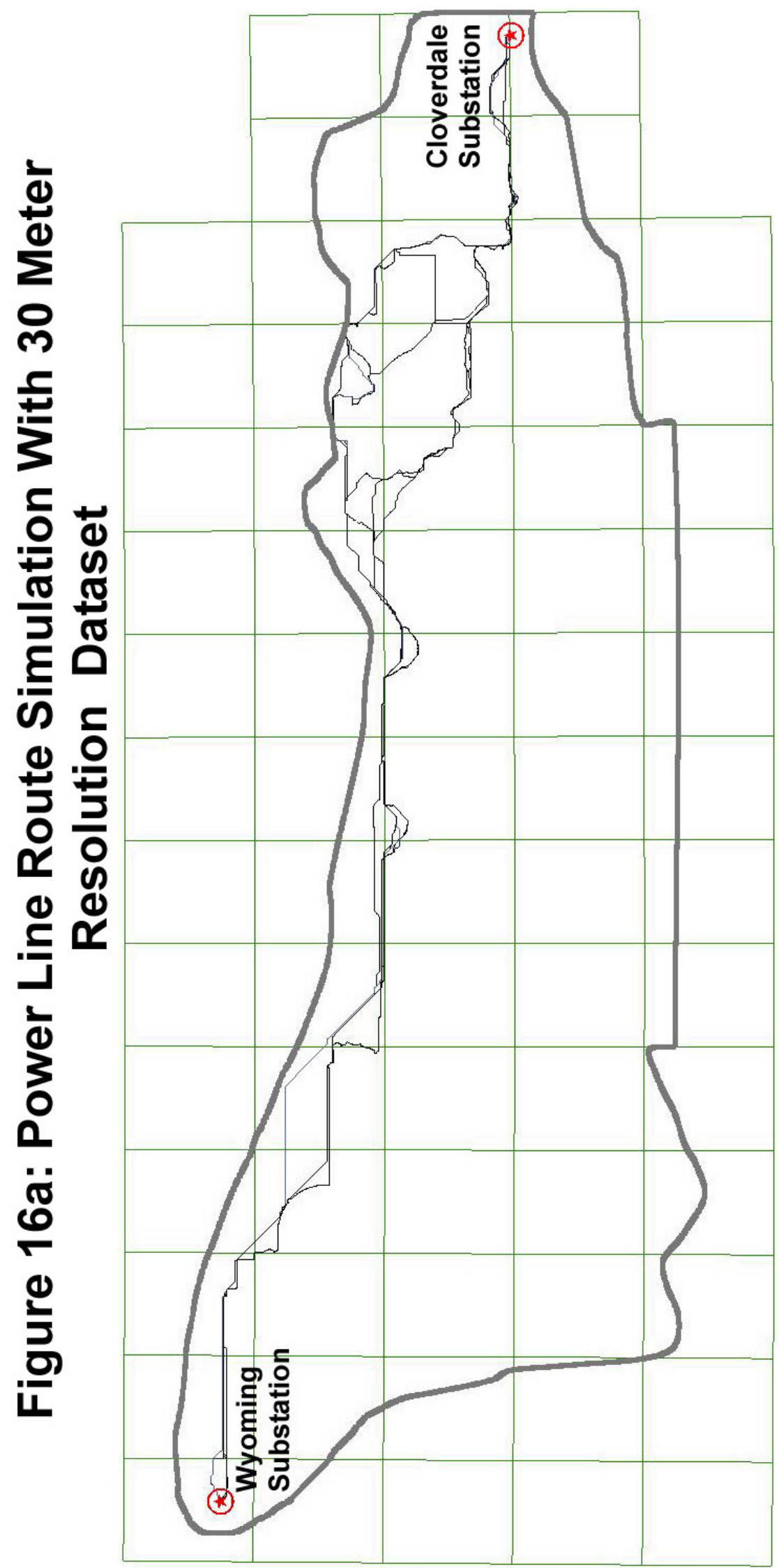




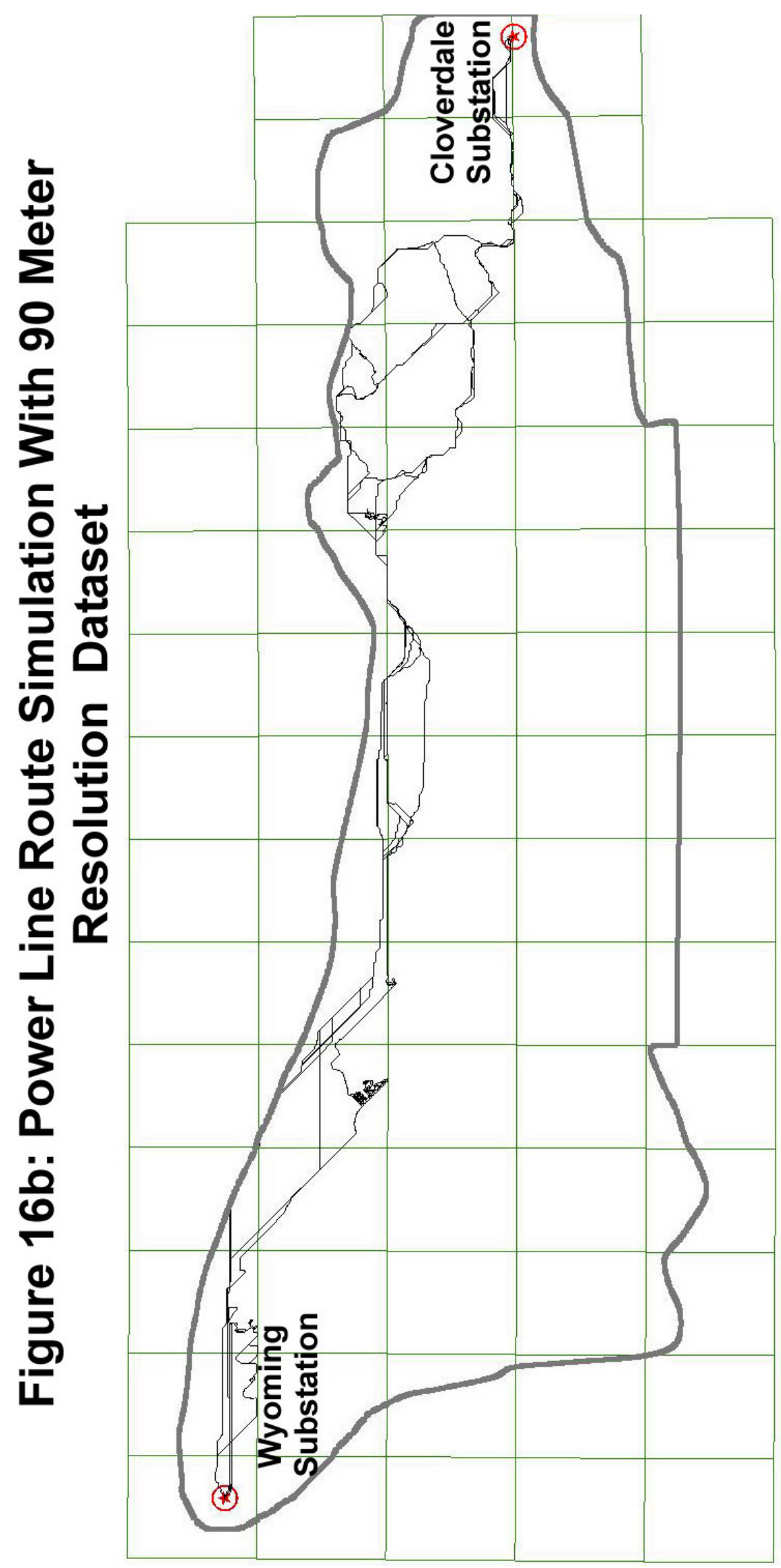




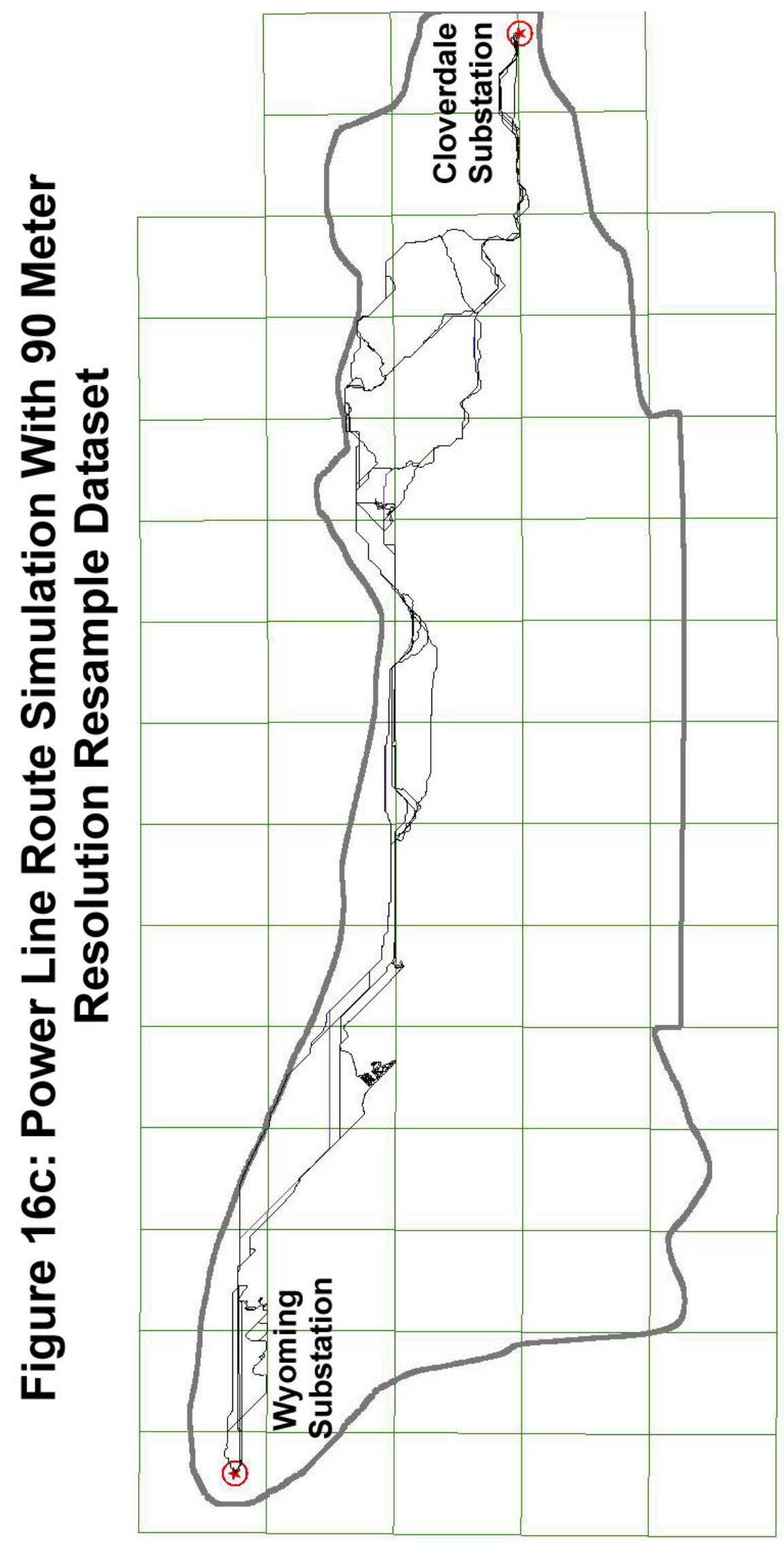


surface construction and pathway analysis in this study.

Surprisingly, most of the corridor route segments generated above are generally located within a limited region. As a point to note, this area also corresponds to areas where detailed current landuse data is not available. It is obvious that the modeling process has been affected greatly by an uneven spatial distribution of information, such as current landuse, and that the least cost pathway analysis cannot be conducted properly without correctly determining the real decision space (DS) in which the linear routing process can occur. Therefore, a further routing process has been conducted in which the limited region was removed. The routing results are shown in Figure 17.

The new results demonstrate that initial data aggregation has a great influence on the linear routing process and resulting route placements. Compared to the aggregation data set input into the IIM2, non-aggregated data set usually causes two routing problems after being used with the IIM1 (Figure 18). One of these problems is that many back-linking route segments are generated. The second problem is that the rapid growth of routing sensitivity to routing directions result in numerous disparity distortions including fishnet linking.

As expected, three different types of IIM used have different behaviors in modeling power line corridor route siting. As demonstrated in Figure 17, a linear combination model (EM4) tends to generate a cost surface which produces a base route distribution. The square combination model (EM6) tends to zigzag the base route to avoid the most sensitive environmental features or regions. Compared to EM6, the ordered weighted combination model (EM5) has a function to smooth the base route based on using weights to tradeoff the importance of the variables. Although very similar corridor route patterns are generated when using IIM2, IIM3, IIM4 and aggregation models such as IIM5, IIM6, IIM7, it takes less computer storage space and computational time for the aggregation models to complete the routing process and yet achieve the same resultant routes. 


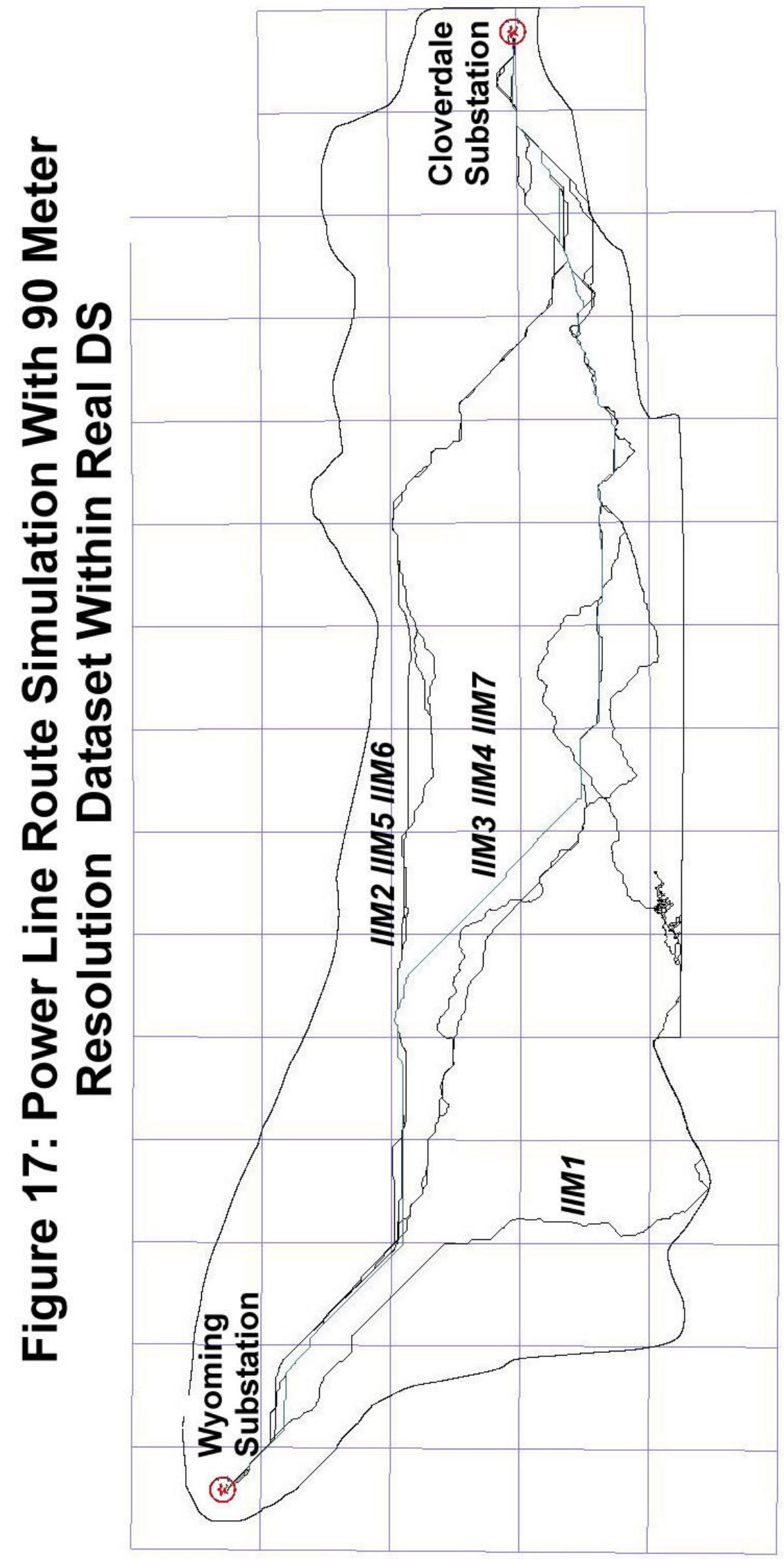




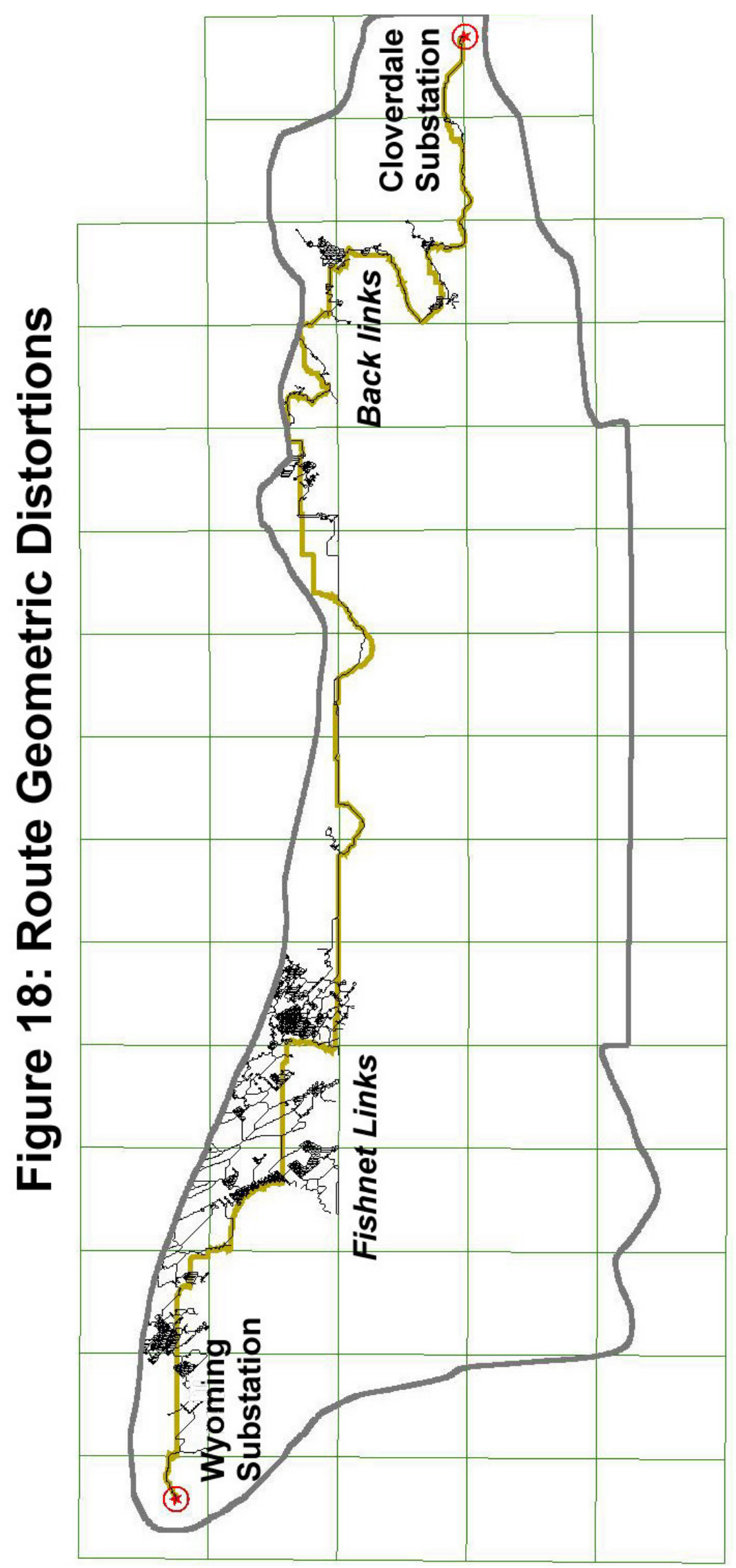




\section{CHAPTER 5: EVALUATING SMA IN LINEAR ROUTE SITING}

Large linear facility siting projects are usually conflictual and often revolve around economic development versus environmental protection issues. Route selection is invariably a multi-objective planning process in which conflicting objectives co-exist. At best any routing procedure can only be regarded as being a limited search toward a suboptimal solution in a multiple objective and dynamic decision space. Therefore, it is very important to test how good the results of an SMA are. Not least, many siting projects are dynamic in that statutory and regulatory protection and preservation orders can be invoked during the course of a siting project. Many new environmental protection regulations have been raised continuously over the past eight years of the AEP project by Congress, federal agencies, and local communities. The UST has been challenged to respond to these dynamic issues (Harris et al., 1991 \& 1997). The following work seeks to simulate part of the situation incurred in the AEP project by incorporating the multi-objective dynamic problems into this SMA modeling framework. The intent it to assess the effectiveness of SMA to large linear facility location problem in as a realistic scenario setting as possible.

\subsection{The Sensitivity of SMA To Multi-Objective Planning Problems}

\subsubsection{Multiple Objective Decision Spaces}

Most power line routing procedures are a multi-objective planning process aimed at minimizing engineering cost and environmental impact. Even in the case of a single objective of minimizing environmental impact, which is the focus of this research, it is necessary to consider many different perspectives of environmental protection. As demonstrated in IIM4 in Chapter 4.3.2, each portion of the cumulative model has both a unique selection of variables and weights that represent the relative importance of environmental protection given to the variables. Provided all of the weighted proportions were merged and accumulated, the routing process becomes one of constructing a multiple objective decision space (MODS) in which the least-cost route selection can be regarded as searching for the best compromise linear route among multiple possible routes. Any 
changes in the weighting or trade-off among objectives inevitably leads to the creation of different MODS, in which different cost-distance surface and corridor routes are generated.

\subsubsection{OWC Based Sensitivity Route Simulation}

As shown in formula (8), a modified ordered weighted combination (OWC) model is adopted here to build additional environmental friction surfaces as well as cost-distance surfaces for sensitivity route simulation. The weights in the model are standardized and summed to 1, and set up in the expression (9), so that there exists a strong degree of risk aversion and some degree of tradeoff between the six variables:

$$
\begin{aligned}
& \text { EM7: } \mathrm{Ai}=\sum_{j, l=1}^{m}(X i j * \mathrm{~V} x i l) \quad\left(\mathrm{i}=1,2, \ldots, \mathrm{n} ; 0 \leq x i l \leq 1 \& \sum V=1\right) \\
& \bar{V}=\left[\begin{array}{llllll}
0.50 & 0.30 & 0.10 & 0.05 & 0.03 & 0.02
\end{array}\right]
\end{aligned}
$$

Although there are more than $P_{6}^{6}$ kinds of weighted order designs for the six variables, only four of these are chosen to represent four different viewpoints on the relative importance of environmental protection. These four are described as follows:

Case 1: Human > Culture > Recreation > Visual > Ecology > Landuse

Case 2: Culture > Human > Recreation > Visual > Ecology > Landuse

Case 3: Culture > Human > Visual > Recreation > Ecology > Landuse

Case 4: Culture > Human > Visual > Ecology > Recreation > Landuse

Given two raster data sets X(i) and Y(i) with 90 meter spatial resolution, eight specific linear combination models are built for the four cases as listed in the following:

$$
\begin{aligned}
& \text { IIM8 }=0.02 * \mathrm{X} 1+0.50 * \mathrm{X} 2+0.30 * \mathrm{X} 3+0.10 * \mathrm{X} 4+0.05 * \mathrm{X} 5+0.03 * \mathrm{X} 6 \\
& \mathrm{IIM} 9=0.02 * \mathrm{X} 1+0.50 * \mathrm{X} 3+0.30 * \mathrm{X} 2+0.10 * \mathrm{X} 4+0.05 * \mathrm{X} 5+0.03 * \mathrm{X} 6 \\
& \mathrm{IIM} 10=0.02 * \mathrm{X} 1+0.50 * \mathrm{X} 3+0.30 * \mathrm{X} 2+0.10 * \mathrm{X} 5+0.05 * \mathrm{X} 4+0.03 * \mathrm{X} 6 \\
& \mathrm{IIM} 11=0.02 * \mathrm{X} 1+0.50 * \mathrm{X} 3+0.30 * \mathrm{X} 2+0.10 * \mathrm{X} 5+0.05 * \mathrm{X} 6+0.03 * \mathrm{X} 4 \\
& \mathrm{IIM} 12=0.02 * \mathrm{Y} 1+0.50 * \mathrm{Y} 2+0.30 * \mathrm{Y} 3+0.10 * \mathrm{Y} 4+0.05 * \mathrm{Y} 5+0.03 * \mathrm{Y} 6 \\
& \mathrm{IIM} 13=0.02 * \mathrm{Y} 1+0.50 * \mathrm{Y} 3+0.30 * \mathrm{Y} 2+0.10 * \mathrm{Y} 4+0.05 * \mathrm{Y} 5+0.03 * \mathrm{Y} 6
\end{aligned}
$$




$$
\begin{aligned}
& \mathrm{IIM} 14=0.02 * \mathrm{Y} 1+0.50 * \mathrm{Y} 3+0.30 * \mathrm{Y} 2+0.10 * \mathrm{Y} 5+0.05 * \mathrm{Y} 4+0.03 * \mathrm{Y} 6 \\
& \mathrm{IIM} 15=0.02 * \mathrm{Y} 1+0.50 * \mathrm{Y} 3+0.30 * \mathrm{Y} 2+0.10 * \mathrm{Y} 5+0.05 * \mathrm{Y} 6+0.03 * \mathrm{Y} 4
\end{aligned}
$$

As a result, eight new MODS are created, in which eight power transmission corridors and sixteen center lines are generated. The results (Figure 19) show that the corridor routes simulated for case 1, in which house and residential areas are given the highest weights (0.5), can obviously be distinguished from cases $2,3,4$. The initial data aggregation still has a great influence on the process of OWC-based sensitivity route simulation. Specifically, the routing process is much more sensitive to small changes in the weighting of variables when non-aggregated data X(i) are input into the OWC model. On the other hand, the routes simulated using X(i) often contain abnormal segments such as backlinking segments, fishnet segments, and abrupt movements to the north or south segments. It further demonstrates that the effectiveness of SMA is greatly restricted by the MODS distribution, IIM selection or varying weight of the constraint variables, and initial data aggregations.

\subsection{Sensitivity Of SMA To Dynamic Routing Problem}

\subsubsection{Dynamic Decision Spaces}

As demonstrated in the AEP project, a large linear facility location project is usually a long process in which local communities, politicians, and federal agencies participate actively. This participation can have a dramatic influence over the final choice of corridor location. This influence is sometimes so powerful that it is far beyond the power of a simple application of any existing algorithmic models, especially when part of the MODS becomes an additional exclusion zone due to geo-political involvement. For example, after a preferred corridor route (GIA_P91) was selected by the UST in 1991, 19.5 miles of the New River was designated as being of Wild and Scenic significance and were not permitted for a power line crossing. Although a new preferred power line corridor (GIA_P96) was determined by the UST which avoided crossing New River in the 


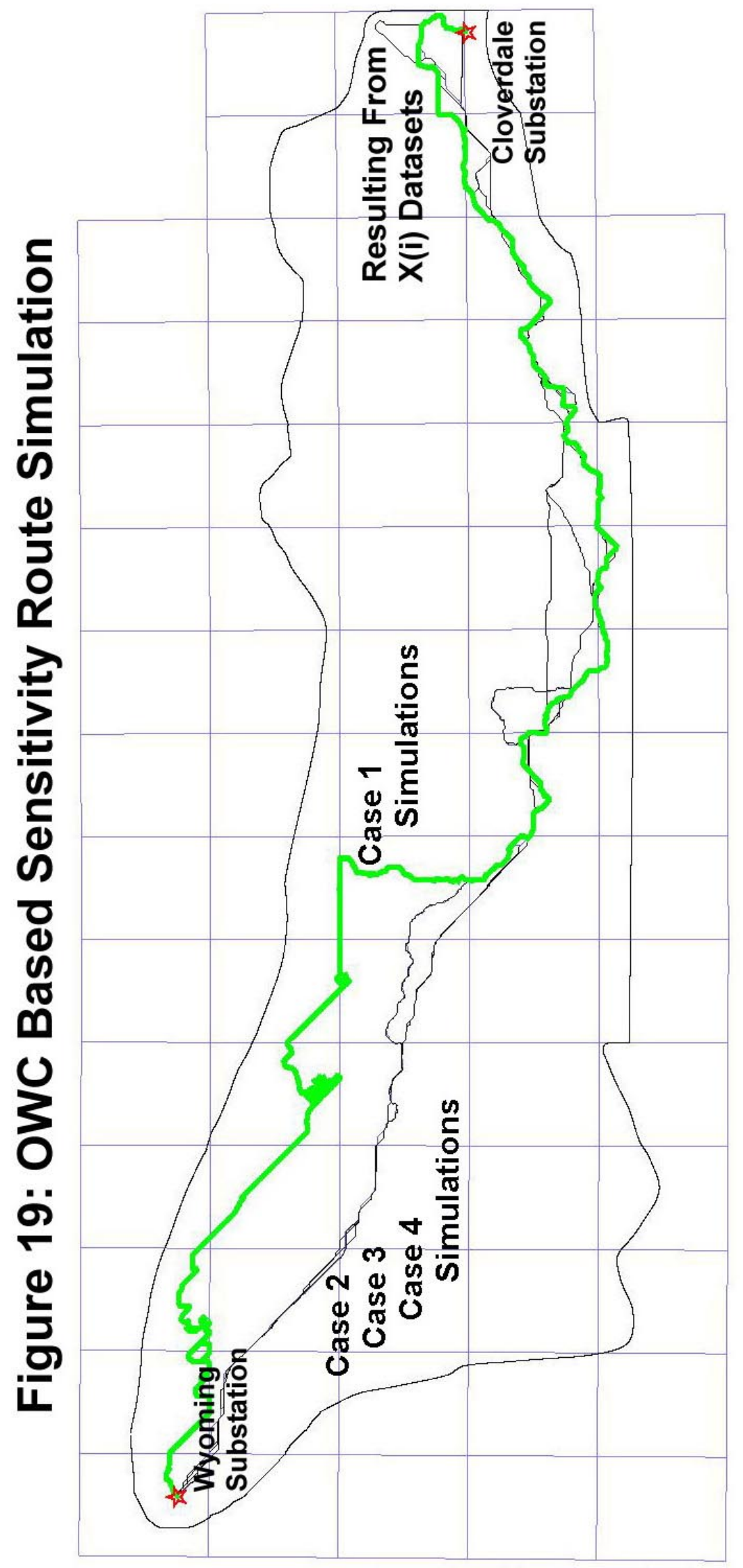


designated Wild and Scenic section, it was still denied access by the Forest Service through the Jefferson National Forest. The UST continued its studies (GIA_P97) and gained acceptance of its West Virginia corridor routing in 1997 but is being requested to examine alternative routes by the Virginia State Corporation Committee due to the public participation (AEP Project Progress, 1998).

As a result routing experts have to be able to respond to changes in the decision space and be able to identify new routes. A new route selection area is specifically defined here as dynamic decision space (DDS), in which new exclusion zones are added. Once given a DDS, experts usually have to determine a new set of crossing points or gateway points, which are targeted for a segment-based corridor route siting, as the UST did in 1991, 1995, and 1997. The following routing simulations seek to evaluate an SMA to modeling in dynamic space. In this study, additional study areas are brought into this dynamic space as a consequence of public participation input. By default, each DDS is associated with a new set of gateway points.

\subsubsection{DDS-Based Sensitivity Route Simulation}

For simplification, two new exclusion zones $\mathrm{N}$ and $\mathrm{V}$ are simulated to generate two new dynamic decision spaces B and C, as described in Table 4 and shown in Figure 20. N represents the 19.5 miles of Wild and Scenic River Area which was protected by the new

Table 4: DDS-Based Friction Surface Generation

\begin{tabular}{|c|c|c|}
\hline \multicolumn{2}{|c|}{ DDS-Based Friction Surface } & New Exclusion Zone(s) \\
\hline Type & IIM & Combination \\
\hline A & IIM1-IIM15 & None \\
B & IIM1-IIM15 & N' \\
C & IIM1-IIM15 & $\mathrm{N}^{\prime}+\mathrm{V}^{\prime}$ \\
\hline Total & 45 & 3 \\
\hline
\end{tabular}

environmental protection law. V represents the ABBS valley, which has a dense population making it inappropriate to cross the $765 \mathrm{KV}$ power line. The two 


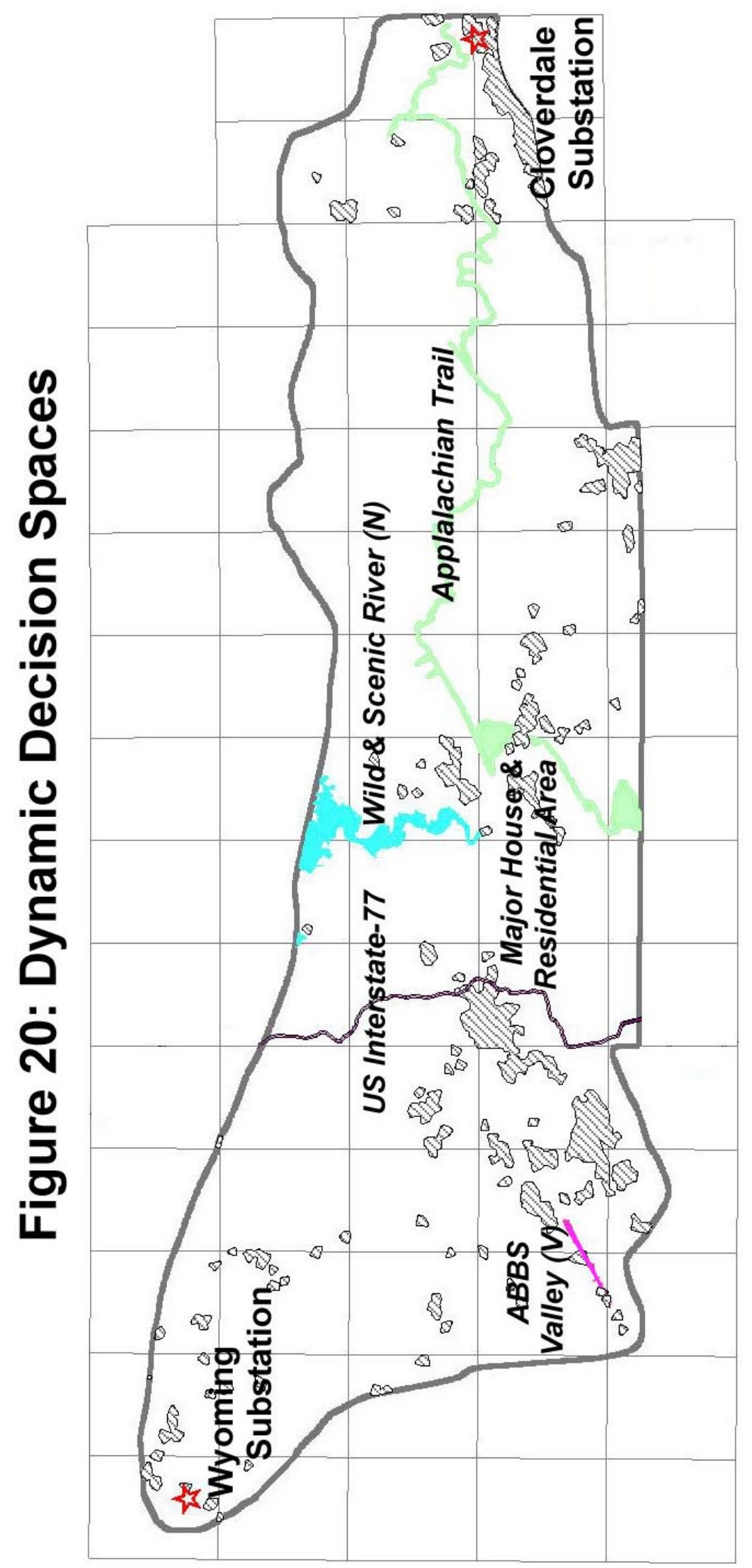




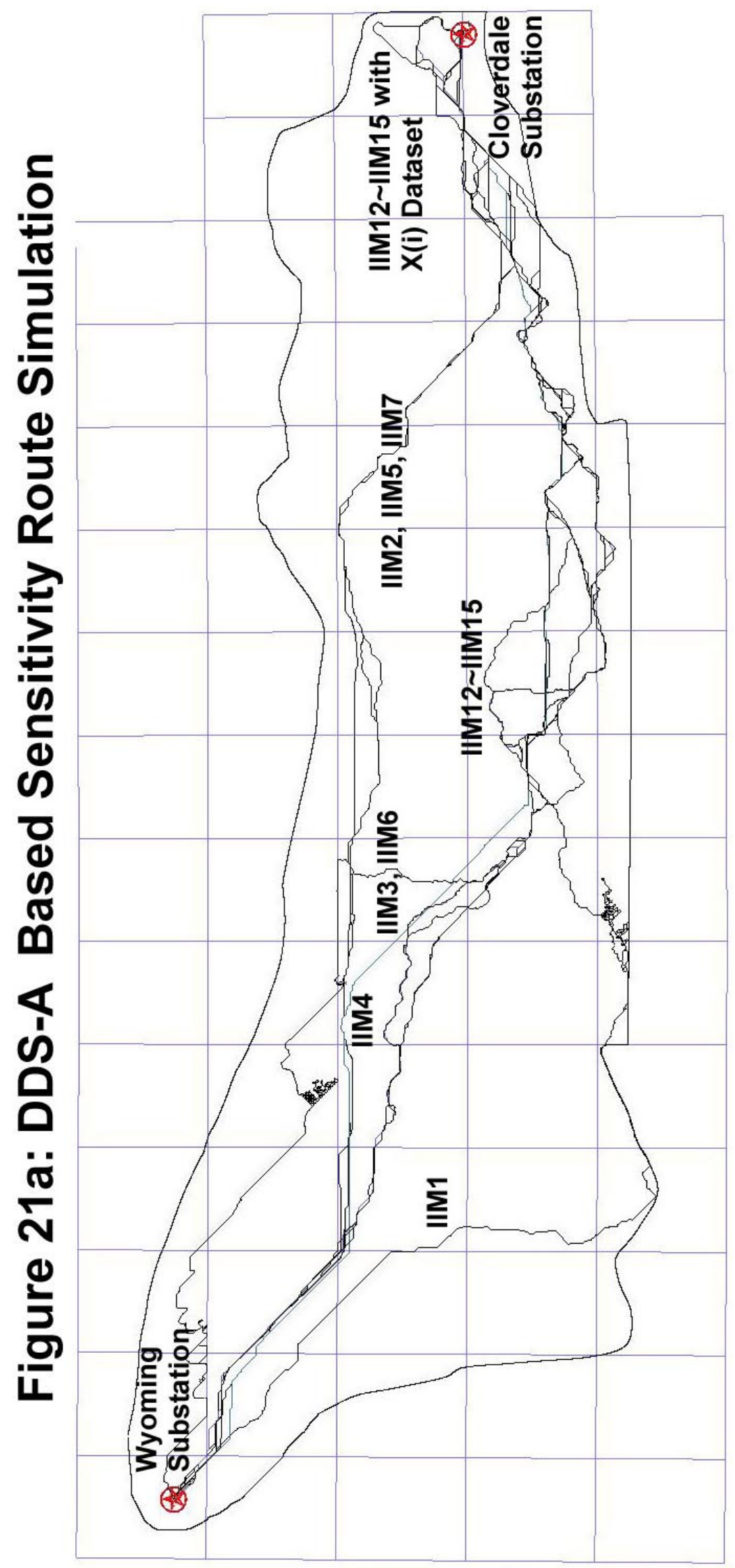




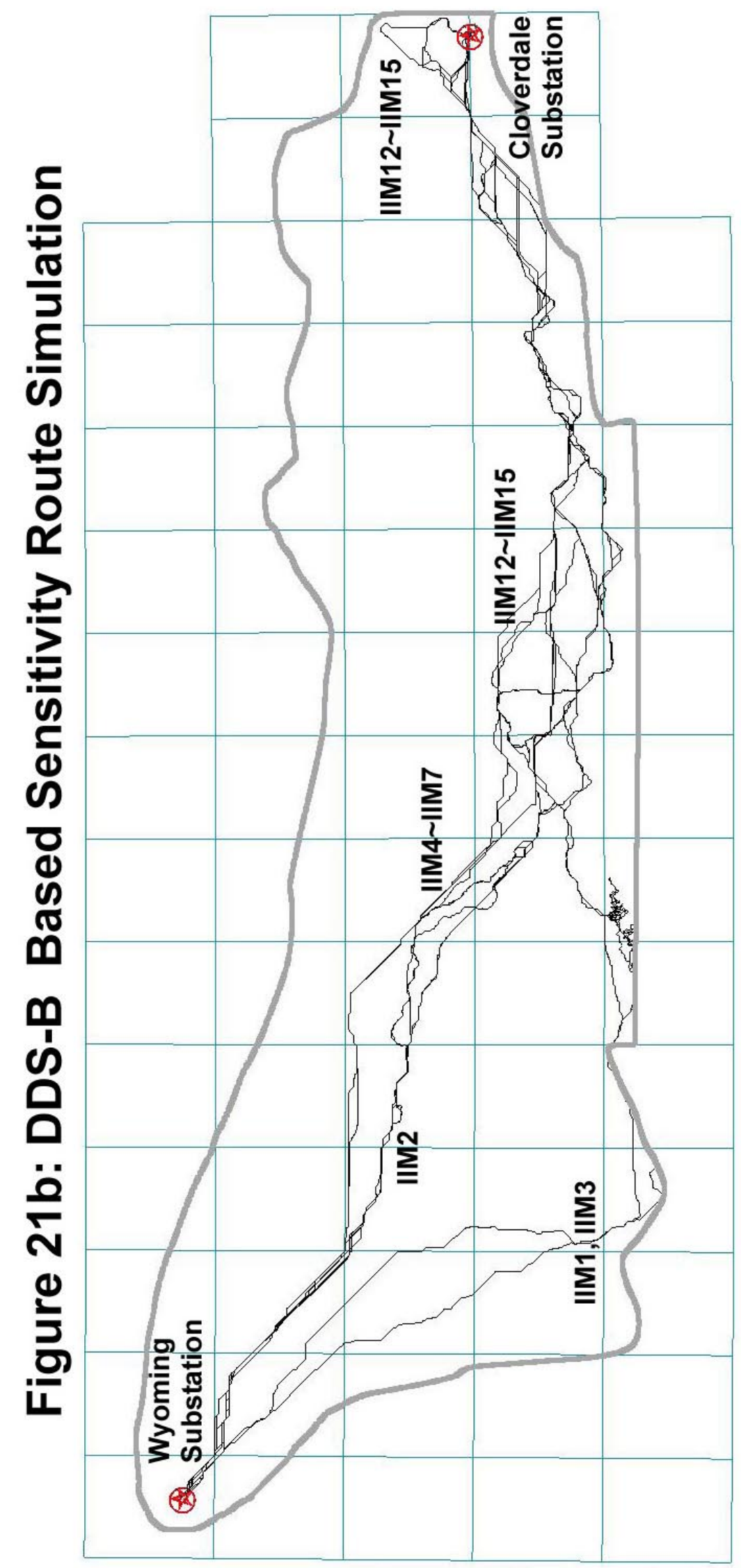




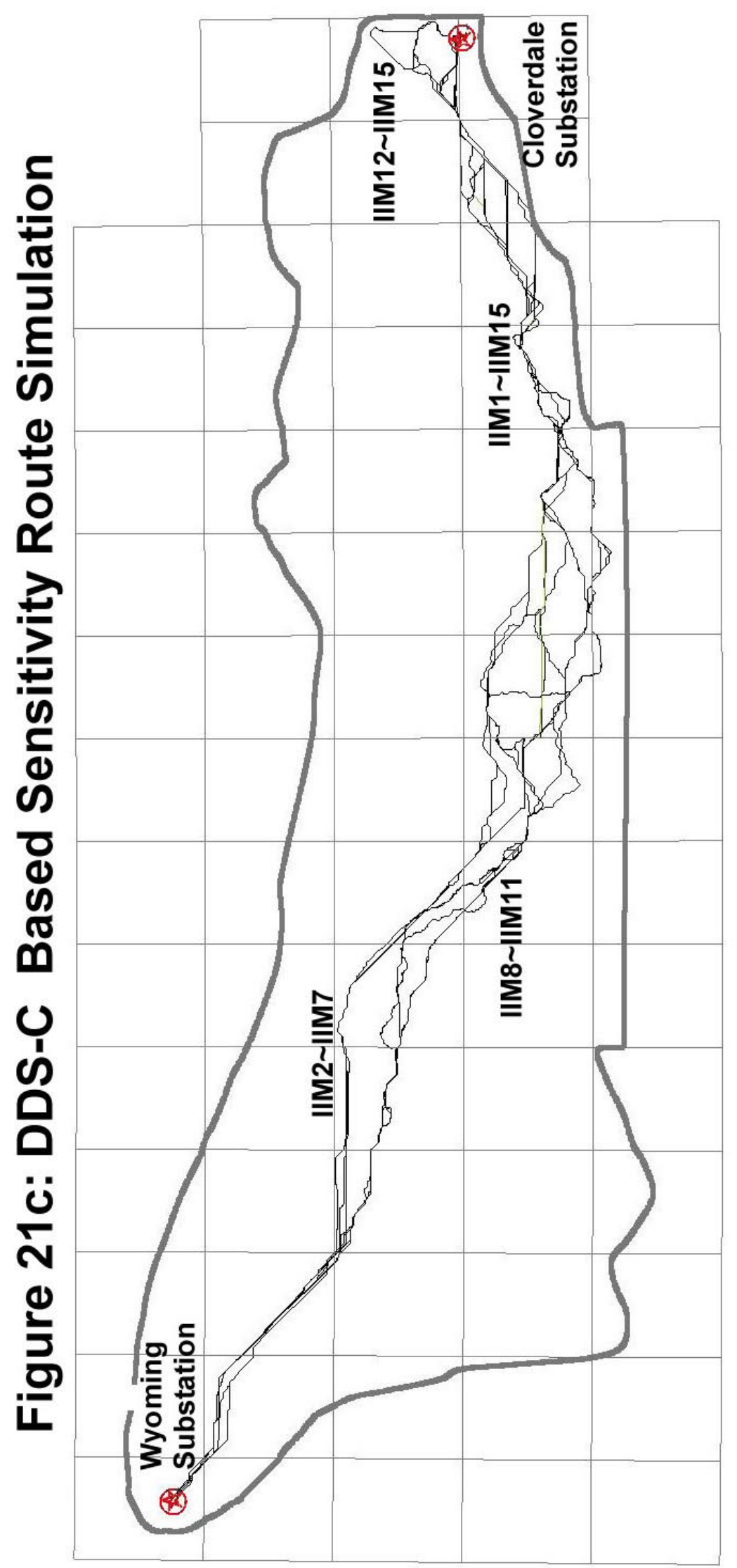


new exclusion zones are first rasterized into two separate data sets with 90 meter spatial resolution, and NODATA are assigned as their cell values to create two friction surface N' and V'. These friction surfaces, or their combination, are then added into the 15 friction surfaces that were generated in Chapter 4.3 and Chapter 5.1.2.

Two new types of DDS-based friction surfaces are created in this study, and 60 new sensitivity power line corridor routes generated based on the 30 new DDS-based friction surface simulations. The resultant routes are illustrated in Figure 21. Although they share the 15 same IIM, the DDS-A, DDS-B, and DDS-C based cost surface generate three completely different patterns of corridor route placement (Figure 21a, 21b, 21c). The results demonstrate that the routing process can be changed dramatically by the inclusion of even relatively small street-like barriers such as $\mathrm{N}$ and $\mathrm{V}$, or that the construction of different DDS can result in the generation of different power line corridor routes as we expected intuitively. Thus, a segment-based modeling approach to linear route siting can be very sensitive to geo-political inputs or public participation.

\subsubsection{Gateway-Based Sensitivity Route Simulation}

The dynamic routing problem is often involved in not only redesigning the DDS but also in generating new combinations of feature crossing points or gateway points. As shown in Figure 22a, many crossing and turning points were involved in the UST manually proposed power line corridor routes over the past eight years. Particularly, the crossing points involve major important linear features in the region, they include the Interstate 77, the New River, and the Appalachian Trail. In this study, many of the major crossing points are directly adopted and grouped into southern, middle, and northern sets for the purpose of routes simulation, which were labeled as GPS, GPM, and GPN, respectively. Each set is associated with a unique decision space (DS) that supported UST route selection in a certain periods. Specifically, as shown in Figure 22b, GPN has three crossing points N1, N2, N3 which were used in the preferred corridor (GIA_P91) location study in 1991. The second set, GPM, has five crossing points M1, M2, M3, M4, and M5, that were used by the UST in siting GIA_P96 in 1996. All three crossing points are contained within the third 


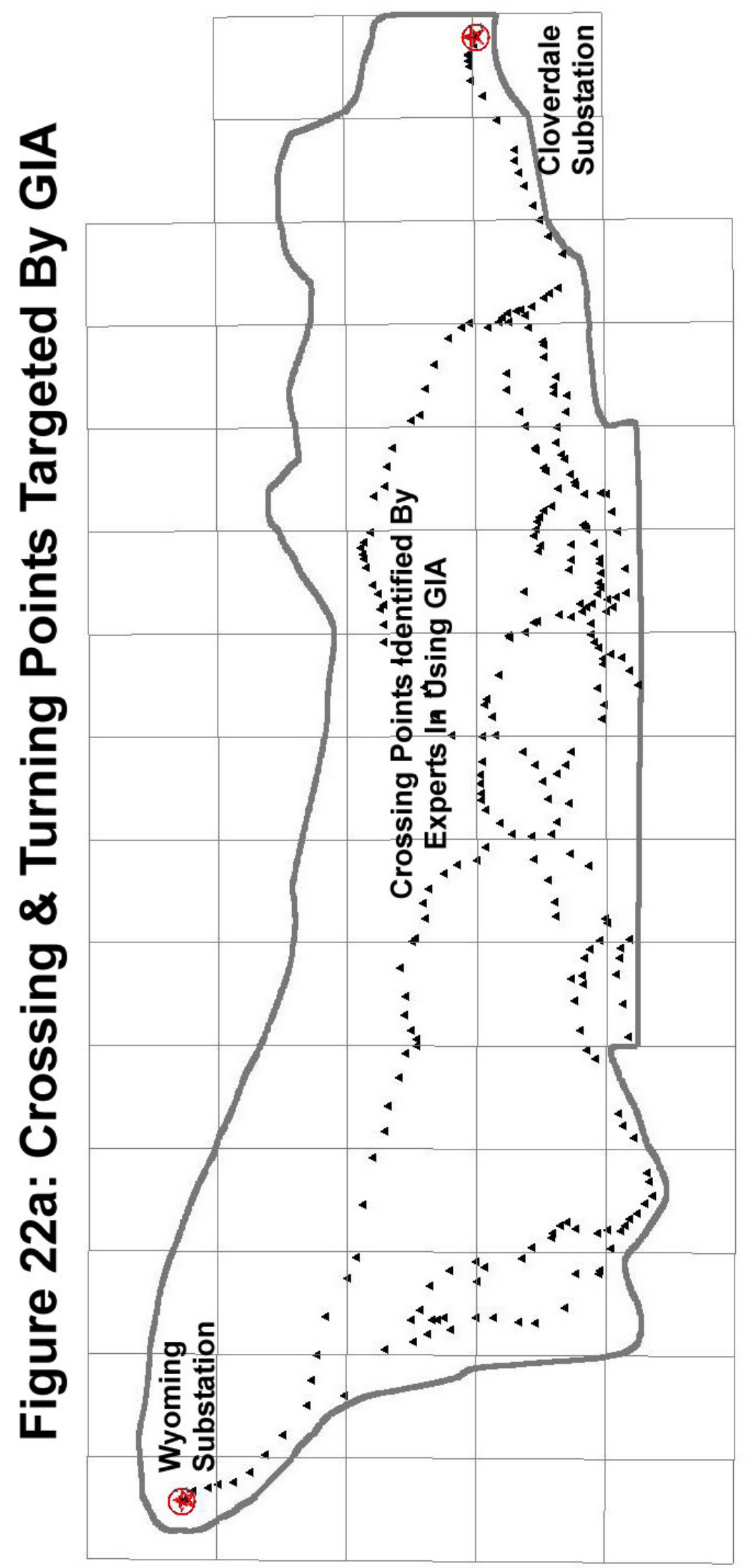




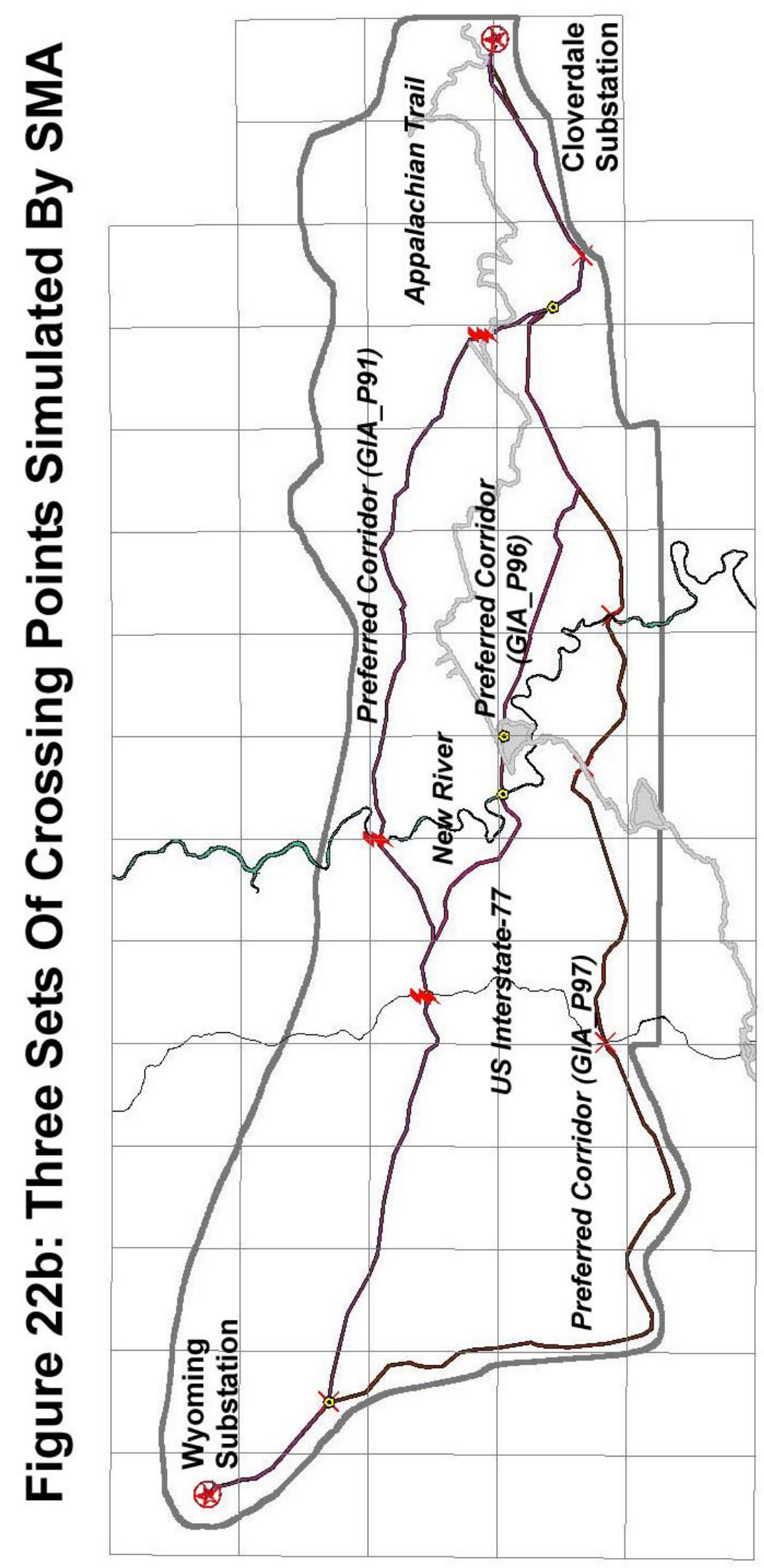




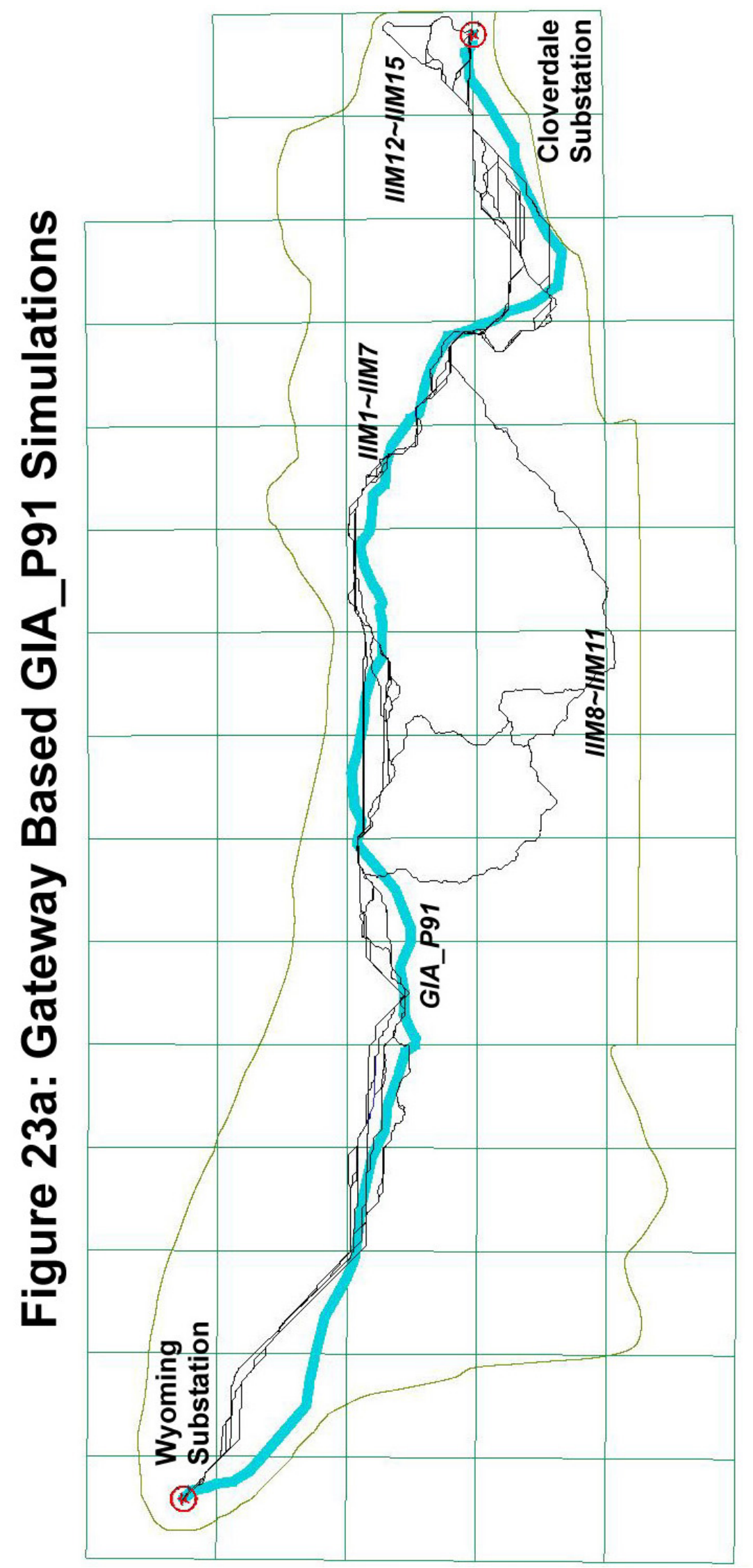




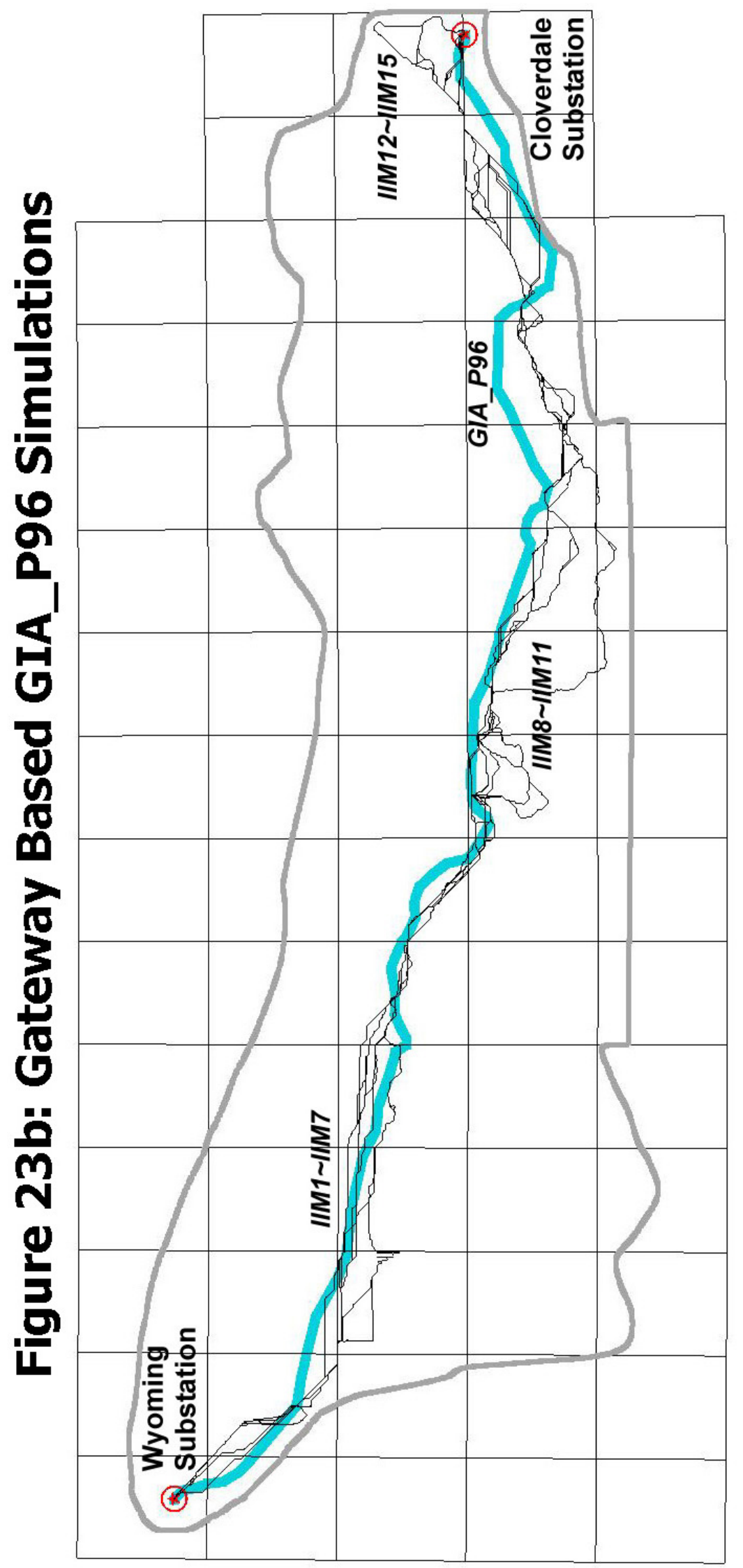




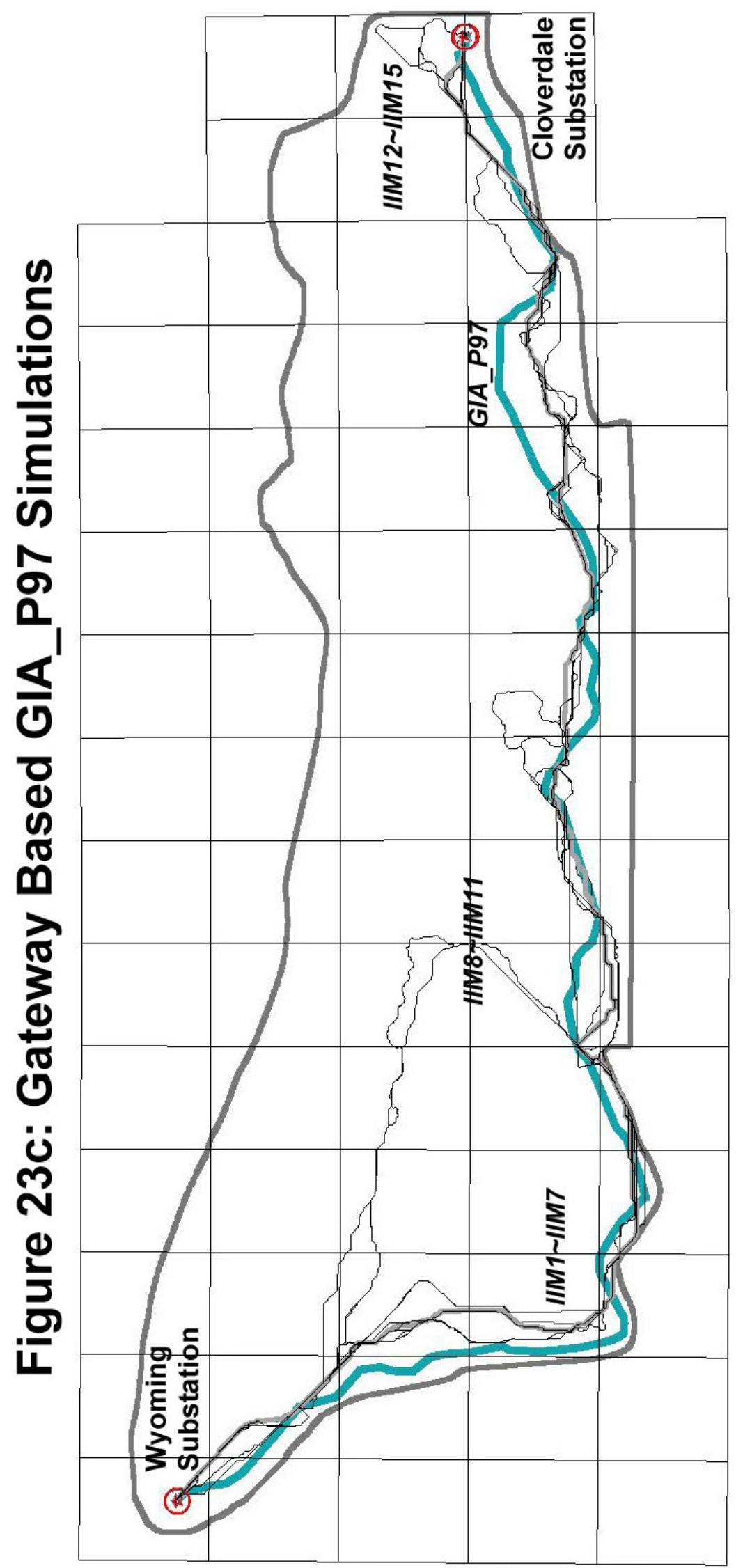


set, GPS, and were used by the UST to site the preferred corridor route GIA_P97 in 1997. By so doing, an application-oriented comparative analysis can be undertaken later.

As shown in Table 5, with 45 DDS-based friction surfaces, 90 sensitivity routes are simulated through the use of gateway-based linear route siting techniques (ESRI, 1991 \&

\section{Table 5: Gateway-Based Sensitivity Route Simulation}

\begin{tabular}{|c|c|c|c|}
\hline DDS & GPTS & IIM & Friction Surfaces \\
\hline A & GPN & IIM1-IIM15 & 15 \\
B & GPM & IIM1-IIM15 & 15 \\
C & GPS & IIM1-IIM15 & 15 \\
\hline Total & 3 Sets & 45 & 45 \\
\hline
\end{tabular}

1992; Lombard \& Church, 1993) Figure 23a, 23b, 23c). Compared with the DDS based route simulation (Figure 21), the gateway approach results in a more uniform power line routing pattern. Besides some generated by using un-aggregated data sets $\mathrm{X}(\mathrm{i})$, most of the route segments deviate only a little from a well defined route which actually approximates closely to the simulated GIA preferred corridor routes. It is interesting to note that previous routing problems, such as back-linking and fishnet segment generation, still happen when the non-aggregated data sets X(i) are used in the cost surface generation.

\subsection{Comparative Analysis of SMA With GIA}

The main purpose of conducting a comparative analysis is to evaluate the effectiveness of using SMA in linear facility siting. By considering the preferred power line corridor routes sited by GIA over the past eight years as real solutions to the proposed route-location problems, assessment of the SMA can be achieved simply by comparing the results of the SMA and GIA approaches. Two specific aspects are selected as a basis for a comparative test comprising the geometric closeness of fit and the net environmental impact. The geometric fit is defined here as the spatial similarity of corridor route distribution. Environmental impact is used to quantitatively evaluate the specific environmental costs posed by the resultant route placements. 


\subsubsection{Spatial Analysis Of Power Line Route Placement}

Generally speaking, three particular semi-automated modeling techniques have been used so far to simulate the proposed power line corridor route siting in routing practice. These include OWC-based sensitivity route simulation; DDS-based route simulation; and gateway based route simulation. With the OWC model, all eight (or sixteen) resulting corridor routes (Figure 19) have spatially different distribution patterns from that of the three preferred corridors, although they do reflect the effect of different modeling human environmental interpretation on solving multi-objective routing problem. It is also found that spatial patterns of corridor route-locations can be changed dramatically with the inclusion of additional spatial barrier(s) to crossing the proposed linear routes even if same environmental evaluation models are used in MODS creations, as show in Figure 21.

Among the three techniques, the gateway approach generates the most similar corridor route-location patterns and many of these routes (IIM2-IIM11) have a close spatial fit to the preferred corridor routes sited by GIA in three different periods (Figure 23). And more importantly, three IIM5, IIM6, IIM7 based cost surfaces best simulate each of the three preferred corridors, including GIA_P91, GIA_P96, and GIA_P97. They not only generate representative corridor routes of the three preferred corridors but save considerable processing time. In addition, among all of the non-aggregated data sets based route simulation, only IIM1 based cost surface appears to be able to generate route-location patterns that are close to the three preferred corridor routes. Its length of corridor route is obviously shorter than any of others generated by using non-aggregated IIM (IIM12 IIM15) based cost surfaces.

\subsubsection{Corridor Impact Matrix Analysis}

The 12 corridor routes modeled using the gateway approach and the best performing four IIM models are used here (Figure 24) for generating the 300 meter wide power line corridor impact matrix. The matrix also contains the respective figures for the three corridors identified by Harris et. al using the GIA approach. In all some 22 major environmental and engineering factors are detailed in the matrix (Table 6). 


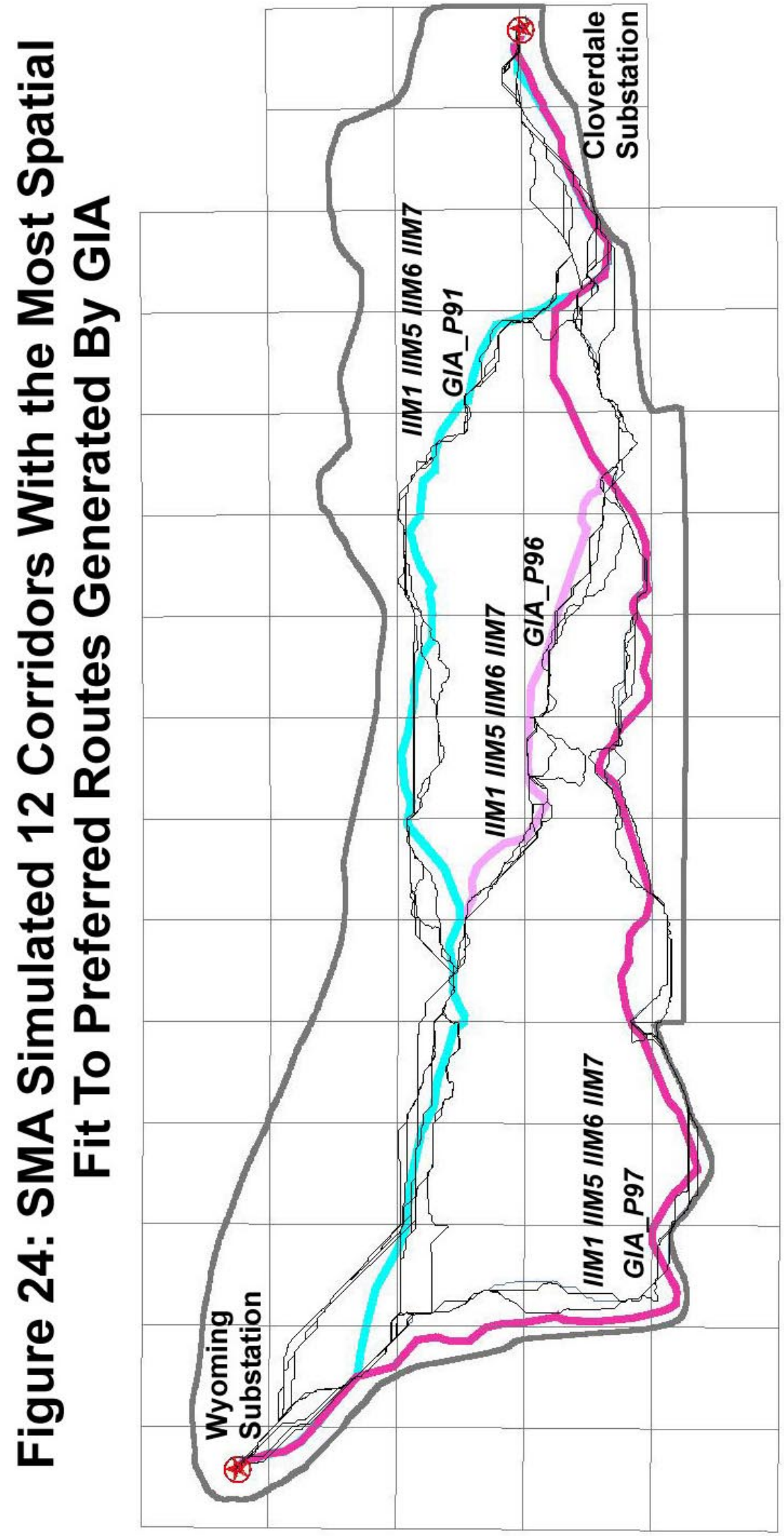




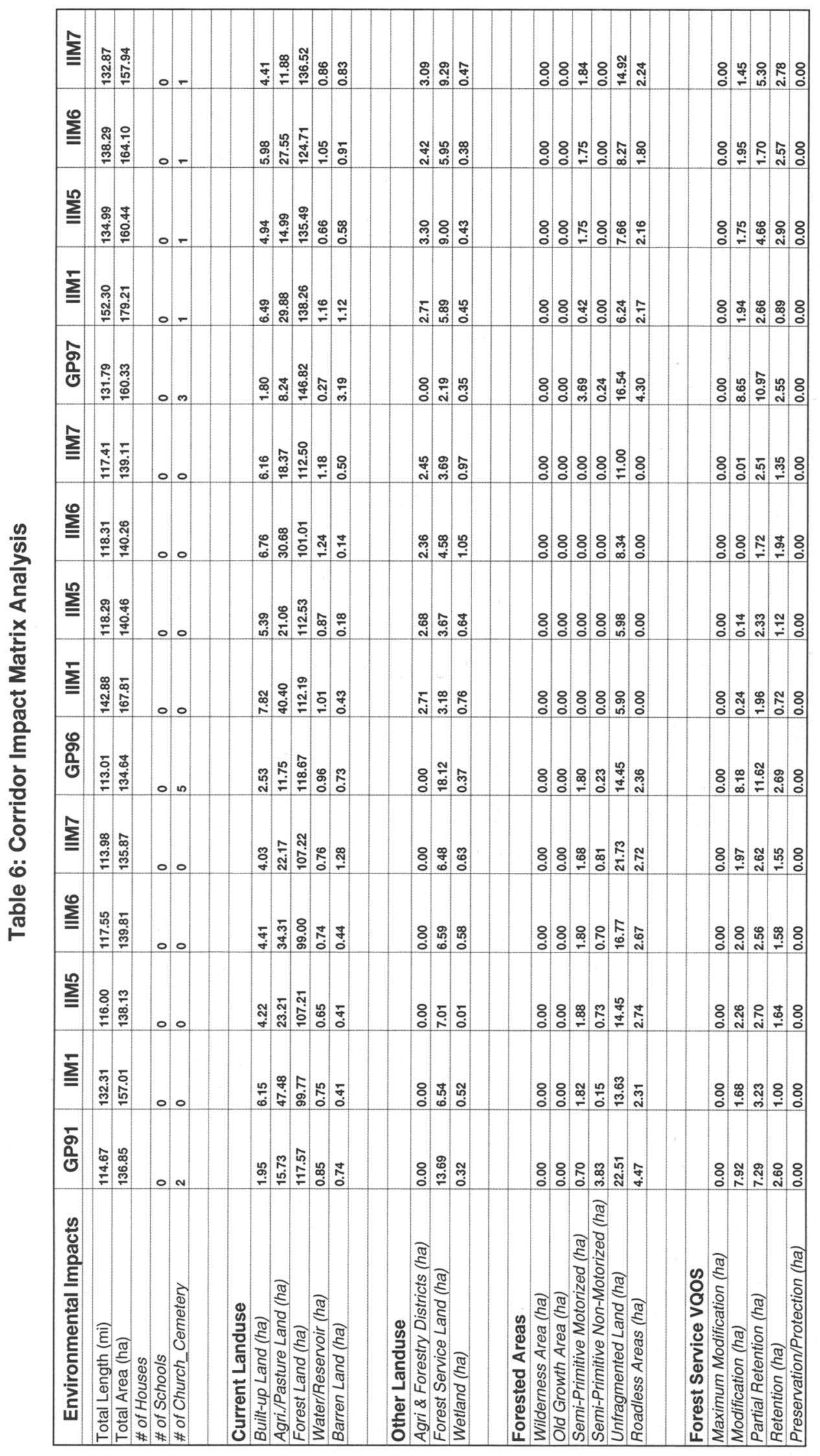


The total length of a corridor is an important criteria in selecting a corridor route. Besides IIM1 associated corridor routes, including SM91a, SM96a, and SM97a, the remaining nine simulated corridor routes (SM91b, SM96b, SM97b; SM91c, SM96c, SM97c; SM91d, SM96d, SM97d) have a total length which closely approximates that of the preferred corridors defined by Harris et al. Notably, residential units were not specifically identified in the SMA siting analysis because this process was always based upon field survey once the corridor had been identified. With this significant exception, however, the IIM5, IIM6, IIM7 associated corridor routes generally have less environmental impact than the three preferred corridor sited by the GIA. It is suggested that the results of the SMA and GIA routing processes are at least comparable - if not slightly in favor of the SMA routes (albeit without the important residential housing count). 


\section{CHAPTER 6: SUMMARY AND CONCLUSIONS}

Some problems inevitably affect the practical value of applying SMA to a large linear facility siting that involves a complex spatial decision making process. These problems come from both the methodology itself in which many hypothetical and approximate assumptions must be made, and from the lack of comparative studies which have addressed the SMA effectiveness in routing practice. This study has emphasized the effectiveness of applying a semi-automated modeling approach to a large $765 \mathrm{KV}$ power transmission line route selection project. Several significant issues were examined including suitable spatial resolution, the function and behavior of different cumulative environmental impact models, and the sensitivity of simulations to multi-objective and dynamic routing problems. The study also examined some basic, but critical, issues relating to the accuracy of any raster defined algorithmic approach to linear facility siting. These issues also include routing sensitivity to different shortest-path algorithms, the inclusion of different diagonal links in cell-based network construction, and the positional accuracy posed by using different cell sizes in vector-to-raster data conversion.

\subsection{Effectiveness And Efficiency Assessment}

As pointed out in Chapters Two and Three, different shortest path algorithms do not result in markedly different linear routes. However, differing results can occur when using different diagonal links in the cell-based route network construction. The significant instability of the optimal routing process was reported with different R-valued systems (Huber \& Church, 1985), and the resulting routes from 4-cell orthogonal links $(\mathrm{R}=0)$ could come close to non-acceptance in linear facility modeling using a discrete lattice surface (Goodchild, 1977). Surprisingly, cell-based algorithmic approaches in both Arc/Info and IDRISI software generate very similar results as those of linear modeling in higher R-value systems $(\mathrm{R}>=2)$ (Figure 8 ) even though only 8 neighboring cell links $(\mathrm{R}=1)$ are included in the modeling approaches supported by the two software. This indicates that different linear 
routing search techniques associated with different software can also lead to different routing results.

Raster defined database accuracy is greatly affected by the selection of different spatial resolutions for use in the vector-to-raster data conversion or raster-to-raster resampling. The positional accuracy of any point feature, including the origin and destination of the proposed linear facility as well as the node centroids of the raster defined network, is influenced by the raster cell size. Both situations lead to errors or uncertainties in the cost surface generation and the least cost path siting. Given a specific shortest-path algorithm and its route searching technique, the use of a finer spatial resolution often results in a narrower or smoother route corridor being defined (Figure 10).

In this study different cumulative environmental impact models have been used to model potential power line corridor routes. As demonstrated in Figure 17, the square combination model (EM6) appears to zigzag along the base routes generated by using the linear combination model (EM4). In contrast, the ordered weighted combination model (EM5) tends to smooth the base routes of EM4. Detailed studies in Chapter 5.1 and 5.2 further indicate that, given the same data sets and scoring schema, the combination theory based aggregation models, including IIM5, IIM6, and IIM7, have a significant advantage in generating the same power line route pattern over their non-aggregated models such as IIM2, IIM3, and IIM4.

From a practical view of point, both multi-objective and dynamic decision space are simulated in this study for evaluating the effectiveness of SMA in routing practice. In the simulations, four cases were proposed to test the sensitivity of SMA to the multi-objective route-location problem by using the OWC modeling techniques. Furthermore, both the DDS-based and the gateway-based simulation techniques were used to address dynamic routing problem in corridor location planning. Two factors were found to be the most sensitive in the route simulations: the initial data aggregation and the additional spatial 
barriers. Only the gateway approach was found to be able to effectively simulate the preferred power line corridor routes generated by the UST using GIA.

Although three different environmental impact functions were shown to have different behaviors in the routing process, their behaviors have been greatly influenced by the initial data aggregation. The most typically sensitive power line corridor routes were found only within the non-aggregated data sets $\mathrm{X}(\mathrm{i})$ based multi-objective decision space (MODS). However, many of these also have unacceptable spatial location phenomena such as fishnet segments, back segment linking, and abrupt orthogonal segments placement (Figure 18). In addition, all aggregation IIM perform well in the linear route generation and the preferred power line corridor routes simulation. The results indicate that data aggregation, before and in the process of the cost-distance surface generation, seem to be not only efficient but also a necessary technique to eliminate geometric distortion of resultant corridor routes generated by using cell-based SMA.

To verify the practical value of SMA in routing large linear routes, a comparative study with GIA was undertaken. The results demonstrate that the inclusion of even a very small additional spatial barrier into the cost surface could result in significantly different power line corridor routes (Figure 21a, 21b, 21c). Furthermore, a gateway-based modeling technique was found to be the best approach to simulate effectively the preferred power line corridor routes generated by the UST using GIA (in terms of both geometrical closeness of fit and environmental impact). This match was deemed to be quite good when aggregation data models are used with a gateway approach to simulate an expert decision making process (Figure 24 and Table 6). Not least, the total length of the simulated corridor routes are almost identical to those of the preferred corridor routes GIA_P91, GIA_P96, and GIA_P97.

\subsection{Study Limitations And Further Questions}


A good match has been found in our study when a gateway-based modeling approach was used to simulate the selected optimal corridor routes generated by using GIA. While the GIA is a very labor intensive and time-consuming method, the SMA seems to be a rather easy and cheap method. Despite what seems to be obvious advantages in using SMA to site large linear facilities, there are some limitations with SMA.

First, the routing process with SMA is greatly affected by the inclusion of additional spatial barriers whose shape could dramatically change the pattern of modeling results. The effectiveness of SMA will be limited when the street-like barriers or the large NODATA areas exist between two origination and destination points in the study area. Secondly, although gateway-based modeling processes can most effectively simulate human intuitive judgments in linear route identification, the questions where and how many gateway points should be targeted cannot be solved by the SMA itself. Thirdly, SMA still could not provide a guaranteed objective and optimizing procedure to solve the subjective corridorlocation problems associated with GIA, since it is very difficult to reach consensus on criteria selection at the beginning and data resolution can be diminished by the data aggregation process that are proven to be necessary for generating acceptable linear routes. Finally, by definition, the underlying basis of cell-based SMA implies several forms of spatial approximation and the final precision of an SMA solution will necessarily depend on the fineness of the lattice and the set of diagonal links permitted.

All these limitations may raise doubts about the optimality of a SMA generated linear route. Further, it is still very difficult for users to select from among several SMA generated routes in terms of their optimality, even though the routes are indeed least-cost corridors with the slight spatial deviations and as illustrated in Figure 24. An 'ideal' SMA should perhaps have additional functions that facilitate and help decision-makers identify and evaluate the best among many good alternatives in the corridor location problemsolving process. 


\section{3: Concluding Remarks}

As suggested in the literature, SMA can simplify the decision-making processes involved in the location of large linear routes. The SMA efficiently generated several 'good', and slightly different, power line corridor routes which bore close resemblance to routes identified under the more labor intensive and complicated human intuitive judgments under the GIA studies. It has been demonstrated to be reliable, replicative, and efficient. Furthermore, the approach has been demonstrated to be flexible with regard to changes in the dynamic decision space. Based on this study it is suggested that a semi-automated approach would have several positive advantages that may well place it alongside, complement, or replace, a graphical intuitive approach to linear route siting. 


\section{BIBLIOGRAPHY}

Buckley D.J., Ulbricht C., and Berry J., 1998. The Virtual Forest: Advanced 3-D Visualization Techniques For Forest Management And Research. GIS-98-Resource Technology Conference, April 6-9, In Toronto, Canada.

Bisset R., 1978. Quantification, Decision-making and Environmental Impact Assessment in the United Kingdom. Journal of Environmental Management. 7:43-58

Carpenter G. and Callen R., 1984. Improved Procedures for Natural Gas Pipeline Routing in Michigan. Environmental Professional. 6:26-31.

Carver S.J., 1991. Integrating Multi-Criteria Evaluation Into Geographic Information Systems. International Journal Of Geographical Information Systems. 5(3):321-339.

Carver S.J. and Brunsdon C.F., 1994. Vector To Raster Conversion Errors And Feature Complexity: An Empirical Study Using Simulated Data. International Journal Of Geographical Information Systems. 8(3):261-270.

Chang C.J. and Chang S.H., 1993. A Heuristic Algorithm For Solving the Discrete Network Design Problem. Transportation Planning Technology. 17:39-50.

Choobineh B.T., 1984. Transmission Line Route Selection: An Application of K-shortest Paths and Goal Programming. IEEE Transaction on Power Apparatus and Systems. 103(11):

Church R.L. et al., 1992. An Interface For Exploring Spatial Alternatives For A Corridor Location Problem. Computers \& Geosciences. 18(8):1095-1105.

Clark R.G. et al., 1994. Using Geographic Information, Image Processing, and Animation Systems to Visualize a Digital Terrain Flyby. Selected Papers In The Applied 
Computer Sciences. U.S.G.S. Bulletin 2103.

Conn W.D. and Phil D., 1986. Review of Techniques for Weighting or Valuing the Benefits Associated With Environmental Quality Improvements. Final Report for International Joint Commission. Urban Planning \& Landscape Architecture of VPI, VA

Dean D.J., 1997. Finding Optimal Routes For Networks of Harvest Site Access Roads Using GIS-Based Techniques. Canadian Journal of Forest Research. 27:11-22.

Dijkstra E.W., 1959. A Note On Two Problems In Connect With Graphs. Numerische Mathematik. 1:269-271.

Dobson, J.E., 1979. A Regional Screening Procedure For Land Use Suitability Analysis. The Geographical Review. 69(2):224-234.

Dreyfuss S.E., 1969. An Appraisal of Some Shortest Path Algorithms. Operations Research. 17:395-412.

Drummond J., 1987. A Framework For Handling Error In Geographic Data Manipulation. International Institute For Aerospace Survey And Earth Sciences, ITC Journal. 1:73-82.

Eastman J.R., 1989. Pushbroom Algorithm For Calculating Distances In Raster Grids. AUTO-CARTO 9, pp.288-297.

Eastman J.R., 1997. IDRISI for Windows: User's Guide Version 2.0. Clark University, Worcester, Mass.

Eastman J.R., Jiang H., 1996. Fuzzy Measures in Multi-Criteria Evaluation. Proceedings of Second International Symposium on Spatial Accuracy Assessment in Natural Resources and Environmental Studies, May 21-23, Fort Collins, Colorado, pp. 527-534. 
Economides S. and Sharifi M., 1978. Environmental Optimization Of Power Lines. Jour. of Environmental Engineering Division, ASCE, 104(4):675-684.

Elmes G.A., Cai G., and Twery M.J., 1994. Estimating Spatial Data Error By Inference On A Causal Network. In Advance in Research, Waugh T.C. and Healey R.G. (eds), Taylor and Francis, Philadelphia.

ESRI, 1997. Cell-Based Modeling with GRID. GIS by ESRI. Arc/Info Software Document Version 7.1.1. ESRI Inc., Relands, CA.

Friesz T.L., 1985. Transportation Network Equilibrium, Design, and Aggregation: Key Developments and Research Opportunities. Transportation Research. 19A:413-427.

Geertman S.C.M. et al., 1995. GIS and Models of Accessibility Potential: An Application in Planning. International Journal of Geographical Information Systems. 9(1):67-80.

Giles R.H. Jr., Jones A.B. III, and Smart C.W., 1976. POWER: A Computer System For Corridor Location. Technical Report. Office of Biological Service; Fish and Wildlife Service, U.S. Department of the Interior, Washington, D.C. , 30 pp..

Goodchild M.F., 1977. An Evaluation of Lattice Solutions to the Problem of Corridor Location. Environment and Planning A. 9:727-738.

Harris T., Shepherd W., and Johnson B., 1991 \& 1997. Environmental assessment for the West Virginia portion of the Wyoming-Cloverdale $765-\mathrm{kV}$ transmission line. Technical report laid before the West Virginia Public Service Commission as part of case No. PUE 910050 'Application for approval and certification of electrical transmission lines' by Appalachian Power Company. 3 vols. pp. 840 
Hopkins L.D., 1973. Design Method Evaluation: An Experiment with Corridor Selection. Socio-economic Planning Sciences. 7:423-436.

Hord M. R. and Brooner W., 1976. Land Use Map Accuracy Criteria. Photogrammetric Engineering and Remote Sensing. 425:671-677.

Howlett B., 1976. Environmental Selection of Transmission Line Routes With Maps and Computers. Symposium on Environmental Concerns in Rights-of-Way Management, Mississippi State University, pp. 36-41.

Huber D.L. and Church R.L., 1985. Transmission Corridor Location Modeling. Journal of Environmental Engineering, ASCE, pp.114-130.

Jackson R.H. and Hudman L.E., 1978. Assessment of the Environmental Impact of High Voltage Power Transmission Lines. Journal of Environmental Management. 6:153-170.

Jankowski P., 1995. Integrating Geographical Information Systems And Multiple Criteria Decision-Making Methods. International Journal of Geographical Information Systems. 9(3):251-73.

Jensen J.R., et al., 1994. Improving Urban Infrastructure Mapping And Forecasting For BellSouth Using Remote Sensing And GIS Technology. Photogrammetric Engineering and Remote Sensing. 60(3):339-346.

Koller D. et al., 1995. Virtual GIS: A Real-Time 3D Geographic Information System. IEEE Visualization 95 Proceedings, Atlanta, Georgia, pp.94-100.

Lawler E.L., 1976. Combinatorial Optimization: Networks and Matroids, Holt, Rinehart, and Winston. 
Lillesand T.W. and Kiefer R.W., 1994. Remote Sensing And Image Interpretation, Third Edition. John Wiley and Sons, New York.

Liu D. et al., 1991. The Application of Numerical Code Analysis To Land Suitability Evaluation. In: Remote Sensing and Mountainous Resources in Loess Plateau, Nanjing Press of China, pp.125-134.

Liu K. and Sessions J., 1993. Preliminary Planning of Road Systems Using Digital Terrain Models. Jour. of Engineering. 4:27-32.

Lombard K. and Church R.L., 1993. The Gateway Shortest Path Problem: Generating Alternative Routes For A Corridor Location Problem. Geographical Systems. 1:25-45.

Lunetta R.S. et al., 1991. Remote Sensing And Geographic Information System Data Integration: Error Sources and Research Issues. Photogrammetric Engineering and Remote Sensing. 57(6):677-687.

Magnanti T. L. and Wong R.T., 1984. Network Design and Transportation Planning: Models and Algorithms. Transportation Science. 18:1-55.

Margaret S. and Schofer J.L., 1973. Goals-Delphis For Urban Planning: Concepts In Their Design. Socio-Econ. Sci.. 7:305-313.

Martin Q.W., 1987. Optimal Canal Location Using Environmental Mapping. Jour. Of Water Resource Planning and Management, ASCE, 113(4):512-521.

Massam B.H., 1982. The Search for the Best route: An Application of A Formal method Using Multiple Criteria. Sistemi Urbani, 1/2 183-184.

McHarg I.L., 1967. Where Should Highway Go? Landscape Architecture, pp.179-181. 
McHarg I.L. 1968. A Comprehensive Highway Route Selection Method.. Highway Research Board, No.246, Highway Research Board, Washington D.C..

Meyers C.R. et al., 1974. Computer Augmentation Of Soil Survey Interpretation For Regional Planning Applications. Oak Ridge National Laboratory Report ORNL-NSF-EP67.

Moreno D., Siegel M., and Moore D., 1988. A GIS Approach For Corridor Siting And Environmental Impact Analysis. GIS/LIS'88, San Antonio. 12:507-514.

Muller J.C., 1986. Fractional Dimension And Inconsistencies In Cartographic Line Representations. The Cartographic Journal. 23:123-130.

Newcomer J.A. and Szajgin J., 1984. Accumulation of Thematic Map Error in Digital Overlay Analysis. The American Cartographer. 11(1):58-62.

Nicols J.D., 1975. Characteristics Of Computerized Soil Maps. Soil Science Society Of America Proceedings. 9:927-932.

Ostresh L.M. Jr., 1973. Computer Programs For Location-Allocation Problems. Monograph No.6, Department of Geography at the University of Iowa.

Rhyne T.M., 1997. Going Virtual Geographic Information and Scientific Visulation. Computer \& Geoscience. 23(4):489-491.

Sandra C. Feldman, Ramonaa E. Pelletier, Ed Walser, James C. Smoot, and Douglas Ahl, 1995. A Prototype For Pipeline Routing Using Remotely Sensed Data And Geographic Information System Analysis. Remote Sensing Of Environment. 53:123-131. 
Schaal H.R., 1972. Constraint Maps: The Newest Tool in Right-of-Way Selection. Transmission and Distribution. Eckbo, Dean, Austin \& Williams Inc., April Report.

Schenkerman S., 1991. The Use And Abuses Of Weights In Multiple Objective Decision Support Models. Decision Sciences. 22(2):369-378.

Shopley J.B., 1984. A Comprehensive Review of Current Environmental Impact Assessment Methods and Techniques. Journal of Environmental Management. 18:25-47.

Smith T.R., Gao P., and Gahinet P., 1989. Asynchronous, Iterative, And Parallel Procedures For Solving The Weighted-Region Least Cost Path Problem. Geographical Analysis. 21(2):147-166.

Singh R. and Treleaven P., 1997. Intelligent Systems For GIS. http://www.cs.ucl.uk/staff/rsandhu/Gisruk/

Solanki R., 1991. Generating The Noninferior Set In Mixed Integer Biobjective Linear Programs: An Application To A Location Problem. Computers And Operations Research. 18(1):1-15.

Sondheim M.W., 1978. A Comprehension Methodology For Assessing Environmental Impact. Journal Of Environmental Management. 6:27-42.

Voogd H., 1983. Multicriteria Evaluation For Urban And Regional Planning. London, Pion.

Wang J., 1992. Road Network Detection From SPOT Imagery For Updating Geographical Information Systems In the Rural-Urban Fringe, International Journal of Geographical Information Systems. 6(2):141-157. 
Warner L.L. and Diab R.D., 1996. The Use of GIS in Environmental Impact Assessment: A Case Study of Power Line Route Selection. Dept. of Geographical and Environmental Sciences, University of Natal, Durban, South Africa. PP.1-11.

Wehde M., 1982. Grid Cell Size In Relation To Errors In Maps And Inventories Produced By Computerized Map Processing. Photogrammetric Engineering \& Remote Sensing. 48(8):1289-1298.

Wilf H.S., 1986. The Network Flow Problem. Algorithm and Complexity. Prentice-Hall, Englewood Cliffs, N. J.. PP.105-136.

Xu J. and Lathrop R.G. Jr., 1995. Improving Simulation Accuracy of Spread Phenomena in A Raster-Based Geographic Information System. International Journal Of Geographical Information Systems. 9(2):153-168.

Zhan C., Sudhakar M., and Gao P., 1993. A Directional Path Distance Model For Raster Distance Mapping. In Spatial Information Theory: Theoretical basis for GIS, Edited by Andrew U. Frank and Irene Campari, Computer Lecture Notes in Computer Science, Springer-Verlag. 716:434-443.

Zhou J. and Civco D.L., 1996. Using Genetic Learning Neural Networks for Spatial Decision Making in GIS. Photogrammetric Engineering and Remote Sensing. 62(11):1287-1295. 


\section{VITA}

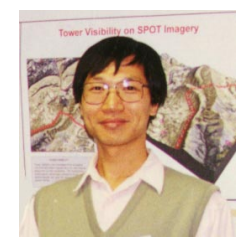

\section{Binfei Chen}

\section{EDUCATION}

1996-1998

Master of Arts in Geography in the Department of Geology and Geography at West Virginia University in Morgantown, WV, USA.

\section{3-1987}

Bachelor of Science in Geography in the Department of Geography at Nanjing University in Nanjing City, Jiangsu, China.

\section{EMPLOYMENT}

\section{6-1998}

Graduate Research Assistant in the Laboratory of Geographic Information and Analysis in the Department of Geology and Geography at West Virginia University in Morgantown, WV, USA.

\section{0-1996}

Research Associate in the Institute of Soil Sciences at the Chinese Academy of Sciences (CAS) in Nanjing City, Jiangsu, China.

\section{7-1990}

Research Assistant in the Institute of Soil Sciences at the Chinese Academy of Sciences (CAS) in Nanjing City, Jiangsu, China. 